\title{
Software Verification and Validation for Commercial Statistical Packages Utilized by the Statistical Consulting Section of SRTC
}

by

T. B. Edwards

Westinghouse Savannah River Company

Savannah River Site

Aiken, South Carolina 29808

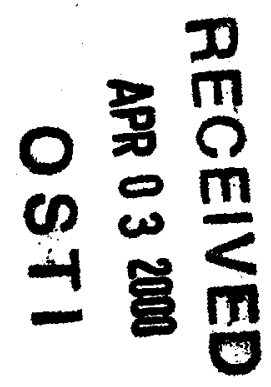

DOE Contract No. DE-AC09-96SR18500

This paper was prepared in connection with work done under the above contract number with the U. S. Department of Energy. By acceptance of this paper, the publisher and/or recipient acknowledges the U.S. Government's right to retain a nonexclusive, royalty-free license in and to any copyright covering this paper, along with the right to reproduce and to authorize others to reproduce all or part of the copyrighted paper. 
Keywords: Regression, ANOVA, Descriptive Statistics, Experimental Design, Fractional Factorial,

Mixture, Control Chart

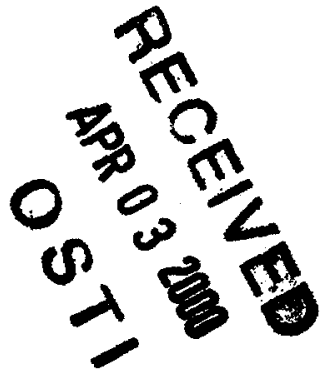

\section{Software Verification \& Validation} for Commercial Statistical Packages Utilized by the Statistical Consulting Section of SRTC (U)

Westinghouse Savannah River Company Savannah River Technology Center Aiken, SC 29808

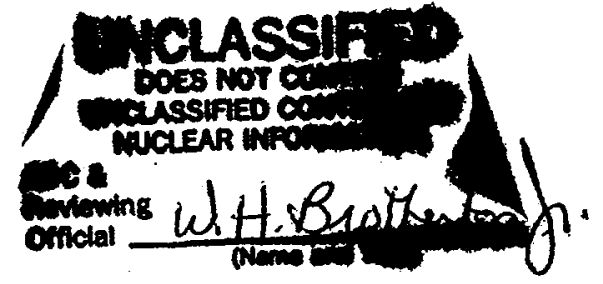

PREPARED FOR THE U.S. DEPARTMENT OF ENERGY UNDER CONTRACT NO. DE-AC09-96SR18500 
WSRC-RP-99-00422

Revision 0

\section{DISCLAIMER}

This report was prepared as an account of work sponsored by an agency of the United States Government. Neither the United States Government nor any agency thereof, nor any of their employees, makes any warranty, express or implied, or assumes any legal liability or responsibility for the accuracy, completeness, or usefulness of any information, apparatus, product or process disclosed, or represents that its use would not infringe privately owned rights. Reference herein to any specific commercial product, process or service by trade name, trademark, manufacturer, or otherwise does not necessarily constitute or imply its endorsement, recommendation, or favoring by the United States Government or any agency thereof. The views and opinions of authors expressed herein do not necessarily state or reflect those of the United States Government or any agency thereof.

This report has been reproduced directly from the best available copy.

Available for sale to the public, in paper, from: U.S. Department of Commerce, National Technical Information Service, 5285 Port Royal Road, Springfield, VA 22161, phone: (800) 553-6847

fax: (703) 605-6900

email: orders@ntis.fedworld.gov

online ordering: http://www.ntis.gov/ordering.htm

Available electronically at http://www.doe.gov/bridge

Available for a processing fee to U.S. Department of Energy and its contractors, in paper, from: U.S. Department of Energy, Office of Scientific and Technical Information, P.O. Box 62, Oak Ridge, TN 37831-0062, phone: (865) 576-8401

fax: (865) 576-5728

email: reports@adonis.osti.gov 


\section{DISCLAIMER}

Portions of this document may be illegible in electronic image products. Images are produced from the best available original document. 
WSRC-RP-99-00422

Revision 0

\section{Software Verification \& Validation for Commercial Statistical Packages Utilized by the Statistical Consulting Section of SRTC (U)}

May 21, 1999

Prepared by

the

Statistical Consulting Section

\begin{tabular}{|c|c|c|c|c|c|}
\hline \multicolumn{2}{|c|}{ Contributors } & Date & \multicolumn{2}{|c|}{ Contributors } & Date \\
\hline R. A. Baker & $\sec 20 \pi$ & 521699 & C. P. Reeve & Cyblen & $57 / 26 / 99$ \\
\hline T. B. Edwards & & $5 / 26 / 99$ & E. P. Shine & $E \not \Delta k$ & $5 / 2</ 94$ \\
\hline S. P. Harris & & $5 / 27 / 9$ & J.H. Weber & Qt. Welees & 5126199 \\
\hline C. D. Harvel & & $5 / 90$ & & 10 & \\
\hline
\end{tabular}

Approvals

W.H.CBuothutan,
W. H. Brotherton
Authorized Derivative Classifier


WSRC-RP-99-00422

Revision 0 


$$
\bar{T}
$$


Revision 0 


\section{AbSTRACT}

The purpose of this report is to provide software verification and validation (v\&v) for the statistical packages utilized by the Statistical Consulting Section (SCS) of the Savannah River Technology Center (SRTC). The need for this v\&v stems from the requirements of the Quality Assurance (QA) programs that are frequently applicable to the work conducted by SCS.

This report covers the following software and computing platforms:

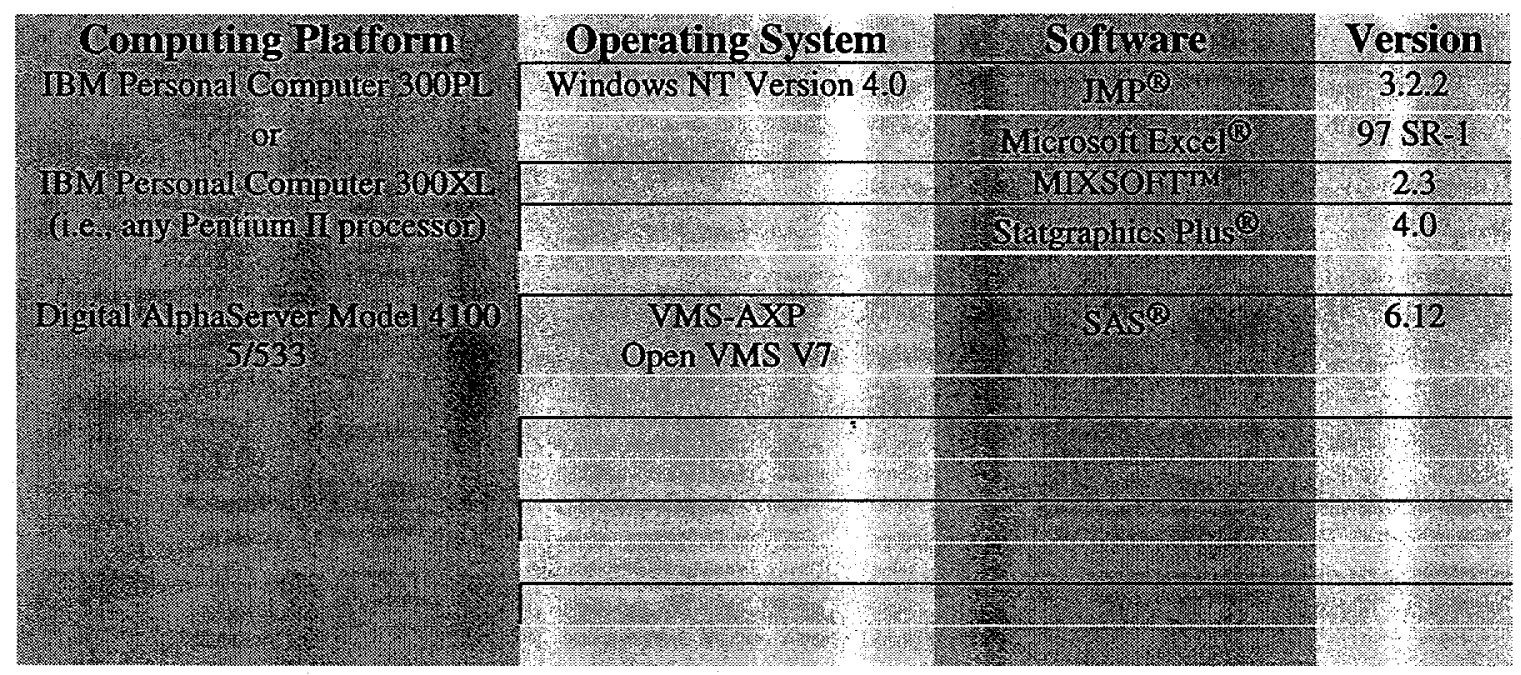

The IBM Personal Computer 300PL and 300XL are both Pentium II based desktops. Therefore, the software verification and validation in this report is valid interchangeably between both platforms. As new computing platforms, statistical packages, or revisions to existing packages are introduced into the Statistical Consulting Section, the appropriate problems from this report are to be re-evaluated using these new tools, and this report is to be revised to address their verification and validation. 
WSRC-RP-99-00422

Revision 0 


\section{CONTENTS}

ABSTRACT

vii

INTRODUCTION 1

BACKGROUND $\quad 1$

DISCUSSION 2

Descriptive Statistics $\quad 2$

Regression $\quad \mathbf{3}$

ANOVA

One-Way ANOVA 5

One-Way ANOVA with Random Factor 6

Two-Way ANOVA $\quad 7$

Two-Factor Nested ANOVA $\quad 8$

Experimental Designs $\quad 10$

Fractional Factorial $\quad 11$

Mixture $\quad 11$

$\begin{array}{ll}\text { Optimal Designs } & 12\end{array}$

Control Charts $\quad 14$

$\begin{array}{ll}\text { CONCLUDING COMMENTS } & 15\end{array}$

$\begin{array}{ll}\text { REFERENCES } & 16\end{array}$

$\begin{array}{ll}\text { APPENDICES } & 17\end{array}$ 


\section{LIST OF TABLES}

$1 \quad$ SCS Computing Platforms and Associated Statistical Software Programs

2 Data on Lot Size and Number of Man-Hours

3 Summary of Descriptive Statistics for Lot-Size Values by Software

\section{Package}

$4 \quad$ Summary of Regression Statistics for Each Software Package

5 Number of Cases Sold by Stores for Each of Four Package Designs--Kenton Food Company Example

$6 \quad$ ANOVA for Kenton Food Company Example

7 One-Way ANOVA Summary Statistics for Each Software Package

8 Ratings by Personnel Officers of Apex Enterprises [8]

9 One-Way ANOVA (Random Factor) Summary Statistics for Each Software Package

10 Insurance Premiums [8]

11 ANOVA for Insurance Example

12 Two-Way ANOVA Summary Statistics for Each Software Package

13 Sample Data for Nested Two-Factor Study (Training School Example from [1])

14 ANOVA for Training School Example

15 Two-Way Nested ANOVA Summary Statistics for Each Software Package

16 Two-Way Nested and Random ANOVA Summary Statistics for Each Software Package

17 Selected Fractional Factorial Experiments of the Complete Factorial Experiment for a 6-Factor Study

18 Extreme Vertices for Region Defined by Equation (2)

19 Face-Centered Cube Design

20 Data in Subgroups Obtained at Regular Intervals (Example 5.1, Table 5.1 of [11])

21 Control Chart Summary Statistics for Each Software Package 


\section{INTRODUCTION}

The mission of the Statistical Consulting Section (SCS) of the Savannah River Technology Center (SRTC) is to apply statistical thinking, methods, and computing in collaborative decision support, technology development, and continuous improvement at the Savannah River Site and to disseminate our knowledge and experience into the Federal Government complex via the Work For Others program. Computers and computer software are essential tools utilized by the SCS statisticians in pursuit of this mission. Many of these software programs are site-licensed and general purpose while some are special-purpose statistical packages.

As a general rule, memoranda, research reports, and technical reports prepared by members of SCS in response to customer requests for assistance are technically reviewed as part of the quality assurance (QA) for the section. ${ }^{1}$ In SRTC, calculations are normally checked by alternate means (e.g., hand calculations) performed by an independent reviewer, but this is not always completely possible on modeling or other complicated calculations performed by some software programs. However, the technical review would certainly include an assessment of the appropriateness of the statistical approach and routines utilized in the document. In addition, validation and verification ( $v \& v)$ of the software utilized for the analysis is frequently a requirement of the applicable QA program directing the investigation. This requirement is typically addressed uniquely in the document or in the supporting task plan, etc. The purpose of this report is to provide a central repository for the software verification and validation $(v \& v)$ for the statistical packages utilized by SCS. This document also demonstrates the $v \& v$ of some simple statistical software such as Excel spreadsheets. As new computing platforms, statistical packages, or revisions to existing packages are introduced into the Statistical Consulting Section, the appropriate problems from this report or new problems are to be evaluated using these new tools, and this report is to be revised to address their verification and validation.

The software considered in this report is commercial software (some of which is site-licensed). This study is to demonstrate that the vendor's software will perform correctly, as designed. The SRTC approach is to take problems with known solutions from peer reviewed publications and run them on the commercial software to demonstrate that the vendor's program does indeed perform as designed. The solutions of these problems are generated using software routines that are frequently utilized at SRTC. Running these routines using SRTC platforms and systems software and generating the appropriate answers to the "textbook" problems demonstrates the $v \& v$ of the software under consideration.

\section{BACKGROUND}

This report covers the software and computing platforms as identified in Table 1:

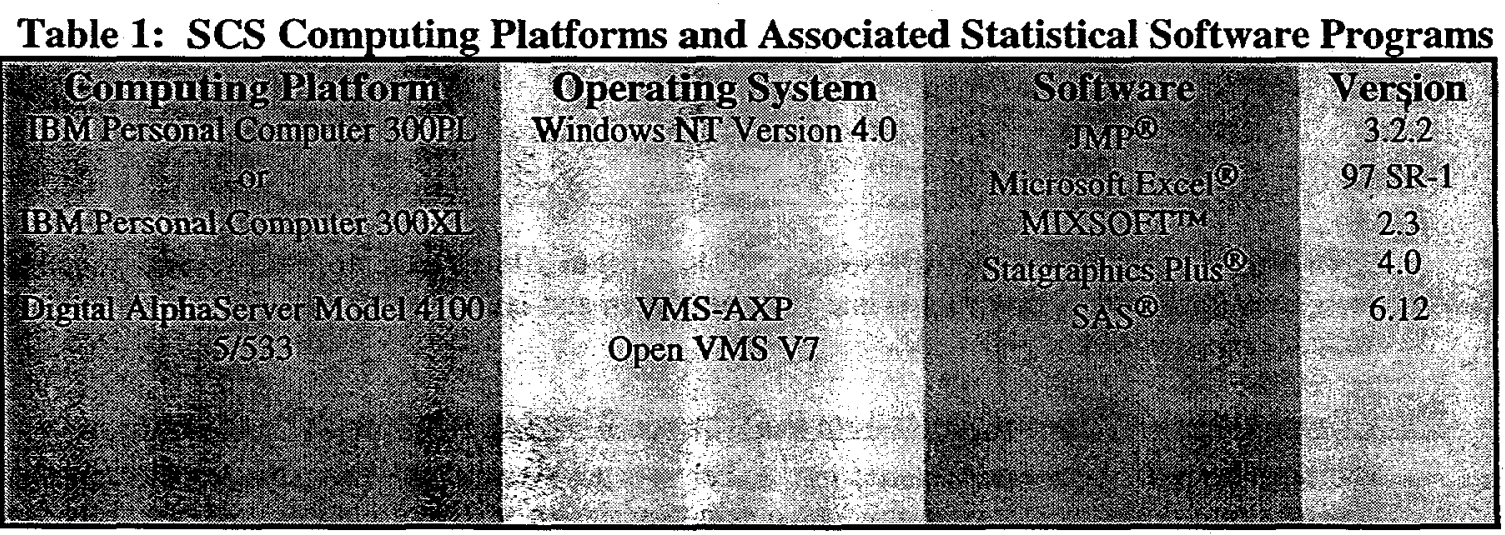

\footnotetext{
${ }^{1}$ Such reviews may be a requirement of the applicable QA program directing a particular technical task.
} 
The IBM Personal Computer 300PL and 300XL are both Pentium II based desktops. Therefore, the software $v \& v$ in this report is valid interchangeably between both platforms. JMP is a product of SAS Institute, Inc. [1]. The SAS system is a set of products. Those considered in this report include Base SAS [2], SAS/QC [3], SAS/STAT [4], and SAS/IML [5 and 6]. Microsoft Excel is a site-licensed product at the Savannah River Site. Mixsoft is a specialized software program for mixtures and other constrained-region problems [7]. Statgraphics contains numerous statistical routines and is a product of Manugistics, Inc.[8]. Other products (such as terminal emulation and virus protection packages) are also involved in the utilization of these platforms and software. These are not deemed important to the performance of the statistical programs and are not reviewed in this report.

The results from using each of the above packages to analyze the problems discussed below are organized by package as an appendix to this report.

\section{DISCUSSION}

In this section, problem types frequently encountered by members of SCS are identified. An example of each problem is selected from a well-established statistical textbook. The example is analyzed using a feature or features of the appropriate software described in the previous section. The results generated by the various software packages are compared to the information from the textbook and/or to each other for validation and verification. Little discussion is provided regarding the details of the problems, the underlying statistical theory, the statistical routines, or the statistical results. Information about the statistical packages, their capabilities, and details regarding their outputs can be found in their respective published documentation. These references, along with those cited as the sources of the problems, may be used to provide these details. The purpose of this report is show that the statistical packages, when used appropriately, provide reliable results.

\section{Descriptive Statistics}

The first area to be explored in this report is that of descriptive statistics, summary information about a set of data. Consider the set of data presented in Table 2, which is taken from Table 2.1 on page 40 of reference [9].

Table 2: Data on Lot Size and Number of Man-Hours

\begin{tabular}{|ccc|}
\hline Production Run & Lot Size & Man-Hours \\
$\mathrm{i}$ & $\mathrm{X}_{\mathbf{i}}$ & $\mathbf{Y}_{\mathrm{i}}$ \\
1 & 30 & 73 \\
2 & 20 & 50 \\
3 & 60 & 128 \\
4 & 80 & 170 \\
5 & 40 & 87 \\
6 & 50 & 108 \\
7 & 60 & 135 \\
8 & 30 & 69 \\
9 & 70 & 148 \\
10 & 60 & 132 \\
\hline
\end{tabular}

From [9], the average of the lot size values, $\bar{X}$, is equal to 50 (see page 46), and several graphical depictions (including a Box Plot, Time Plot, and Stem-and-leaf Plot) of these lot size values are provided on page 114 of [9].

\section{Using Excel Version 97 SR-1 on a Pentium II Processor Running Windows NT Version 4}

The data from Table 2 were entered into Excel and the Excel Tools/Data Analysis/Descriptive Statistics pull-down menus were used to obtain descriptive statistics on the lot-size values that were cut and pasted into this report as Table A.1a in Appendix A. There are Excel functions that provide descriptive statistics as well. Table A.1b provides the results of applying some of these functions to the lot-size values. 
Using JMP Version 3.2.2 on a Pentium II Processor Running Windows NT Version 4

The data from Table 2 were entered into JMP and the descriptive statistics capability of JMP (the Distribution-of-Y platform) was used to generate Exhibit B.1 in Appendix B for the lot size values. These results were determined by JMP, saved using JMP's journal feature, and imported (electronically) directly into this report. The average of the lot size values, 50 , is included in the information presented by JMP. A Box Plot, a Stem-and-leaf plot, and a time plot (a plot by production run number) are also provided; these compare very favorably to the information on page 114 of [9].

\section{Using SAS Version 6.12 on the AlphaServer Running Open VMS V7}

The data from Table 2 were included in a SAS program that used PROC MEANS, PROC SUMMARY, and PROC UNIVARIATE to generate some descriptive statistics for the lot size values. The SAS program and results were downloaded to the $P C$ and incorporated in this report. This information is provided in Exhibit C. 1 of Appendix C.

\section{Using Statgraphics, Version 4.0 on a Pentium II Processor Running Windows NT Version 4}

The data from Table 2 were entered into Statgraphics and the numeric data one variable analysis routine of Statgraphics was used to generate Exhibit E.1 in Appendix E for the lot size values. These results were saved using Statgraphics StatReporter feature, and imported (electronically) directly into this report. The average of the lot size values, 50 , is included in the information presented by Statgraphics. A Scatter Plot, Box-and-Whisker Plot, Histogram, a Stem-and-leaf plot, and a Normal Probability Plot are also provided. The results compare very favorably to the information on page 114 of [9] and to the JMP output in Exhibit B.1.

\section{Descriptive Statistics Summary Table}

The critical descriptive information generated by the software packages reviewed above is summarized in Table 3.

Table 3: Summary of Descriptive Statistics for Lot-Size Values by Software Package

\begin{tabular}{|cccc|}
\hline $\begin{array}{c}\text { Source of Information/ } \\
\text { Software Package }\end{array}$ & Standard & $\begin{array}{c}\text { Standard } \\
\text { As described in [9] on page 46 }\end{array}$ & 50 Deviation \\
Excel Version 97 SR-1 on PC running Windows NT Version 4 & 50 & 19.4365 & 6.1464 \\
JMP Version 3.2.2 on PC running Windows NT Version 4 & 50 & 19.4365 \\
SAS Version 6.12 on AlphaServer Running OpenVMS V7 & 50 & 19.4365 & 6.1464 \\
PROCs MEAN, SUMMARY, and UNIVARIATE & 50 & 19.4365 \\
Statgraphics Version 4.0 on PC running Windows NT Version 4.0 & 6.1464 \\
\hline
\end{tabular}

Table 3 summarizes what is revealed in the details of the exhibits covering this example: a consistent set of values for the descriptive statistics for these software packages across these computer platforms for the data of Table 2. Please note, however, that the ouput from the different packages often include different statistics.

\section{Regression}

The information presented in Table 2 also provides an opportunity for a look at various regression routines in fitting the simple linear model

$$
Y=\beta_{0}+\beta_{1} X+\varepsilon
$$

where $Y$ represents man-hours, $X$ represents lot-size, the $\beta$ 's represent the unknown coefficients that are to be estimated, and $\varepsilon$ represents the error term (assumed to be independently, normally distributed with zero mean and constant variance over the $Y$ 's.)

From page 44 of [9], the estimate of $\beta_{0}$, the y-intercept represented by $b_{0}$, is determined to be 10.0 and the estimate of $\beta_{1}$, the slope represented by $b_{1}$, is determined to be 2.0 . 


\section{Using Excel Version 97 SR-1 on a Pentium II Processor Running Windows NT Version 4}

The data from Table 2 were entered into Excel and used to fit the model given in equation (1). Two methods were used to analyze these data with Excel. Tools/Data Analysis/Regression pulldown menus were used to fit the data to the model given by equation (1). The results were cut and pasted into this report as Table A.2 in Appendix A.

The matrix handling capabilities of Excel were also used to perform the least squares estimation of the regression parameters. The discussion of this approach to the data of Table 2 is provided in [9] on pages 207 and 208. The results from using Excel's matrix handling capabilities to analyze this problem were cut and pasted into this report as Table A.3 in Appendix A.

\section{Using JMP Version 3.2.2 on a Pentium II Processor Running Windows NT Version 4}

The data from Table 2 were entered into JMP and used to fit the model given in equation (1). Two methods were used to analyze these data with JMP. Exhibit B.2 in Appendix B provides the results from using the Fit Y By X platform to perform this analysis. Exhibit B.3 in Appendix B provides the results from using the Fit Model platform to perform the analysis. In both cases, the JMP results were journaled and imported into this report, and in both cases, the estimates for the slope and y-intercept are 2 and 10, respectively.

\section{Using SAS Version 6.12 on AlphaSever Running Open VMS V7}

The SAS set of procedures provides several ways of analyzing the data from Table 2. Exhibit C.2 in Appendix $C$ provides the SAS/STAT program that utilizes PROC REG to perform the regression. Exhibit C. 3 in Appendix C provides a SAS/ML program that estimates the $\beta$ 's .

\section{Using Statgraphics, Version 4.0 on a Pentium II Processor Running Windows NT Version 4}

The data from Table 2 were entered into Statgraphics and used to fit the model given in equation (1). The Simple Regression method was used. The results are included in Exhibit E.2 in Appendix E. The StatReporter routine in Statgraphics was used to import the results into this report. The estimates for the slope and y-intercept are 2 and 10 , respectively.

\section{Regression Summary Table}

The critical regression information generated by the software packages reviewed above is summarized in Table 4 along with the results from [9].

Table 4: Summary of Regression Statistics for Each Software Package

\begin{tabular}{|c|c|c|c|c|}
\hline $\begin{array}{l}\text { Source of Information/ } \\
\text { Software Package }\end{array}$ & $\begin{array}{c}\text { Estimate } \\
\text { of } \\
\text { Intercept }\end{array}$ & $\begin{array}{c}\text { Estimate } \\
\text { of } \\
\text { Slope }\end{array}$ & $\mathbf{R}^{2}$ & $\begin{array}{c}\text { Root Mean } \\
\text { Square } \\
\text { Error }\end{array}$ \\
\hline As discussed in [9] on page 44 & 10 & 2 & , & \\
\hline $\begin{array}{l}\text { Excel Version } 97 \text { SR-1 on a PC running Windows NT Version 4--. } \\
\text { Regression }\end{array}$ & 10 & 2 & 0.9956 & 2.7386 \\
\hline $\begin{array}{l}\text { Excel Version } 97 \text { SR-1 on a PC running Windows NT Version 4--- } \\
\text { Matrix handling capability }\end{array}$ & 10 & 2 & & \\
\hline JMP Version 3.2 .2 on a PC running Windows NT Version 4 --- Fit $Y$ by $X$ & 10 & 2 & 0.9956 & 2.7386 \\
\hline $\begin{array}{l}\text { JMP Version } 3.2 .2 \text { on a PC running Windows NT Version } 4 \text {... Fit Model } \\
\text { SAS Version } 6.12 \text { on AlphaServer Running OpenVMS V7 }\end{array}$ & 10 & 2 & 0.9956 & 2.7386 \\
\hline PROC REG & 10 & 2 & 0.9956 & 2.7386 \\
\hline SAS/ML Version 6.12 on Alphaserver Running OpenVMS V7 & 10 & 2 & & \\
\hline Statgraphics Version 4.0 on a PC running Windows NT Version 4.0 & 10 & 2 & 0.9956 & 2.73861 \\
\hline
\end{tabular}

Table 4 summarizes what is revealed in the exhibits covering this example: a consistent set of regression results from these software packages across these computer platforms for the data of Table 2. 


\section{ANOVA}

Analysis of variance (ANOVA) models are versatile statistical tools for studying the relation between a dependent variable and one or more independent variables [9]. Several of these models are investigated in this section.

\section{One-Way ANOVA}

The example provided in Table 5 is from Table 14.1 on page 533 of [9]. In this table are recorded the number of cases sold by store for each of four package designs. An ANOVA is used to investigate for differences in sales across the four package designs.

Table 5: Number of Cases Sold by Stores for Each of Four Package Designs--Kenton Food Company Example

\begin{tabular}{|cccc|}
\hline \multicolumn{4}{c|}{ Cases Sold by Store } \\
Package & \multicolumn{3}{c|}{ Store } \\
Design & 1 & 2 & 3 \\
1 & 12 & 18 & \\
2 & 14 & 12 & 13 \\
3 & 19 & 17 & 21 \\
4 & 24 & 30 & \\
\hline
\end{tabular}

The discussion in [9] leads to the ANOVA results presented in Table 6 (this information appears as Table 14.4 on page 543 in [9]).

Table 6: ANOVA for Kenton Food Company Example

\begin{tabular}{|cccc|}
\hline Source of Variation & SS & df & MS \\
\hline Between designs & 258 & 3 & 86 \\
Error & 46 & 6 & 7.67 \\
\hline Total & 304 & 9 & \\
\hline
\end{tabular}

\section{Using Excel Version 97 SR-1 on a Pentium II Processor Running Windows NT Version 4}

The data from Table 5 were entered into Excel, and Tools/Data Analysis/ANOVA: Single Factor pull-down menus were used conduct the analysis of variance. The results were cut and pasted into this report as Table A.4 in Appendix A.

\section{Using JMP Version 3.2.2 on a Pentium I Processor Running Windows NT Version 4}

The data from Table 5 were entered into JMP, and the Fit Model platform was used to analyze these data. Exhibit B.4 in Appendix B provides the JMP results that were journaled and imported into this report.

\section{Using SAS Version 6.12 on AlphaServer Running Open VMS V7}

Two different tools available in the SAS system were used to analyze the data from Table 5. Exhibit C. 4 in Appendix C provides the input and results of PROC ANOVA, and Exhibit C.5 in Appendix $C$ provides this information for PROC GLM.

\section{Using Statgraphics, Version 4.0 on a Pentium II Processor Running Windows NT Version 4}

The data from Table 5 were entered into Statgraphics, and the One-Way ANOVA routine was used to analyze these data. Exhibit E.3 in Appendix E provides the Statgraphics results that were imported into this report using StatReporter.

\section{One-Way ANOVA Summary Table}

Some of the critical information from the ANOVA tables generated by the software packages reviewed above is summarized in Table 7 along with the results from [9]. 
WSRC-RP-99-00422

Revision 0

Table 7: One-Way ANOVA Summary Statistics for Each Software Package

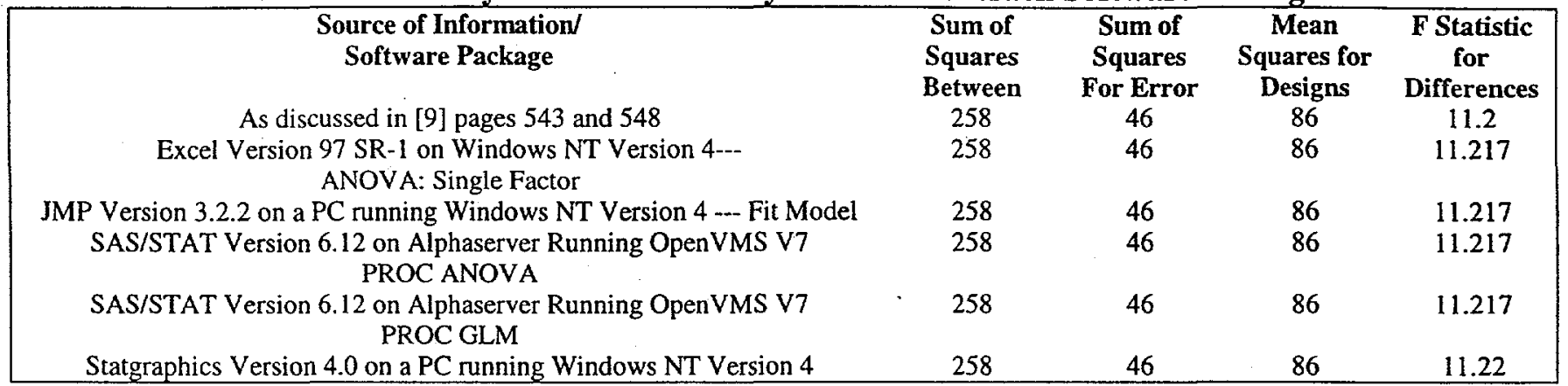

Table 7 summarizes what is revealed in the exhibits covering this example: a consistent set of ANOVA results from these software packages across these computer platforms for the data of Table 3.

\section{One-Way ANOVA with Random Factor}

The example provided in Table 8 is from Table 17.3 on page 654 of [9]. In this table are recorded the ratings by five (randomly selected) personnel officers of Apex Enterprises for four randomly assigned (to each officer) candidates. An ANOVA is used to estimate the variation in ratings among all personnel officers of this company.

Table 8: Ratings by Personnel Officers of Apex Enterprises [9]

\begin{tabular}{|c|c|c|c|c|}
\hline Officer & \multicolumn{4}{|c|}{ Candidate (j) } \\
\hline (i) & 1 & 2 & 3 & 4 \\
\hline A & 76 & 64 & 85 & 75 \\
\hline B & 58 & 75 & 81 & 66 \\
\hline C & 49 & 63 & 62 & 46 \\
\hline D & 74 & 71 & 85 & 90 \\
\hline E & 66 & 74 & 81 & 79 \\
\hline
\end{tabular}

The ANOVA for this problem is generated as in the previous section, but the interpretation of the information in the ANOVA under the conditions of a random factor lead to some additional calculations used to estimate the variance in ratings among the personnel officers. A discussion of the details of this estimation process is provided on page 660 of [9], leading to an estimate of 73.6 for this variance. Currently, Excel does not automatically generate this estimate as part of its ANOVA: Single Factor routine.

\section{Using JMP Version 3.2.2 on a Pentium II Processor Running Windows NT Version 4}

The data from Table 8 were entered into JMP, and the Fit Model platform was used (with a random factor designated in the fit) to analyze these data. Exhibit B.5 in Appendix B provides the JMP results that were journaled and imported into this report.

\section{Using SAS Version 6.12 on AlphaServer Running Open VMS V7}

PROC GLM and PROC VARCOMP demonstrate the capability of SAS to handle this type of problem for the data in Table 8 . The inputs and results from each of these two procedures for solving this problem are provided in Exhibits C.6 and C.7 in Appendix C.

Using Statgraphics, Version 4.0 on a Pentium II Processor Running Windows NT Version 4 The data from Table 8 were entered into Statgraphics, and the ANOVA-Variance Components routine was used to analyze these data. Exhibit E.4 in Appendix E provides the Statgraphics results that were imported into this report using StatReporter 


\section{One-Way ANOVA (with a Random Factor) Summary Table}

Some of the critical information from the ANOVA tables generated by the software packages reviewed above is summarized in Table 9 along with the results from [9]. Note that PROC GLM provides the equation for solving for the desired estimate. Using this equation along with the ANOVA information leads to an estimate of 73.6 for the rating variance.

Table 9: One-Way ANOVA (Random Factor) Summary Statistics for Each Software Package

\begin{tabular}{|c|c|c|c|c|}
\hline $\begin{array}{l}\text { Source of Information' } \\
\text { Software Package }\end{array}$ & $\begin{array}{c}\text { Sum of } \\
\text { Squares } \\
\text { Between }\end{array}$ & $\begin{array}{c}\text { Sum of } \\
\text { Squares } \\
\text { For Error }\end{array}$ & $\begin{array}{l}\text { Mean } \\
\text { Squares for } \\
\text { Offices }\end{array}$ & $\begin{array}{c}\text { Estimate of } \\
\text { Rating } \\
\text { Variance }\end{array}$ \\
\hline As discussed in [9] pages 655 and 660 & 1480 & 1134 & 370 & 73.6 \\
\hline $\begin{array}{c}\text { JMP Version } 3.2 .2 \text { on a PC running Windows NT Version } 4 \text {--. } \\
\text { Fit Model (random) } \\
\text { SAS Version } 6.12 \text { on Alphaserver Running OpenVMS V7 }\end{array}$ & 1480 & 1134 & 370 & 73.6 \\
\hline $\begin{array}{l}\text { PROC GLM } \\
\text { SAS Version } 6.12 \text { on Alphaserver Running OpenVMS V7 }\end{array}$ & 1480 & 1134 & 370 & 73.6 \\
\hline PROC VARCOMP & 1480 & 1134 & 370 & 73.6 \\
\hline Statgraphics Version 4.0 on a PC running Windows NT Version 4.0 & 1480 & 1134 & 370 & 73.6 \\
\hline
\end{tabular}

Table 9 summarizes what is revealed in the details of the exhibits covering this example: a consistent set of ANOVA results for these software packages across these computer platforms for the data of Table 8 .

\section{Two-Way ANOVA}

The example provided in Table 10 is from Table 21.2 on page 787 of [9]. In this table automobile insurance premiums (in dollars) are provided for a city of small, medium, and large size in each of two regions (East and West) of the US. An ANOVA is used to investigate differences between the regions and among the cities. An assumption is made that there is no interaction between these two factors.

Table 10: Insurance Premiums [9]

\begin{tabular}{|c|l|c|c|}
\hline \multicolumn{3}{|c|}{ Insurance Premiums in Dollars } \\
\hline & \multicolumn{3}{|c|}{ Region } \\
\hline \multirow{3}{*}{$\begin{array}{c}\text { Size } \\
\text { of } \\
\text { City }\end{array}$} & & East & West \\
\cline { 2 - 4 } & Small & 140 & 100 \\
\cline { 2 - 4 } & Medium & 210 & 180 \\
\cline { 2 - 4 } & Large & 220 & 200 \\
\hline
\end{tabular}

The discussion in [9] leads to the ANOVA results presented in Table 11 (this information also appears in Table 21.2 on page 787 in [9]).

Table 11: ANOVA for Insurance Example

\begin{tabular}{|cccr|}
\hline Source of Variation & SS & df & MS \\
\hline Size of City & 9,300 & 2 & 4,650 \\
Region & 1,350 & 1 & 1,350 \\
Error & 100 & 2 & 50 \\
\hline Total & 10,750 & 5 & \\
\hline
\end{tabular}




\section{Using Excel Version 97 SR-1 on a Pentium II Processor Running Windows NT Version 4}

The data from Table 10 were entered into Excel, and Tools/Data Analysis/ANOVA: Two Factors Without Replication pull-down menus were used conduct the analysis of variance. The results were cut and pasted into this report as Table A.5 in Appendix A.

\section{Using JMP Version 3.2.2 on a Pentium II Processor Running Windows NT Version 4}

The data from Table 10 were entered into JMP, and the Fit Model platform was used to analyze these data. Exhibit B.6 in Appendix B provides the JMP results that were journaled and imported into this report.

\section{Using SAS Version 6.12 on AlphaServer Running Open VMS V7}

The data from Table 10 were analyzed using PROC ANOVA and PROC GLM of the SAS system. Exhibits C. 8 and C.9 in Appendix C provide the inputs and results from using these two procedures to perform this analysis.

Using Statgraphics, Version 4.0 on a Pentium II Processor Running Windows NT Version 4 The data from Table 10 were entered into Statgraphics, and the Multi Factor ANOVA routine was used to analyze these data. Exhibit E.5 in Appendix E provides the Statgraphics results that were imported into this report using StatReporter

\section{Two-Way ANOVA Summary Table}

Some of the critical information from the ANOVA tables generated by the software packages reviewed above is summarized in Table 12 along with the results from [9].

Table 12: Two-Way ANOVA Summary Statistics for Each Software Package

\begin{tabular}{|c|c|c|c|c|}
\hline $\begin{array}{l}\text { Source of Information/ } \\
\text { Software Package }\end{array}$ & $\begin{array}{c}\text { Sum of } \\
\text { Squares for } \\
\text { City Size }\end{array}$ & $\begin{array}{c}\text { Sum of } \\
\text { Squares } \\
\text { For Region }\end{array}$ & $\begin{array}{l}\text { Sum of } \\
\text { Squares for } \\
\text { Error }\end{array}$ & $\begin{array}{l}\text { F Statistic } \\
\text { for Region }\end{array}$ \\
\hline $\begin{array}{l}\text { As discussed in [9] pages } 787 \text { and } 788 \\
\text { Excel Version } 97 \text { SR-1 }\end{array}$ & 9300 & 1350 & 100 & 27 \\
\hline $\begin{array}{l}\text { JMP Version } 3.2 .2 \text { on a PC running Windows NT Version } 4 \ldots \text { Fit Model } \\
\text { SAS Version } 6.12 \text { on Alphaserver Running OpenVMS V7 }\end{array}$ & 9300 & 1350 & 100 & 27 \\
\hline $\begin{array}{l}\text { PROC ANOVA } \\
\text { SAS Version } 6.12 \text { on Alphaserver Running OpenVMS V7 }\end{array}$ & 9300 & 1350 & 100 & 27 \\
\hline PROC GLM & 9300 & 1350 & 100 & 27 \\
\hline Statgraphics Version 4.0 on a PC running Windows NT Version 4 & 9300 & 1350 & 100 & 27 \\
\hline
\end{tabular}

Table 12 summarizes what is revealed in the exhibits covering this example: a consistent set of ANOVA results from these software packages across these computer platforms for the data of Table 10.

\section{Two-Factor Nested ANOVA}

A nested two-factor model differs from the previous two-factor (crossed) model in that the levels of the second factor are unique to each level of the first factor. An example of this situation is provided in Table 13 (this example is provided as Table 26.1 on page 971 of [9]). 
Table 13: Sample Data for Nested Two-Factor Study (Training School Example from [1])

\begin{tabular}{|c|cc|}
\hline \multirow{2}{*}{ Factor A (School) } & \multicolumn{2}{|c|}{ Factor B (Instructor) } \\
\hline Atlanta & 1 & 2 \\
& 25 & 14 \\
Chicago & 29 & 11 \\
& 11 & 22 \\
San Francisco & 6 & 18 \\
& 17 & 5 \\
& 20 & 2 \\
\hline
\end{tabular}

The discussion in [9] leads to the ANOVA results presented in Table 14 (this information appears in Table 26.5 on page 981 in [9]).

Table 14: ANOVA for Training School Example Example

\begin{tabular}{|cccr|}
\hline Soure of Variation & SS & df & \multicolumn{1}{c|}{ MS } \\
\hline Schools & 156.5 & 2 & 78.25 \\
Instructors within Schools & 567.5 & 3 & 189.17 \\
Error & 42.0 & 6 & 7.00 \\
\hline Total & 766.0 & 11 & \\
\hline
\end{tabular}

\section{Using JMP Version 3.2.2 on a Pentium II Processor Running Windows NT Version 4}

JMP does provide the desired estimate. The data from Table 13 were entered into JMP, and the Fit Model platform was used to analyze these data. Exhibit B.7 in Appendix B provides the JMP results that were journaled and imported into this report.

If both of these factors were random instead of fixed for the data in Table 13, the questions of interest would be different (what variation in scores is due to school? and what variation in scores is due to instructor?) and the test statistics to answer these questions would be different (this is discussed on page 984 of [9]). JMP handles this type of problem in its Fit Model platform. Using this approach leads to the results presented in Exhibit B.8 in Appendix B.

From the discussion of page 985 of [9], the test statistics for this random effects problem are given by

and

$$
\text { Test for schools }: F=\operatorname{MSA} / \operatorname{MSB}(A)=78.25 / 189.17=0.414
$$

$$
\text { Test for instructors }: F=\operatorname{MSB}(\mathrm{A}) / \mathrm{MSE}=189.17 / 7=27.0
$$

From Exhibit B.8, the test statistic for schools is 0.414 and for instructors is 27.0.

\section{Using SAS Version 6.12 on AlphaServer Running Open VMS V7}

The SAS system's PROC ANOVA was used to analyze the data in Table 13 and the results are presented in Exhibit C.10. Exhibit C.11 provides the results from the use of PROC GLM to analyze these same data.

If both factors are assumed to be random, there are still at least two-ways to analyze these data with SAS: PROC GLM and PROC VARCOMP. Exhibits C.12 and C.13 provide the inputs and results for these two procedures. Note that PROC VARCOMP does not compute the F statistic for schools, but the procedure does estimate this variance $(-27.7)$ as does the JMP procedure, by following the equation on page 985 of [9]. (A negative estimate indicates that this variance is not statistically significant for these data.) 


\section{Using Statgraphics, Version 4.0 on a Pentium II Processor Running Windows NT Version 4}

The data from Table 13 were entered into Statgraphics, and the Special, Advanced Regression, General Linear Model platform was used to analyze these data. Exhibit E. 6 in Appendix E provides the Statgraphics results that were imported into this report using StatReporter. No option is provided for allowing both factors to be random. However, the Statgraphics results using Variance Components are presented in Exhibit E.7.

\section{Two-Factor Nested ANOVA Summary Table}

Some of the critical information from the ANOVA tables generated by the software packages reviewed above is summarized in Table 15 along with the results from [9].

Table 15: Two-Way Nested ANOVA Summary Statistics for Each Software Package

\begin{tabular}{|ccccc|}
\hline $\begin{array}{c}\text { Source of Information/ } \\
\text { Software Package }\end{array}$ & $\begin{array}{c}\text { Sum of } \\
\text { Squares for } \\
\text { School }\end{array}$ & $\begin{array}{c}\text { Sum of } \\
\text { Squares } \\
\text { For } \\
\text { Instructor }\end{array}$ & $\begin{array}{c}\text { Sum of } \\
\text { Squares for } \\
\text { Error }\end{array}$ & $\begin{array}{c}\text { F Statistic } \\
\text { for Schools }\end{array}$ \\
As discussed in [9] pages 981 - 984 & 156.5 & 567.5 & 42 & 11.2 \\
JMP Version 3.2.2 on Windows NT Version 4 -.- Fit Model & 156.5 & 567.5 & 42 & 11.2 \\
SAS/STAT Version 6.12 on Alphaserver Running OpenVMS V7 & & & & 11.2 \\
PROC ANOVA & 156.5 & 567.5 & 42 & 11.2 \\
SAS/STAT Version 6.12 on Alphaserver Running OpenVMS V7 & & & & 11.18 \\
PROC GLM & 156.5 & 567.5 & 42 & 42 \\
Statgraphics for Windows Version 4.0 & 156.5 & 567.5 & 42 & \\
\hline
\end{tabular}

Table 15 summarizes what is revealed in the exhibits covering this example: a consistent set of ANOVA results from these software packages across these computer platforms for the data of Table 13.

Some of the critical information from the ANOVA tables generated by the software packages reviewed above for the situation in which the two factors of Table 13 are random is summarized in Table 16 along with the results from [9].

Table 16: Two-Way Nested and Random ANOVA Summary Statistics for Each Software Package

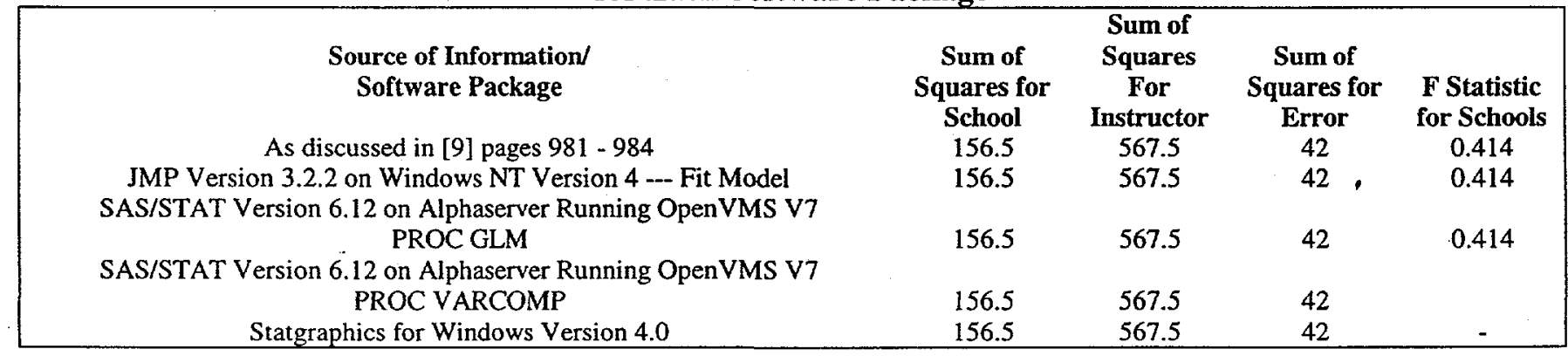

Table 16 summarizes what is revealed in the exhibits covering this example: a consistent set of ANOVA results from these software packages across these computer platforms for the data of Table 13 with both factors random.

\section{Experimental Designs}

Another major area of interest is that of experimental design. Two important types of problems in this area, which are addressed in this section, are fractional factorial experiments and mixture experiments. Several packages are utilized by SCS in planning these types of experiments. 


\section{Fractional Factorial}

An excellent aid in the planning of these types of experiments is provided in Table 9A.1 on pages 182 and 183 of [10]. A portion of this table covering 6-factors experiments is provided in Table 17.

Table 17: Selected Fractional Factorial Experiments of the Complete Factorial Experiment for a 6-Factor Study

\begin{tabular}{|cccccc|}
\hline $\begin{array}{c}\text { Number of } \\
\text { Factors }\end{array}$ & $\begin{array}{c}\text { Number of Test } \\
\text { Runs }\end{array}$ & Fraction & Resolution & $\begin{array}{c}\text { Defining } \\
\text { Equations }\end{array}$ & $\begin{array}{c}\text { Added } \\
\text { Factors } \\
4\end{array}$ \\
8 & $1 / 8$ & III & I = ABD & $\begin{array}{c}\text { I=ACE } \\
5=13 \\
\end{array}$ \\
& 16 & & & I=BCF & $6=23$ \\
& $1 / 4$ & IV & I=ABCE & $5=123$ \\
\hline
\end{tabular}

The features of this quarter fraction design for this 6-factor study of interest

\section{Using JMP Version 3.2.2 on a Pentium II Processor Running Windows NT Version 4}

Using the Design platform of JMP, candidate designs involving 6 factors can be explored. One option presented is a 16-run experiment (a quarter fraction of the complete factorial experiment). Exhibit B.9 in Appendix B provides the results of selecting this option from the list of JMP candidates.

\section{Using SAS Version 6.12 on AlphaServer Running Open VMS V7}

PROC FACTEX in SAS/QC can be used to generate such designs. The input and results for this SAS procedure are provided in Exhibit C.14 of Appendix C.

\section{Using Mixsoft Version 2.3 on a Pentium II Processor Running Windows NT Version 4}

This is a specialized software program that aids in experimental designs. Exhibit D. 1 in Appendix $D$ provides the results of using this program to select a fractional factorial experiment consisting of 16 trials for a 6 -factor problem.

\section{Using Statgraphics Version 4.0 on a Pentium II Processor Running Windows NT Version 4}

Using the Experimental Design platform of Statgraphics a quarter fraction of the complete factorial experiment for a 6-factor problem was selected. The results appear in Exhibit E.8 in the Appendix.

\section{Fractional Factorial Summary}

Four different packages were used to generate this fractional factorial experiment, and the results are identical except that the columns for the Mixsoft results are in a different order (these' can be rearranged to match results from the other packages exactly).

\section{Mixture}

Mixture experiments have been of critical importance in the support of DWPF and in other studies of the vitrification of legacy materials. In mixture experiments, the factors are ingredients of a mixture, and their levels are not independent. Extreme vertices designs are used to support these types of problems. For a full discussion, see Chapter 9 of reference [11]. An example from this reference will be used to illustrate the capabilities of the software utilized by SCS in support of mixture experiments. This example is discussed in Section 9.3.2 and involves a mixture of three components with each component being bounded as given in the equation (2)

$$
0.20 \leq \mathrm{x}_{1} \leq 0.60 \quad 0.10 \leq \mathrm{x}_{2} \leq 0.60 \quad 0.10 \leq \mathrm{x}_{3} \leq 0.50
$$


where the three components are represented by the $x_{i}{ }^{\prime} s$. The discussion in [4] on pages 353 through 358 identifies 6 extreme vertices for the region defined by equation (2). These extremes are given in Table 18 [10].

Table 18: Extreme Vertices for Region Defined by Equation (2)

\begin{tabular}{|c|c|c|c|c|}
\hline Count & $\mathbf{x}_{1}$ & $\mathbf{x}_{2}$ & $\mathbf{x}_{\mathbf{3}}$ & Sum \\
\hline 1 & 0.6 & 0.3 & 0.1 & 1 \\
\hline 2 & 0.3 & 0.6 & 0.1 & 1 \\
\hline 3 & 0.2 & 0.6 & 0.2 & 1 \\
\hline 4 & 0.2 & 0.3 & 0.5 & 1 \\
\hline 5 & 0.4 & 0.1 & 0.5 & 1 \\
\hline 6 & 0.6 & 0.1 & 0.3 & 1 \\
\hline
\end{tabular}

\section{Using JMP Version 3.2.2 on a Pentium II Processor Running Windows NT Version 4}

Using the Design platform of JMP, the region defined by equation (2) was entered and the Extreme Vertices design option invoked. Exhibit B.10 in Appendix B provides the results of selecting this option under the JMP software.

\section{Using Mixsoft Version 2.3 on a Pentium II Processor Running Windows NT Version 4}

Once again, Mixsoft is specialized software; one of its capabilities is mixture experimental design. Exhibit D. 2 in Appendix D provides the inputs and outputs generated by this program to select generate the extreme vertices for the problem defined by equation (2).

\section{Using SAS Version 6.12 on AlphaServer Running Open VMS V7}

Exhibit $\mathrm{C} .15$ in Appendix $\mathrm{C}$ provides the input and results from using the mixture design capabilities provided in SAS/QC to generate the extreme vertices for the region defined by equation (2).

\section{Using Statgraphics, Version 4.0 on a Pentium II Processor Running Windows NT Version 4}

Using the Experimental Design platform of Statgraphics, the region defined by equation (2) was entered and the Extreme Vertices design option selected. Exhibit E.9 in the Appendix provides the Statgraphics results.

\section{Mixture Summary}

Four different packages were used to generate the set of extreme vertices for the mixture experiment described by equation (2), and the results are identical to those of Table 18 across all four packages.

\section{Optimal Designs}

Selecting an optimal design from a set of candidate points is frequently a necessity during the planning of an experiment. Computer-aided design of experiments routines utilize one or more of design optimality criteria to choose such a set of points (the design) from a candidate list of points. Almost all of these computer-aided design routines are model dependent. Once a model is chosen. and a list of candidate design points is specified, a particular design (of a designated size) that minimizes or maximizes a particular criterion is selected from the candidate points. One of the more frequently selected criteria for choosing a design is

D-optimality, which seeks to minimize the determinant of $\left(X^{\prime} \mathbf{X}\right)^{-1}$ where each row of the matrix $X$ is a design point, i.e., a set of explanatory variables: $x_{1}, x_{2}, \ldots, x_{p}$.

This is a model-dependent criterion, and a design that is optimal for one model form, for example a first-degree model such as (3), will not necessarily be optimal for another model such as a second- 
degree model. The example to be considered as part of this report is the use of this criterion to select 8 design points from those listed in Table 19.

Table 19: Face-Centered Cube Design

\begin{tabular}{|ccccc|}
\hline Pattern & $\mathbf{x}_{1}$ & $\mathbf{x}_{2}$ & $\mathbf{x}_{3}$ & Comment \\
+00 & 1 & 0 & 0 & Axial \\
++ & 1 & 1 & -1 & FF \\
\hline & 1 & -1 & -1 & FF \\
000 & 0 & 0 & 0 & Center-FF \\
$00-$ & 0 & 0 & -1 & Axial \\
000 & 0 & 0 & 0 & Center-FF \\
-00 & -1 & 0 & 0 & Axial \\
$00+$ & 0 & 0 & 1 & Axial \\
++ & 1 & 1 & 1 & FF \\
++ & 1 & -1 & 1 & FF \\
000 & 0 & 0 & 0 & Center-FF \\
$+t$ & -1 & 1 & 1 & FF \\
+- & -1 & 1 & -1 & FF \\
$0-0$ & 0 & -1 & 0 & Axial \\
+ & 1 & -1 & 1 & FF \\
$0+0$ & 0 & 1 & 0 & Axial \\
000 & 0 & 0 & 0 & Center-Ax \\
000 & 0 & 0 & 0 & Center-Ax \\
000 & 0 & 0 & 0 & Center-FF \\
\hline++ & -1 & 1 & 1 & FF \\
\hline
\end{tabular}

The design points provided in this table represent a "face-centered cube design," similar to that discussed in [10]. The optimal design for a linear model in $x 1, x 2$, and $\times 3$ with an intercept term is given by the shaded rows of Table 19. These points make up the fractional factorial part of the face-centered cube design.

\section{Using JMP Version 3.2.2 on a Pentium II Processor Running Windows NT Version 4}

A feature of the JMP software package is its D-Optimal Design routine to choose a set of points (the design) from a candidate list of points [1]. The data from Table 19 were entered into JMP and the D-optimal routine evoked to select the best set of 8 points from the set of 20 points. The results from this process are provided in Exhibit B.11 in Appendix B. Values of the D-Optimality criteria, including D-efficiency, are provided as part of the output from this routine. The JMP spreadsheet resulting from the process is also provided in Exhibit B.11, and it shows the rows selected as "optimal" for a linear model.

\section{Using SAS Version 6.12 on AlphaServer Running Open VMS V7}

Exhibit C.16 in Appendix C provides the results form using PROC OPTEX in SAS to select an optimal design.

\section{Using Statgraphics Version 4.0 on a Pentium II Processor Running Windows NT Version 4}

Exhibit E.10 in Appendix E provides the results from using the D-Optimal Design routine in Statgraphics.

\section{Optimal Design Summary}

Three different packages were used to generate a set of eight design points from those in Table 19 that would be D-optimal for a linear model. The two data sets resulting from the JMP and SAS procedures were identical. Statgraphics had a mirror image design point (+--) for one of the eight points selected by JMP $(-++)$. However, the design efficiencies are identical. The Statgraphics design was input into JMP and the efficiency statistics reproduced. 


\section{Control Charts}

As a final area of interest in this review of software, a problem in statistical process control is explored. The construction of $\mathrm{x}$-bar and $\mathrm{s}$ charts will be illustrated using an example from [12] (these data are provided in Table 5.1 on page 83 of [12]). These data (along with summary information) are presented in Table 20.

Table 18: Data in Subgroups Obtained at Regular Intervals (Example 5.1, Table 5.1 of [12])

\begin{tabular}{|ccccccc|}
\hline Subgroup & $\times 1$ & $\times 2$ & $\times 3$ & $x 4$ & Average & Std Dev \\
1 & 72 & 84 & 79 & 49 & 71.00 & 15.47 \\
2 & 56 & 87 & 33 & 42 & 54.50 & 23.64 \\
3 & 55 & 73 & 22 & 60 & 52.50 & 21.70 \\
4 & 44 & 80 & 54 & 74 & 63.00 & 16.85 \\
5 & 97 & 26 & 48 & 58 & 57.25 & 29.68 \\
6 & 83 & 89 & 91 & 62 & 81.25 & 13.28 \\
7 & 47 & 66 & 53 & 58 & 56.00 & 8.04 \\
8 & 88 & 50 & 84 & 69 & 72.75 & 17.23 \\
9 & 57 & 47 & 41 & 46 & 47.75 & 6.70 \\
10 & 13 & 10 & 30 & 32 & 21.25 & 11.35 \\
11 & 26 & 39 & 52 & 48 & 41.25 & 11.53 \\
12 & 46 & 27 & 63 & 34 & 42.50 & 15.76 \\
13 & 49 & 62 & 78 & 87 & 69.00 & 16.87 \\
14 & 71 & 63 & 82 & 55 & 67.75 & 11.53 \\
15 & 71 & 58 & 69 & 70 & 67.00 & 6.06 \\
16 & 67 & 69 & 70 & 94 & 75.00 & 12.73 \\
17 & 55 & 63 & 72 & 49 & 59.75 & 9.98 \\
18 & 49 & 51 & 55 & 76 & 57.75 & 12.42 \\
19 & 72 & 80 & 61 & 59 & 68.00 & 9.83 \\
20 & 61 & 74 & 62 & 57 & 63.50 & 7.33 \\
\hline
\end{tabular}

\section{$\mathrm{x}$-Bar and s Charts}

The values were entered into Excel, and the summary statistics were computed using the AVERAGE and STDEV functions of Excel. These are the values that appear in the last two columns of Table 20, and they agree with the information in [12]. The data were also entered into JMP, and the sample means and standard deviations were computed. These summary statistics were computed using JMP's "grouping" feature. Table B.1 in Appendix B provides these values (which agree with Table 20).

\section{Using JMP Version 3.2.2 on a Pentium II Processor Running Windows NT Version 4}

Using the Graph/Control Charts platform of JMP, the $\mathrm{x}$-bar and $s$ charts for the data of Table 20 were generated after the values were entered into JMP. These charts appear as Exhibit B.12 in Appendix B.

\section{Using SAS Version 6.12 on AlphaServer Running Open VMS V7}

Exhibit C.17 in Appendix C provides the inputs to and results from using PROC SHEWHART in SAS to generate these control charts.

\section{Using Statgraphics Version 4.0 on a Pentium II Processor Running Windows NT Version 4}

Using the Special/Quality Control/Variables Control Charts/X-bar and s option of Statgraphics, the $\mathrm{x}$-bar and $\mathrm{s}$ charts for the data in Table 20 were generated using Statgraphics. These charts appear as Exhibit E.11 in Appendix E.

\section{Control Chart Summary Table}

Some of the critical information from the control charts generated by the software packages reviewed above is provided in Table 21 along with the results from [12]. 


\section{Table 21: Control Chart Summary Statistics for Each Software Package}

\begin{tabular}{|ccccc|}
\hline $\begin{array}{c}\text { Source of Information/ } \\
\text { Software Package }\end{array}$ & $\begin{array}{c}\text { Center-line } \\
\text { for } \\
\text { X-bar Chart }\end{array}$ & $\begin{array}{c}\text { Control limit } \\
\text { for x-bar } \\
\text { Chart }\end{array}$ & $\begin{array}{c}\text { Center- line } \\
\text { for } \\
\text { s Chart }\end{array}$ & $\begin{array}{c}\text { Upper } \\
\text { Control limit } \\
\text { for } \\
\text { s Chart }\end{array}$ \\
As discussed in [12] pages 83-96 & 59.4 & 82.1 & 13.9 & 31.5 \\
JMP Version 3.2.2 on a PC running Windows NT Version 4 _.- Fit Model & 59.4 & $\mathbf{8 2 . 1}$ & 13.9 & 31.5 \\
SAS/QC Version 6.12 on AlphaServer Running OpenVMS V7 & & & & \\
PROC SHEWHART & 59.4 & 82.1 & 13.9 & 31.5 \\
Statgraphics Version 4.0 on a PC running for Windows Version 4.0 & 59.4 & 82.1 & 13.9 & 31.5 \\
\hline
\end{tabular}

Table 21 summarizes what is revealed in the exhibits covering this example: a consistent set of control charts from these software packages across these computer platforms for the data of Table 20.

\section{CONCLUDING COMMENTS}

The statistical analyses completed in this study provide an important verification and validation of the statistical software and computer platforms utilized by the members of SCS. The IBM Personal Computer 300PL and 300XL are both Pentium II based desktops. Therefore, the software $v \& v$ in this report is valid interchangeably between both platforms.

Problems frequently encountered by members of SCS are identified; an example of each problem is selected from a well-established statistical textbook; the example is analyzed using a feature or features of the software (as appropriate) described in the previous section; and the results generated by the various software packages are compared to the information from the textbook and/or to each other for validation and verification. Little discussion is provided regarding the details of the problems, the underlying statistical theory, the statistical routines, or the statistical results. Information about the statistical packages, their capabilities, and details regarding their outputs can be found in their respective published documentation. These references along with those cited as the sources of the problems may be used to provide these details.

This report has shown that these statistical packages, when used appropriately, provide reliable results over a broad range of problem types. This effort is not intended to diminish the importance of the technical review process. As seen in the discussion above, selecting the appropriate statistical approach and model for the problem at hand and the appropriate feature of the available software for its solution are important issues. An important part of the technical review process is to confirm the appropriateness of these decisions. 


\section{REFERENCES}

[1] SAS Institute, JMP ${ }^{\circledR}$ Statistics and Graphics Guide: Version 3 of JMP, SAS Institute, Inc., Cary, NC, 1995.

[3] SAS Institute, SAS Procedures Guide, Version 6, Third Edition, SAS Institute, Inc., Cary, NC, 1990.

[3] SAS Institute, SAS/QC ${ }^{\circledR}$ Software: Reference, Version 6, First Edition, SAS Institute, Inc., Cary, NC, 1989.

[4] SAS Institute, SAS/STAT ${ }^{\circledR}$ User's Guide, Version 6, Fourth Edition, Volume 1, SAS Institute, Inc., Cary, NC, 1990.

[5] SAS Institute, SAS/STAT ${ }^{\circledR}$ User's Guide, Version 6, Fourth Edition, Volume 2, SAS Institute, Inc., Cary, NC, 1990.

[6] SAS Institute, SAS/IML ${ }^{\circledR}$ Software: Usage and Reference, Version 6, First Edition, SAS Institute, Inc., Cary, NC, 1990.

[7] Piepel, G.F., MIXSOFT - Software for the Design and Analysis of Mixture and Other Constrained Region Experiments, User's Guide Version 2.3, MIXSOFT-Mixture Experiment Software, Richland, Washington, 1998.

[8] Manugistics, Inc., Statgraphics Plus ${ }^{\circledR}$ for Windows, Version 4.0, Rockville, Maryland.

[9] Neter, John, William Wasserman, and Michael H. Kutner, Applied Linear Statistical Models: Regression, Analysis of Variance, and Experimental Designs, Third Edition, Richard D. Irwin, Inc., Homewood, IL, 1990.

[10] Mason, Robert L., Richard F. Gunst, and James L. Hess, Statistical Design and Analysis of Experiments With Applications to Engineering and Science, John Wiley \& Sons, Inc., New York, 1989.

[11] Khuri, Andre' I. And John A. Cornell, Response Surfaces: Designs and Analyses, Marcel Dekker, Inc., New York, 1987.

[12] Ryan, Thomas P., Statistical Methods for Quality Improvement, John Wiley \& Sons, Inc., New York, 1989.

[13] Hayes, W.L., Statistics, third edition. New York: Holt, Rinehart and Winston, 1981. 


\section{APPENDICES}

\section{Appendix A: Excel Results}

Table A.la: Excel Descriptive Statistics for Lot-Size Values in Table 2

Table A.1b: Excel Functions for Lot-Size Values in Table 2

Table A.2: Excel Regression of Information in Table 2

Table A.3: Excel Matrix Handling Capabilities Used to Conduct Regression Analysis for Information in Table 2

Table A.4: Excel ANOVA

Table A.5: Excel ANOVA: Two-Factor Without Replication

\section{Appendix B: JMP Results}

Table B.1: JMP Sample Statistics for Data from Table 20

Exhibit B.1: JMP Output for Descriptive Statistics of Lot Size Information in Table 2

Exhibit B.2: JMP Output for Regression Model for Information in Table 2 Using Fit $\mathrm{Y}$ by X

Exhibit B.3: JMP Output for Regression Model for Information in Table 2 Using Fit Model

Exhibit B.4: JMP Output for ANOVA of Information in Table 5 Using Fit Model

Exhibit B.5: JMP Output for ANOVA of Information in Table 8 Using Fit Model with Random Factor

Exhibit B.6: JMP Output for ANOVA of Information in Table 8 Using Fit Model with Two Factors

Exhibit B.7: JMP Output for Nested ANOVA of Information in Table 13 Using Fit Model with A Nested Factor

Exhibit B.8: JMP Output for Nested ANOVA of Information in Table 13 Using Fit Model with Random Factors

Exhibit B.9: JMP Output for a Fractional Factorial Experiment using the Design Experiment Feature

Exhibit B.10: JMP Output for Mixture Problem Defined by Equation (2)

Exhibit B.11: JMP's D-Optimality Results

Exhibit B.12: JMP Results for $\mathrm{x}$-Bar and s Charts for Data in Table 20

\section{Appendix C: SAS Results}

Exhibit C.1: SAS Input for and Results from Descriptive Statistics for Lot Size Values in Table 2 Exhibit C.2: SAS Input for and Results from Proc Reg for Table 2 Data

Exhibit C.3: SAS Input for and Results from SAS/IML Program for Regression of Table 2 Data Exhibit C.4: SAS Input for and Results from SAS/STAT Proc ANOVA for Analyzing of Table 5 Data Exhibit C.5: SAS Input for and Results from SAS/STAT Proc GLM for Analyzing of Table 5 Data Exhibit C.6: SAS Input for and Results from SAS/STAT Proc GLM for Analyzing of Table 8 Data Exhibit C.7: SAS Input for and Results from SAS/STAT Proc VARCOMP for Analyzing of Table 8 Data Exhibit C.8: SAS Input for and Results from SAS/STAT Proc ANOVA for Analyzing of Table 8 Data Exhibit C.9: SAS Input for and Results from SAS/STAT Proc GLM for Analyzing of Table 8 Data Exhibit C.10: SAS Input for and Results from SAS/STAT Proc ANOVA for Analyzing of Table 13 Data Exhibit C.11: SAS Input for and Results from SAS/STAT Proc GLM for Analyzing of Table 13 Data Exhibit C.12: SAS Input for and Results from SAS/STAT Proc GLM for Analyzing of Table 13 Data Exhibit C.13: SAS Input for and Results from SAS/STAT Proc VARCOMP for Analyzing of Table 13 Data

Exhibit C.14: SAS Input for and Results from SAS/QC Proc Factex for Experimental Design

Exhibit C.15: SAS Input and Output for Mixture Problem Defined by Equation (2) Exhibit C.16: SAS Input for and Results from SAS/QC Proc Optex for D-Optimality Exhibit C.17: SAS Input and Output for Control Chart Example from Table 20 


\section{Appendix D: Mixsoft Results}

Exhibit D.1: Mixsoft Output for a Fractional Factorial Experiment using the Design Experiment Feature

Exhibit D.2: Mixsoft Input and Output for Mixture Problem Defined by Equation (2)

\section{Appendix E: Statgraphics Results}

Exhibit E.1: Statgraphics Output for Statistics of Lot Size Information in Table 2

Exhibit E.2: Statgraphics Output for Table 2 Data Using Simple Regression

Exhibit E.3: Statgraphics Output for Table 5 Data Using One-Way ANOVA

Exhibit E.4: Statgraphics Output for Table 8 Data using Variance Components Analysis

Exhibit E.5: Statgraphics Output for Table 10 Data using Two Factor ANOVA

Exhibit E.6: Statgraphics Output for Table 13 Data using a Nested

Exhibit E.7: Statgraphics Output for Table 13 Data using Variance Component Analysis

Exhibit E.8: Statgraphics Output for Fractional Factorial Design

Exhibit E.9: Statgraphics Output for Extreme Vertices

Exhibit E.10: Statgraphics D-Optimality Results

Exhibit E.11: Statgraphics X-bar and S Charts - X 
Table A.1a: Excel Descriptive Statistics for Lot-Size Values in Table 2

\begin{tabular}{|cc|}
\hline \multicolumn{2}{|c|}{ Lot Size $\left(X_{i}\right)$} \\
\hline Mean & 50 \\
Standard Error & 6.146362972 \\
Median & 55 \\
Mode & 60 \\
Standard Deviation & 19.43650632 \\
Sample Variance & 377.7777778 \\
Kurtosis & -1.066608997 \\
Skewness & -0.113491711 \\
Range & 60 \\
Minimum & 20 \\
Maximum & 80 \\
Sum & 500 \\
Count & 10 \\
Largest(1) & 80 \\
Smallest $(1)$ & 20 \\
Confidence Level(95.0\%) & 13.90404962 \\
\hline
\end{tabular}

Table A.1b: Excel Functions for Lot-Size Values in Table 2

\begin{tabular}{|c|c|}
\hline EXCEL Function & Description \\
\hline Count & 10 Number of data \\
\hline Average & 50 Average of data \\
\hline Sum & 500 Sum of data \\
\hline Minimum & 20 Minimum of data \\
\hline Maximum & 80 Maximum of data \\
\hline Median & 55 Median of data \\
\hline Mode & 60 Mode of data \\
\hline DEVSQ & 3400 Sum of Squares of Deviations about the Mean \\
\hline Std Dev & 19.43650632 Standard deviation of data \\
\hline Skew & -0.11349171 Skewness of data \\
\hline Kurt & -1.06660900 Kurtosis of data \\
\hline Geomean & 46.12054471 Geometric mean of data \\
\hline Harmean & 41.93709436 Harmonic mean of data \\
\hline
\end{tabular}




\section{Appendix A: Excel Results}

Table A.2: Excel Regression of Information in Table 2

\begin{tabular}{|c|c|c|c|c|c|c|c|}
\hline \multicolumn{8}{|c|}{ SUMMARY OUTPUT } \\
\hline \multicolumn{2}{|c|}{ Regression Statistics } & & & & & & \\
\hline Multiple R & 0.997801 & & & & & & \\
\hline R Square & 0.995608 & & & & & & \\
\hline Adjusted R Square & 0.995059 & & & & & & \\
\hline Standard Error & 2.738613 & & & & & & \\
\hline Observations & 10 & & & & & & \\
\hline \multicolumn{8}{|l|}{ ANOVA } \\
\hline & $d f$ & $S S$ & $M S$ & $F$ & Significance $F$ & & \\
\hline Regression & 1 & 13600 & 13600 & 1813.333 & $1.02 \mathrm{E}-10$ & & \\
\hline Residual & 8 & 60 & 7.5 & & & & \\
\hline \multirow[t]{2}{*}{ Total } & 9 & 13660 & & & & & \\
\hline & Coefficients & $\begin{array}{c}\text { Standard } \\
\text { Error }\end{array}$ & $t$ Stat & $P$-value & Lower $95 \%$ Upper $95 \%$ & $\begin{array}{l}\text { Lower } \\
95.0 \% \\
\end{array}$ & $\begin{array}{l}\text { Upper } \\
95.0 \%\end{array}$ \\
\hline Intercept & 10 & 2.502939 & 3.995302 & 0.003976 & 4.228208 & 4.228208 & 15.77179 \\
\hline Lot Size $(\mathrm{Xi})$ & 2 & 0.046967 & 42.58325 & $1.02 \mathrm{E}-10$ & 1.891694 & 1.891694 & 2.108306 \\
\hline
\end{tabular}


Table A.3: Excel Matrix Handling Capabilities Used to Conduct Regression Analysis for Information in Table 2

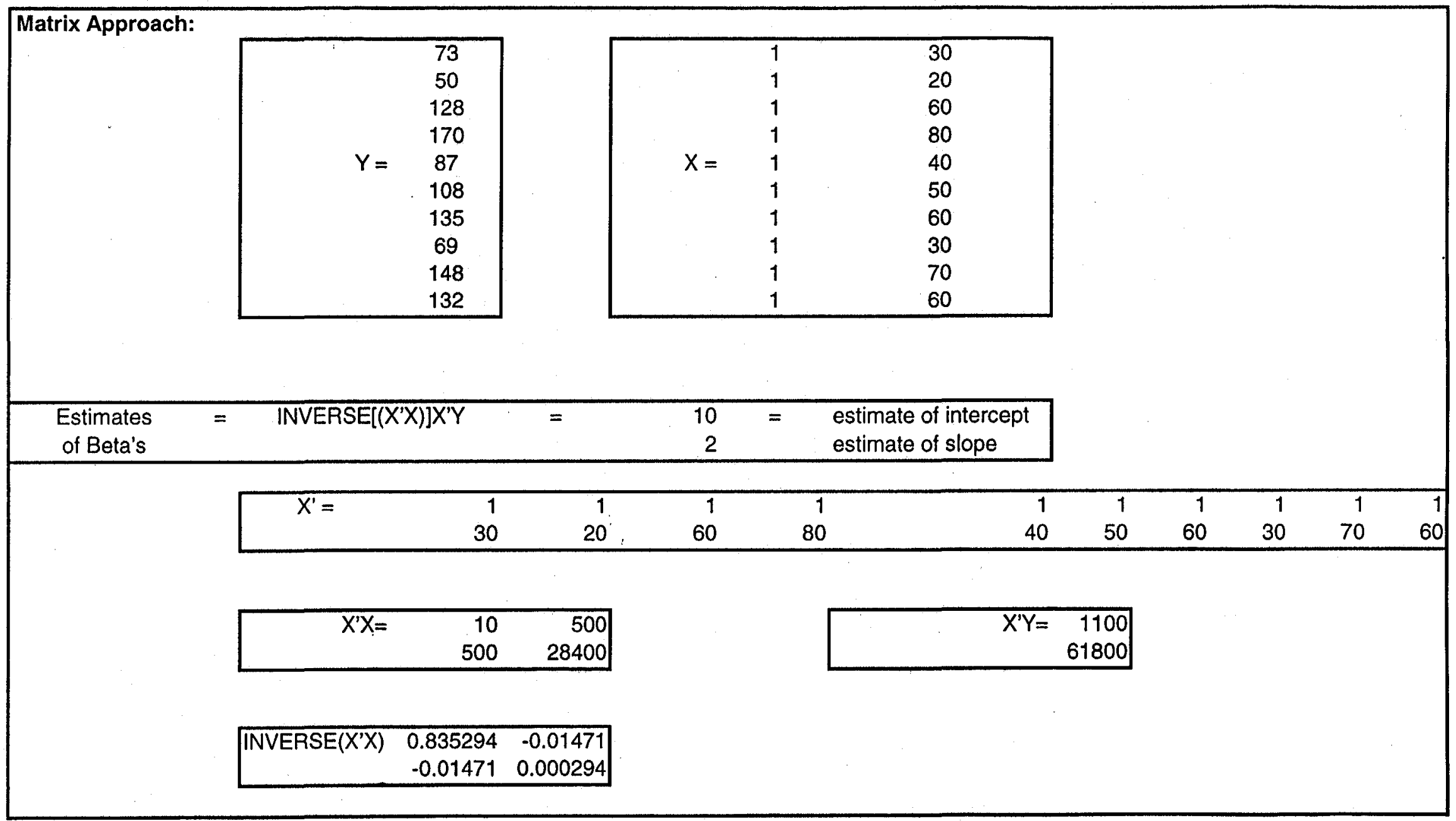


Appendix A: Excel Results

Table A.4: Excel ANOVA

Anova: Single Factor

SUMMARY

\begin{tabular}{crrrrr}
\hline Groups & \multicolumn{1}{c}{ Count } & Sum & Average & Variance \\
\hline & 1 & 2 & 30 & 15 & 18 \\
& 2 & 3 & 39 & 13 & 1 \\
& 3 & 3 & 57 & 19 & 4 \\
& 4 & 2 & 54 & 27 & 18 \\
\hline
\end{tabular}

ANOVA

\begin{tabular}{|c|c|c|c|c|c|c|}
\hline Source of Variation & SS & $d f$ & MS & $F$ & $P$-value & F crit \\
\hline Between Groups & 258 & 3 & 86 & 11.21739 & 0.007135 & 4.757055 \\
\hline Within Groups & 46 & 6 & 7.666667 & & & \\
\hline Total & 304 & 9 & & & & \\
\hline
\end{tabular}




\section{Appendix A: Excel Results}

Table A.5: Excel ANOVA: Two-Factor Without Replication

\begin{tabular}{|l|r|r|r|r|r|r|}
\hline Anova: Two-Factor Without Replication & & & & & & \\
\hline \multicolumn{1}{|c|}{ SUMMARY } & & & & & & \\
\hline Small & Count & Sum & Average & Variance & & \\
\hline Medium & 2 & 240 & 120 & 800 & & \\
\hline Large & 2 & 390 & 195 & 450 & & \\
\hline & 2 & 420 & 210 & 200 & & \\
\hline East & 3 & 570 & 190 & 1900 & & \\
\hline West & 3 & 480 & 160 & 2800 & & \\
\hline & & & & & & \\
\hline & & & & & & \\
\hline ANOVA & & & & & & \\
\hline & $S S$ & $d f$ & $M S$ & $F$ & $P$-value & Fcrit \\
\hline Rows Source of Variation & 9300 & 2 & 4650 & 93 & 0.010638 & 19.00003 \\
\hline Columns & 1350 & 1 & 1350 & 27 & 0.035099 & 18.51276 \\
\hline Error & 100 & 2 & 50 & & & \\
\hline & & & & & & \\
\hline Total & 10750 & 5 & & & & \\
\hline
\end{tabular}


Appendix B: JMP Results

Table B.1: JMP Sample Statistics for Data from Table 20

\begin{tabular}{|cccc|}
\hline Subgroup & N Rows & Mean(x) & Std Dev(x) \\
1 & 4 & 71 & 15.4704 \\
2 & 4 & 54.5 & 23.64318 \\
3 & 4 & 52.5 & 21.70253 \\
4 & 4 & 63 & 16.8523 \\
5 & 4 & 57.25 & 29.68024 \\
6 & 4 & 81.25 & 13.27592 \\
7 & 4 & 56 & 8.041559 \\
8 & 4 & 72.75 & 17.23127 \\
9 & 4 & 47.75 & 6.70199 \\
10 & 4 & 21.25 & 11.35415 \\
11 & 4 & 41.25 & 11.52895 \\
12 & 4 & 42.5 & 15.7586 \\
13 & 4 & 69 & 16.87207 \\
14 & 4 & 67.75 & 11.52895 \\
15 & 4 & 67 & 6.055301 \\
16 & 4 & 75 & 12.72792 \\
17 & 4 & 59.75 & 9.979145 \\
18 & 4 & 57.75 & 12.41974 \\
19 & 4 & 68 & 9.831921 \\
20 & 4 & 63.5 & 7.325754 \\
\hline
\end{tabular}


Appendix B: JMP Results

Exhibit B.1: JMP Output for Descriptive Statistics of Lot Size Information in Table 2

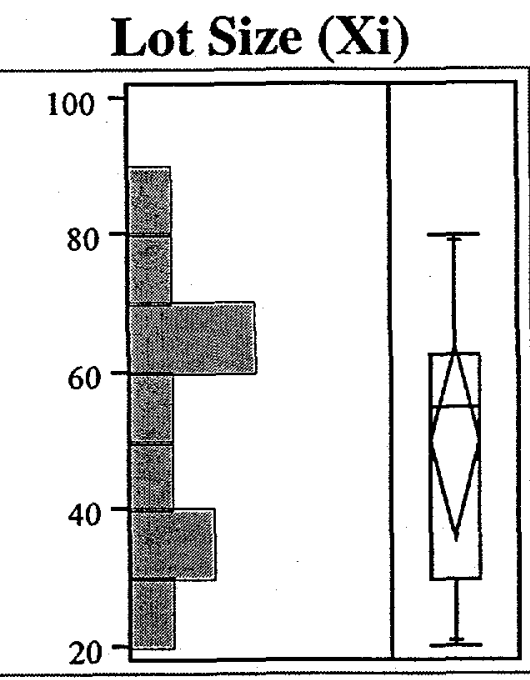

$\begin{array}{lcc} & \text { Quantiles } & \\ \text { maximum } & 100.0 \% & 80.000 \\ & 99.5 \% & 80.000 \\ & 97.5 \% & 80.000 \\ & 90.0 \% & 79.000 \\ \text { quartile } & 75.0 \% & 62.500 \\ \text { median } & 50.0 \% & 55.000 \\ \text { quartile } & 25.0 \% & 30.000 \\ & 10.0 \% & 21.000 \\ & 2.5 \% & 20.000 \\ & 0.5 \% & 20.000 \\ \text { minimum } & 0.0 \% & 20.000\end{array}$

Note: There are several ways to determine estimates of quantiles. JMP computes them as follows [1]

"To compute the Pth quantile of $\mathrm{N}$ nonmissing values in a column, arrange the $\mathrm{N}$ values in ascending order and call these column values $y_{1}, y_{2}, \ldots y_{N}$. Compute the rank number for the $P$ th quantile as $\frac{P}{100}(N+1)$

If the result is an integer, the Pth quantile is that rank's corresponding value. If the result is not an integer, the Pth quantile is found by interpolation. Denote the integer portion of the computed rank number as I and the fractional portion as $f$. The Pth quantile, denoted $q_{P}$, is computed $q_{P}=(1-f) y_{I}+(f) y_{I+1}$

If $\mathrm{I}=\mathrm{N}$, then $\mathrm{y}_{\mathrm{N}}$ is taken as the quantile."

\section{Moments}

Mean

Std Dev

Std Error Mean

Upper 95\% Mean

Lower $95 \%$ Mean

$\mathrm{N}$

Sum Weights
50.00000

19.43651

6.14636

63.90416

36.09584

10.00000

10.00000 


\section{Appendix B: JMP Results}

Exhibit B.1: JMP Output for Descriptive Statistics of Lot Size Information in Table 2 (continued)

Stem and Leaf

\begin{tabular}{|rll|}
\hline Stem & Leaf & Count \\
$\mathbf{8}$ & 0 & 1 \\
7 & 0 & 1 \\
6 & 000 & 3 \\
5 & 0 & 1 \\
4 & 0 & 1 \\
3 & 00 & 2 \\
2 & 0 & 1 \\
\hline
\end{tabular}

Multiply Stem.Leaf by 10

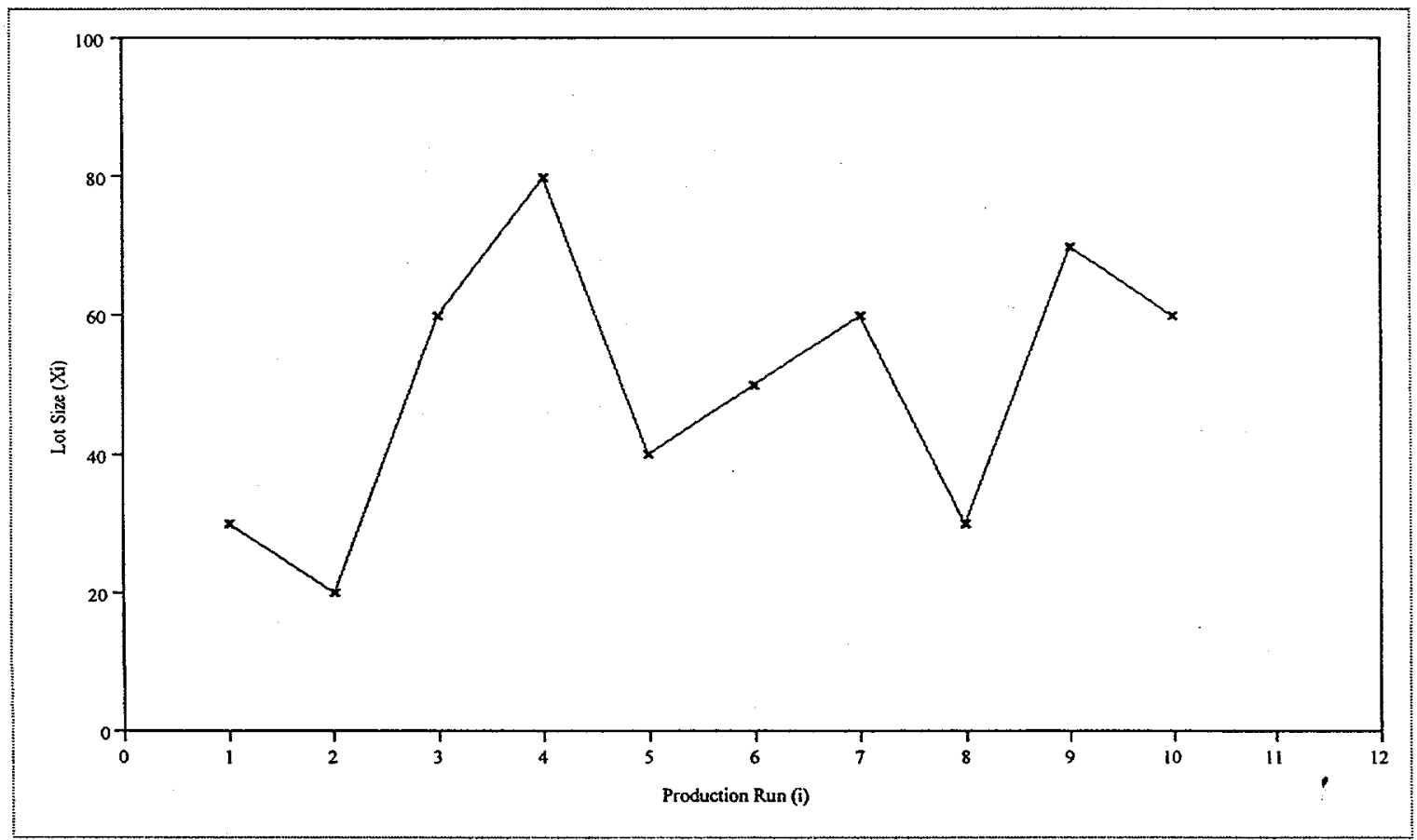


Appendix B: JMP Results

WSRC-RP-99-00422

Revision 0

Exhibit B.2: JMP Output for Regression Model for Information in Table 2 Using Fit $\mathrm{Y}$ by $\mathrm{X}$

\section{Man-Hours (Yi) By Lot Size (Xi)}

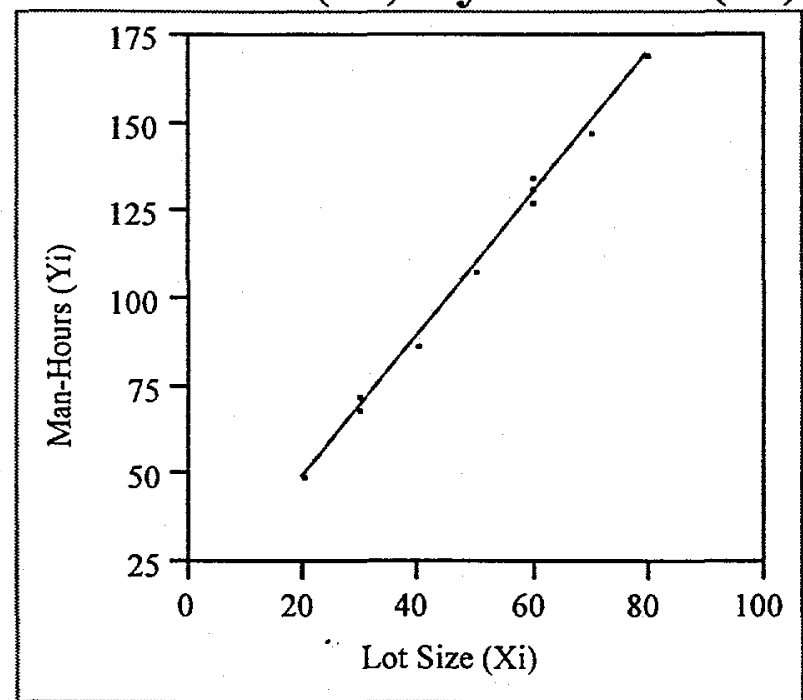

- Linear Fit

\section{Linear Fit}

Man-Hours (Yi) $=10+2$ Lot Size (Xi)

Summary of Fit

RSquare

RSquare Adj

Root Mean Square Error

Mean of Response

Observations (or Sum Wgts)
0.995608

0.995059

2.738613

110

10
Source

Model

Error

C Total

Term

Intercept

Lot Size (Xi)
Analysis of Variance

DF
1
8
9
Sum of Squares 13600.000

60.000

13660.000 $\begin{array}{rr}\text { Mean Square } & \text { F Ratio } \\ 13600.0 & \begin{array}{r}1813.333 \\ 7.5\end{array} \text { Prob }>\text { F }^{<.0001}\end{array}$

\section{Parameter Estimates} Estimate Std Error 2.502939 0.046967 t Ratio 4.00

42.58
Prob $>|t|$

0.0040

$<.0001$ 
Appendix B: JMP Results

Exhibit B.3: JMP Output for Regression Model for Information in Table 2 Using Fit Model

\section{Response: Man-Hours (Yi) Summary of Fit}

RSquare

RSquare Adj

Root Mean Square Error

Mean of Response

Observations (or Sum Wgts)
0.995608

0.995059

2.738613

110

10

\section{Lack of Fit}

\section{Source \\ Lack of Fit \\ Pure Error \\ Total Error \\ Max RSq \\ 0.9976}

$\begin{array}{rrr}\text { DF } & \text { Sum of Squares } & \text { Mean Square } \\ 5 & 27.333333 & 5.4667 \\ 3 & 32.666667 & 10.8889 \\ 8 & 60.000000 & \end{array}$

F Ratio

0.5020

Prob $>$ F

0.7662

\section{Parameter Estimates}

\section{Term}

Intercept

Lot Size (Xi)
Estimate

10

2
Std Error

2.502939

0.046967 t Ratio

4.00

42.58
Prob $>|t|$

0.0040

$<.0001$

\section{Effect Test}

Source

Lot Size (Xi) $\underset{1}{\text { Nparm }}$ DF

Sum of Squares

13600.000
F Ratio Prob $>$ F

$1813.333<.0001$
Whole-Model Test

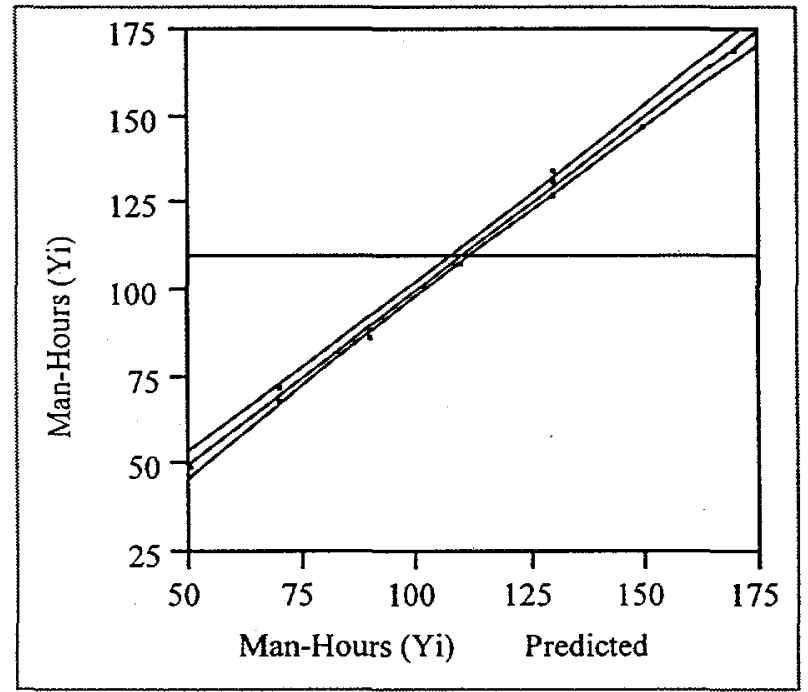


Appendix B: JMP Results

Exhibit B.3: JMP Output for Regression Model for Information in Table 2 Using Fit Model (continued)

Source
Model
Error
C Total

Source

Error

C Total

\section{(1)}

Analysis of Variance

DF

1

8

9

Sum of Squares 13600.000

60.000

13660.000
Lot Size (Xi)

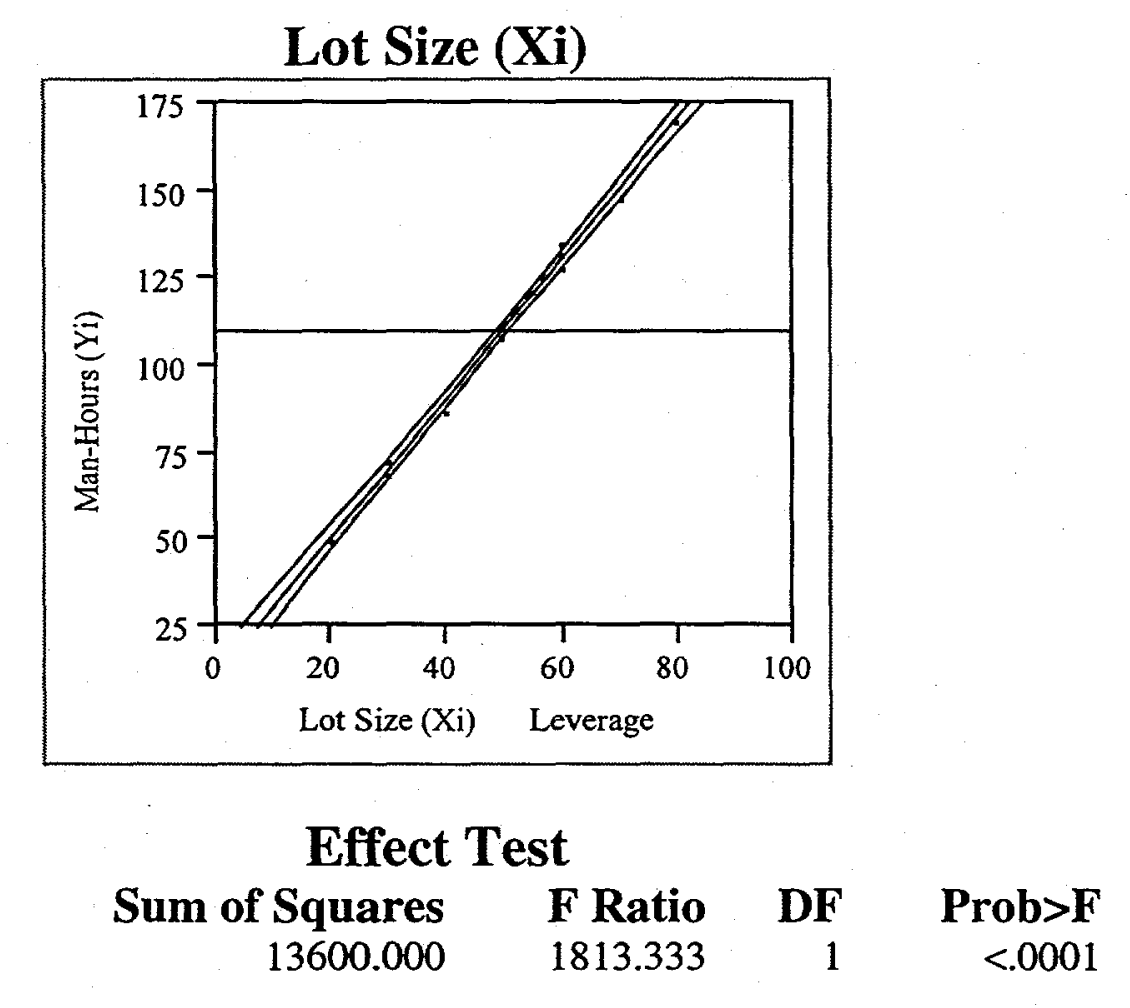

Effect Test

$\begin{array}{rrrr}\text { Sum of Squares } & \text { F Ratio } & \text { DF } & \text { Prob }>\text { F } \\ 13600.000 & 1813.333 & 1 & <.0001\end{array}$

$\begin{array}{rr}\text { Mean Square } & \text { F Ratio } \\ 13600.0 & 1813.333 \\ 7.5 & \begin{array}{r}\text { Prob }>\text { F } \\ <.0001\end{array}\end{array}$


Appendix B: JMP Results

Exhibit B.4: JMP Output for ANOVA of Information in Table 5 Using Fit Model

\section{Response: Case Sold Summary of Fit}

RSquare

RSquare Adj

Root Mean Square Error

Mean of Response

Observations (or Sum Wgts)
0.848684

0.773026

2.768875

18

10

\section{Parameter Estimates}

Term

Intercept

Package [1-4]

Package [2-4]

Package [3-4]

Source

Package Design

\section{Estimate}

18.5

$-3.5$

$-5.5$

0.5
Std Error

0.89365

1.64781

1.440968

1.440968 t Ratio

20.70

$-2.12$

$-3.82$

0.35
Prob $>|t|$

$<.0001$

0.0778

0.0088

0.7404

\section{Effect Test}

Nparm DF Sum of Squares F Ratio Prob $>$ F $\begin{array}{lll}258.00000 & 11.2174 & 0.0071\end{array}$

\section{Whole-Model Test}

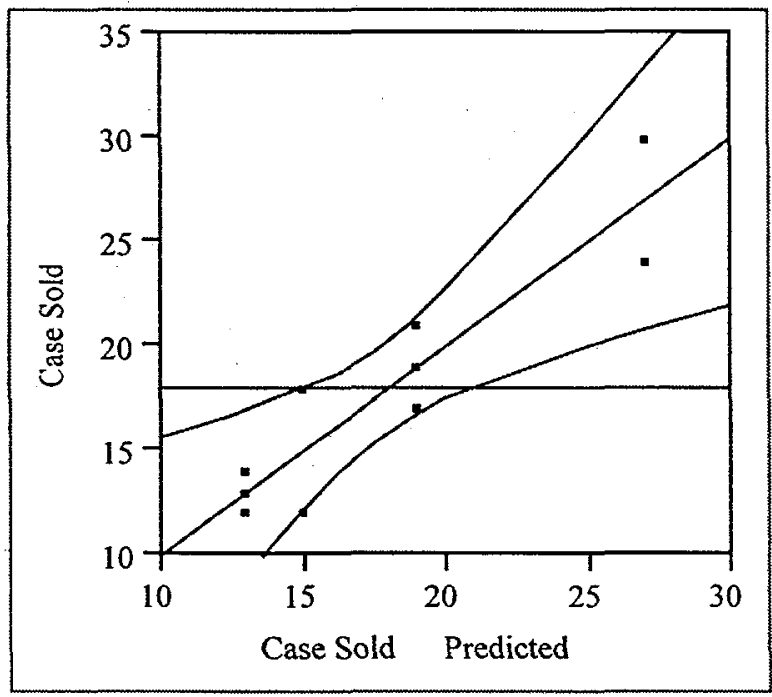

Source

Model

Error

C Total

Analysis of Variance

DF

3

6

9 Sum of Squares

258.00000

46.00000

304.00000
Mean Square F Ratio

86.0000

7.6667
11.2174

Prob $>$ F

0.0071 
Appendix B: JMP Results

Exhibit B.4: JMP Output for ANOVA of Information in Table 5 Using Fit Model (continued)

Package Design

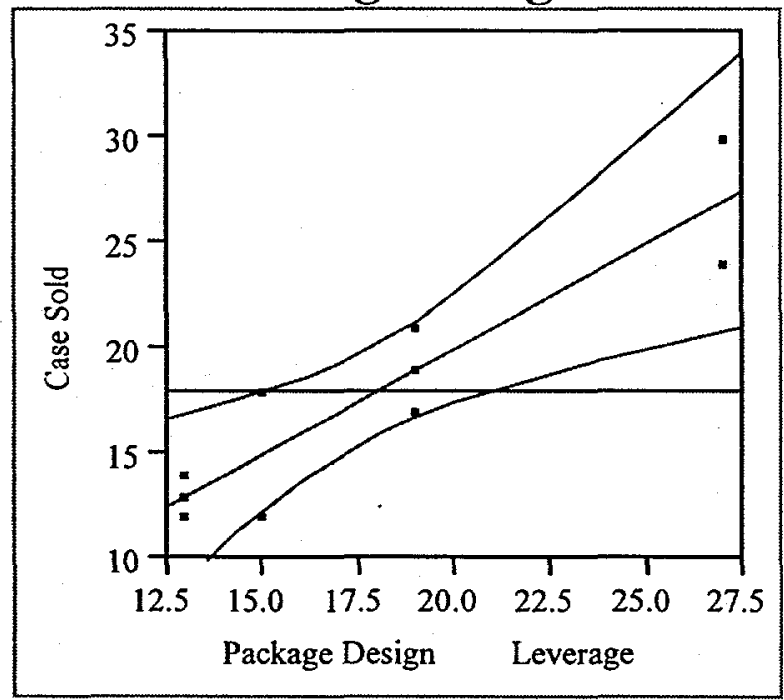

Effect Test

$\begin{array}{rrrr}\text { Sum of Squares } & \text { F Ratio } & \text { DF } & \text { Prob }>\text { F } \\ 258.00000 & 11.2174 & 3 & 0.0071\end{array}$

Level
1
2
3
4

Least Squares Means

Least Sq Mean

Std Error

Mean

15.00000000

1.957890021

15.0000

13.00000000

1.598610508

13.0000

19.00000000

1.598610508

19.0000

27.00000000

1.957890021

27.0000 
Appendix B: JMP Results

Exhibit B.5: JMP Output for ANOVA of Information in Table 8 Using Fit Model with Random Factor (continued)

\section{Response: Rating Summary of Fit}

RSquare

0.566182

RSquare Adj

0.450497

Root Mean Square Error

8.694826

Mean of Response

Observations (or Sum Wgts)

20

Parameter Estimates

$\begin{array}{lrrrr}\text { Term } & \text { Estimate } & \text { Std Error } & \text { t Ratio } & \text { Prob>|t| } \\ \text { Intercept } & 71 & 1.944222 & 36.52 & <.0001 \\ \text { Officer [A-E] } & 4 & 3.888444 & 1.03 & 0.3199 \\ \text { Officer [B-E] } & -1 & 3.888444 & -0.26 & 0.8005 \\ \text { Officer [C-E] } & -16 & 3.888444 & -4.11 & 0.0009 \\ \text { Officer [D-E] } & 9 & 3.888444 & 2.31 & 0.0352\end{array}$

\section{Expected Mean Squares}

The Mean Square per row by the Variance Component per column

$\begin{array}{lrr}\text { EMS } & \text { Intercept } & \text { Officer (i) } \\ \text { Intercept } & 0 & 0 \\ \text { Officer (i) } & 0 & 4\end{array}$

plus 1.0 times Residual Error Variance

\section{Variance Component Estimates \\ Component \\ Officer (i) \\ Residual \\ Var Comp Est \\ 73.6 \\ 75.6}

These estimates based on equating Mean Squares to Expected Value.

Test Denominator Synthesis

Source

Officer (i)

Source

Officer (i)
MS Den

75.6
DF Den Denom MS Synthesis

15 Residual

\section{Tests wrt Random Effects}

$\begin{array}{rrrrr}\text { SS } & \text { MS Num } & \text { DF Num } & \text { F Ratio } & \text { Prob }>\text { F } \\ 1480 & 370 & 4 & 4.8942 & 0.0100\end{array}$


Appendix B: JMP Results

Exhibit B.5: JMP Output for ANOVA of Information in Table 8 Using Fit Model with Random Factor (continued)

Source

Model

Error

C Total

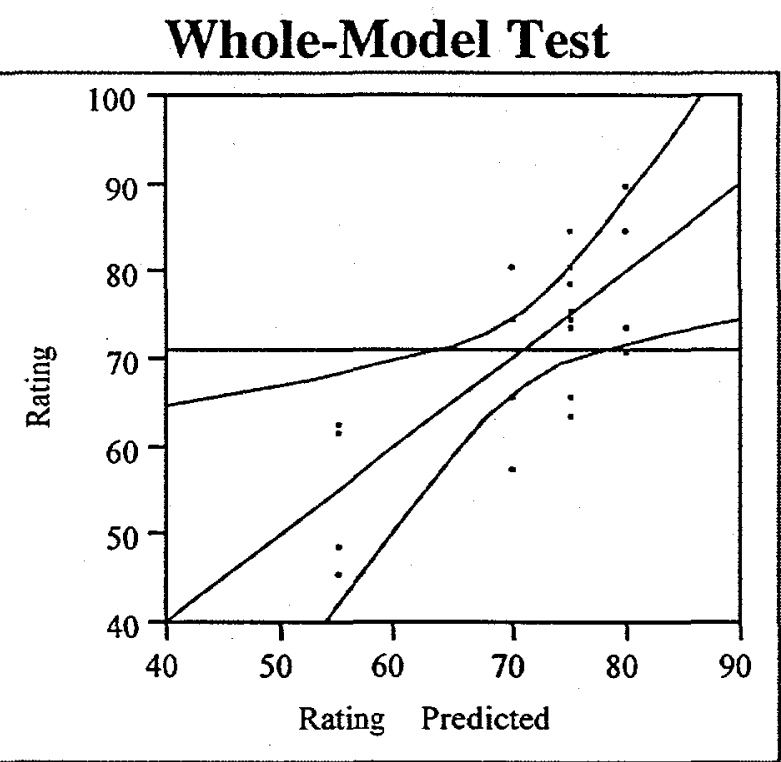

Analysis of Variance

$\begin{array}{rrrr}\text { DF } & \text { Sum of Squares } & \text { Mean Square } & \text { F Ratio } \\ 4 & 1480.0000 & 370.000 & 4.8942 \\ 15 & 1134.0000 & 75.600 & \text { Prob }>\text { F } \\ 19 & 2614.0000 & & 0.0100\end{array}$

Officer (i)

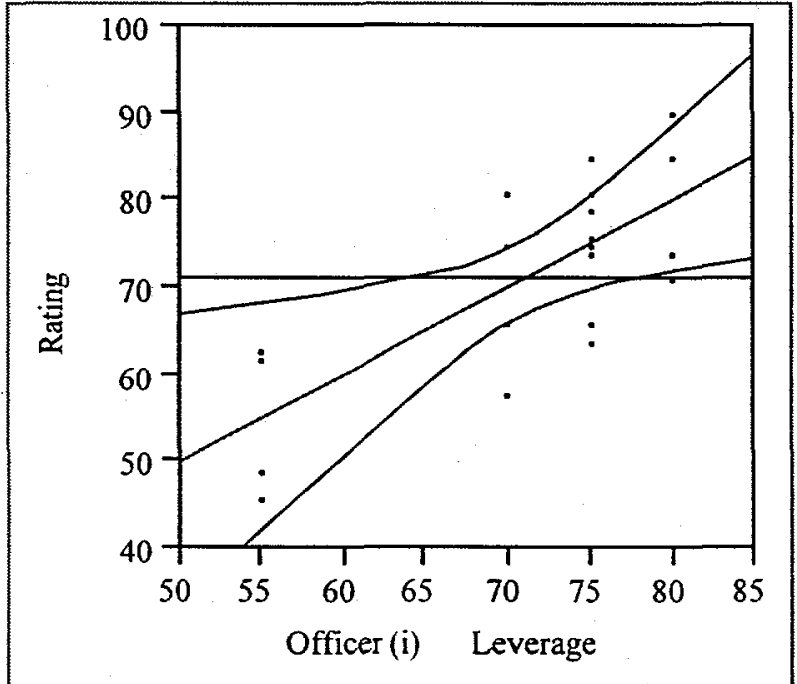


Appendix B: JMP Results

Exhibit B.5: JMP Output for ANOVA of Information in Table 8 Using Fit Model with Random Factor (continued)

\section{Effect Test Sum of Squares F Ratio DF Prob $>$ F $\begin{array}{llll}1480.0000 & 4.8942 & 4 & 0.0100\end{array}$}

Denominator MS Synthesis: Residual Least Squares Means

Level

A

B

C

D

E

\section{Least Sq Mean}

75.00000000

70.00000000

55.00000000

80.00000000

75.00000000
Std Error

4.347413024

4.347413024

4.347413024

4.347413024

4.347413024
Mean

75.0000

70.0000

55.0000

80.0000

75.0000

Warning: Std Err calculated with respect to Synthetic Denominator. 
Exhibit B.6: JMP Output for ANOVA of Information in Table 10 Using Fit Model with Two Factors

\section{Response: Premium (\$) \\ Summary of Fit}

RSquare

RSquare Adj

Root Mean Square Error

Mean of Response

Observations (or Sum Wgts)
0.990698

0.976744

7.071068

175

6
Term

Intercept

Size of [Large-Small]

Size of [Medium-Small]

Region[East-West]

\section{Parameter Estimates}

Estimate

175

35

20

15
Std Error

2.886751

4.082483

4.082483

2.886751 t Ratio

60.62

8.57

4.90

5.20
Prob $>|t|$

0.0003

0.0133

0.0392

0.0351

\section{Effect Test}

Source

Size of City

Region

\section{Nparm}

$\begin{array}{ll}2 & 2 \\ 1 & 1\end{array}$

Sum of Squares

9300.0000

1350.0000

$\begin{array}{rr}\text { F Ratio } & \text { Prob }>\text { F } \\ 93.0000 & 0.0106 \\ 27.0000 & 0.0351\end{array}$

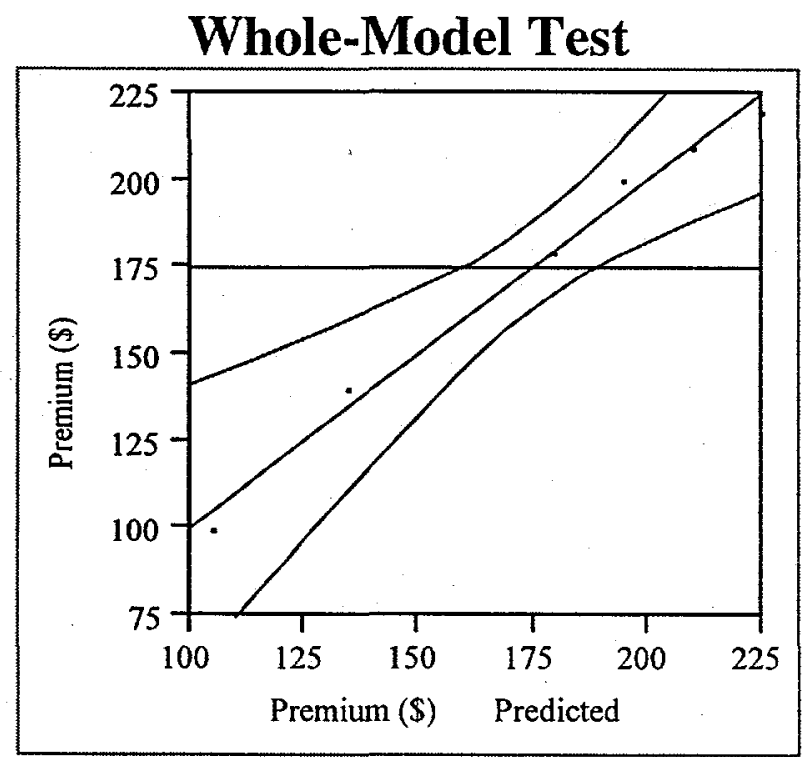


Appendix B: JMP Results

Exhibit B.6: JMP Output for ANOVA of Information in Table 10 Using Fit Model with Two Factors (continued)

Analysis of Variance

$\begin{array}{lrrrr}\text { Source } & \text { DF } & \text { Sum of Squares } & \text { Mean Square } & \text { F Ratio } \\ \text { Model } & 3 & 10650.000 & 3550.00 & 71.0000 \\ \text { Error } & 2 & 100.000 & 50.00 & \text { Prob }>\text { F } \\ \text { C Total } & 5 & 10750.000 & & 0.0139\end{array}$

Size of City

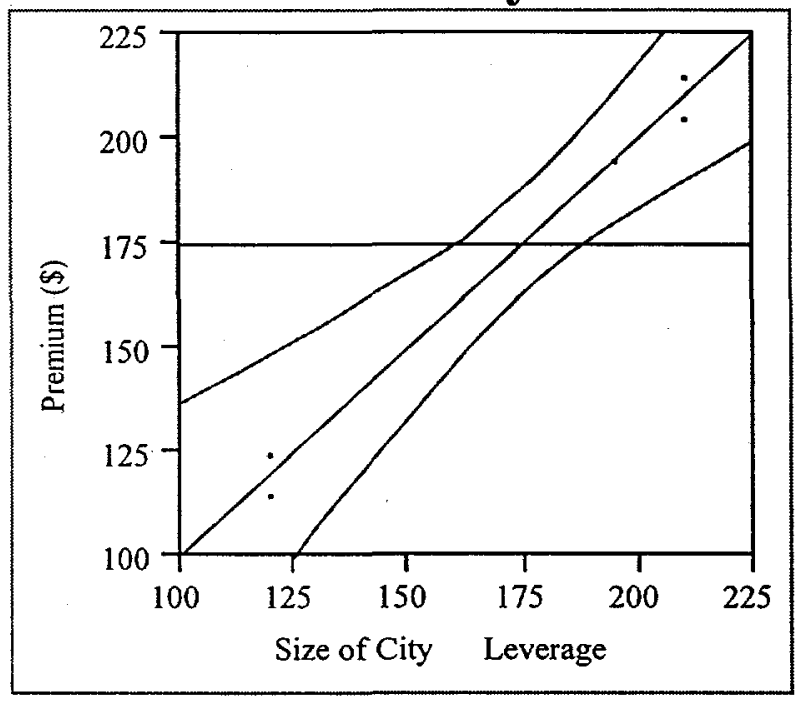

\section{Effect Test \\ Sum of Squares F Ratio DF Prob $>$ F \\ $\begin{array}{llll}9300.0000 & 93.0000 & 2 & 0.0106\end{array}$}

Least Squares Means

Level

Large

Medium

Small
Least Sq Mean

210.0000000

195.0000000

120.0000000
Std Error

5.000000000

5.000000000

5.000000000
Mean

210.000

195.000

120.000 
Appendix B: JMP Results

Exhibit B.6: JMP Output for ANOVA of Information in Table 10 Using Fit Model with Two Factors (continued)

Region

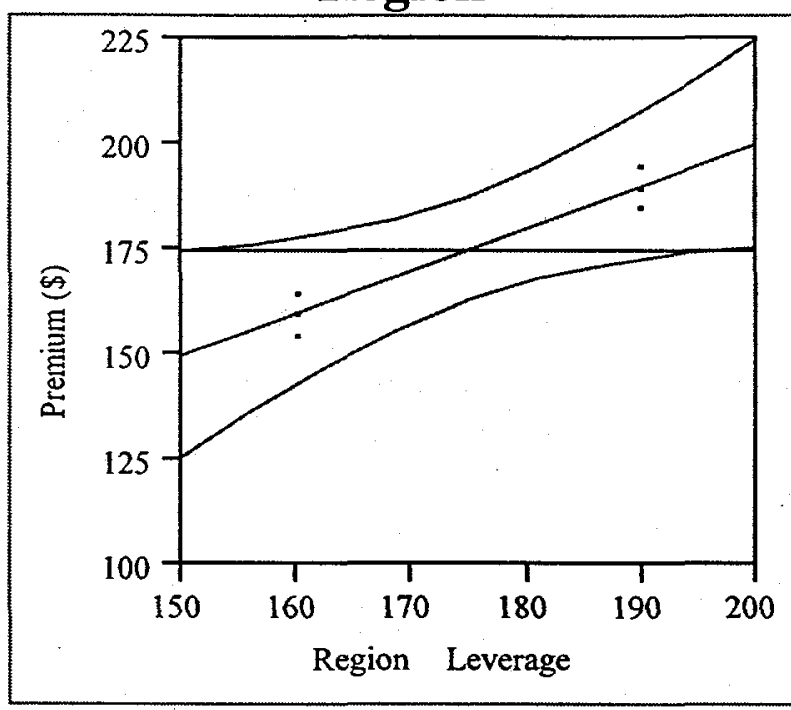

Effect Test

$\begin{array}{rrrr}\text { Sum of Squares } & \text { F Ratio } & \text { DF } & \text { Prob }>\text { F } \\ 1350.0000 & 27.0000 & 1 & 0.0351\end{array}$

Level

Least Squares Means

East

Least Sq Mean

Std Error

Mean

West

190.0000000

4.082482905

190.000

160.0000000

4.082482905

160.000 
Appendix B: JMP Results

Exhibit B.7: JMP Output for Nested ANOVA of Information in Table 13 Using Fit Model with A Nested Factor

\section{Response: Class Learning Scores (coded) Summary of Fit}

RSquare

0.94517

RSquare Adj

0.899478

Root Mean Square Error

2.645751

Mean of Response

Observations (or Sum Wgts)

\section{Parameter Estimates}

\section{Term}

Intercept

School[Atlanta-San Fra]

School[Chicago-San Fra]

School[Atlanta]:Instruct[1-2]

School[Chicago]:Instruct[1-2]

School[San Fra]:Instruct[1-2]

\section{Estimate}

15

4.75

$-0.75$

7.25

$-5.75$

7.5
Std Error

0.763763

1.080123

1.080123

1.322876

1.322876

1.322876 t Ratio

19.64

4.40

$-0.69$

5.48

$-4.35$

5.67
Prob $>|t|$

$<.0001$

0.0046

0.5134

0.0015

0.0048

0.0013

Effect Test

$\begin{array}{lrrrrr}\text { Source } & \text { Nparm } & \text { DF } & \text { Sum of Squares } & \text { F Ratio } & \text { Prob>F } \\ \text { School } & 2 & 2 & 156.50000 & 11.1786 & 0.0095 \\ \text { Instructor[School] } & 3 & 3 & 567.50000 & 27.0238 & 0.0007\end{array}$

Whole-Model Test

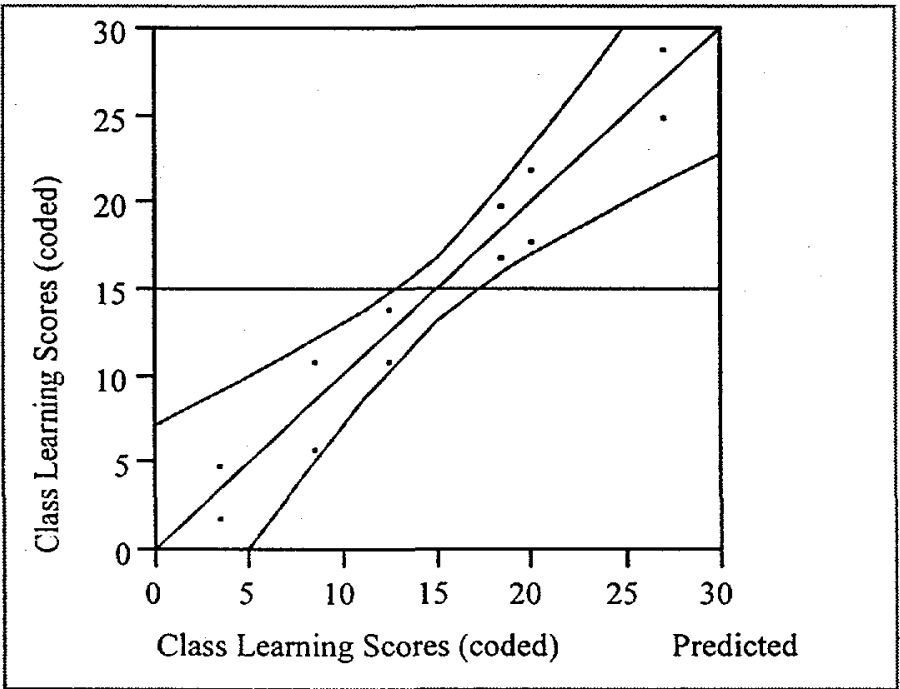




\section{Appendix B: JMP Results}

Exhibit B.7: JMP Output for Nested ANOVA of Information in Table 13 Using Fit Model with A Nested Factor (continued)

\begin{tabular}{lrrrr}
\multicolumn{5}{c}{ Analysis of Variance } \\
Source & DF & Sum of Squares & Mean Square & F Ratio \\
Model & 5 & 724.00000 & 144.800 & 20.6857 \\
Error & 6 & 42.00000 & 7.000 & Prob $>$ F \\
C Total & 11 & 766.00000 & & 0.0010
\end{tabular}

\section{School}

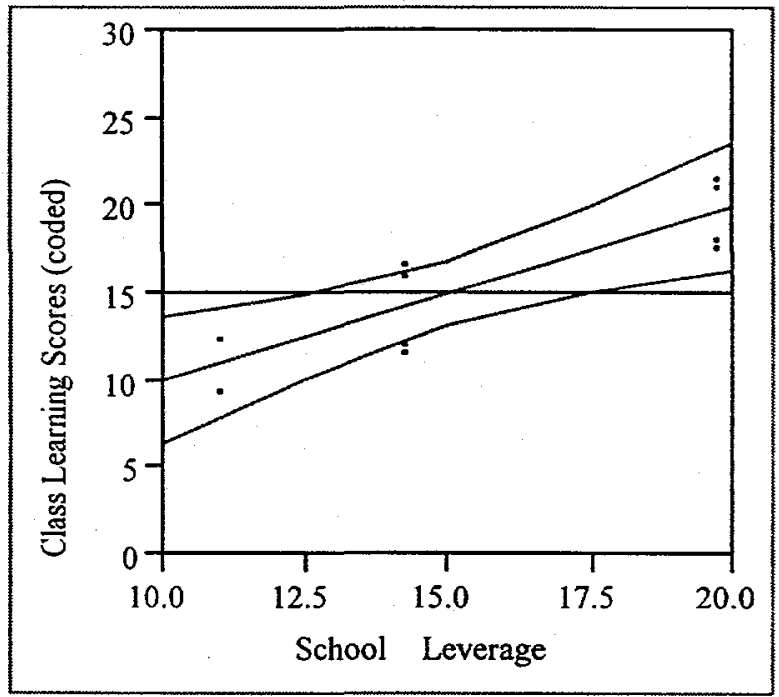

Effect Test

$\begin{array}{rrrr}\text { Sum of Squares } & \text { F Ratio } & \text { DF } & \text { Prob }>\text { F } \\ 156.50000 & 11.1786 & 2 & 0.0095\end{array}$

Level

Atlanta

Chicago

San Francisco

\section{Least Squares Means}

Least Sq Mean

19.75000000

14.25000000

11.00000000
Std Error

1.322875656

1.322875656

1.322875656
Mean

19.7500

.14 .2500

11.0000 
Appendix B: JMP Results

Exhibit B.7: JMP Output for Nested ANOVA of Information in Table 13 Using Fit Model with A Nested Factor (continued)

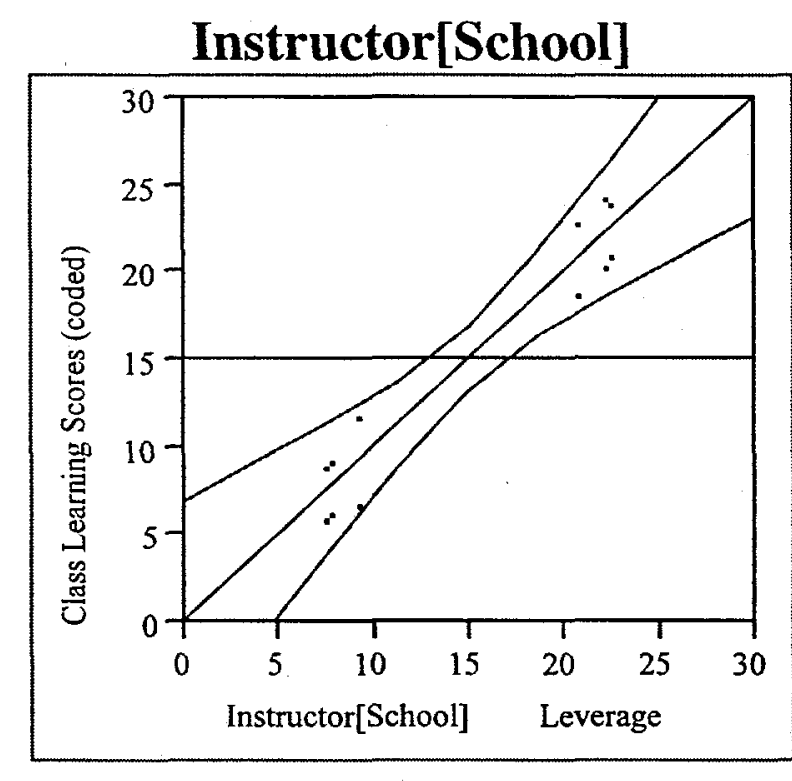

\section{Effect Test Sum of Squares F Ratio DF Prob $>$ F $\begin{array}{llll}567.50000 & 27.0238 & 3 & 0.0007\end{array}$}

Level

[Atlanta] 1

[Atlanta] 2

[Chicago]1

[Chicago]2

[San Francisco]1

[San Francisco]2

\section{Least Squares Means}

$$
\begin{array}{r}
\text { Least Sq Mean } \\
27.00000000 \\
12.50000000 \\
8.50000000 \\
20.00000000 \\
18.50000000 \\
3.50000000
\end{array}
$$

Std Error

1.870828693

1.870828693

1.870828693

1.870828693

1.870828693

1.870828693 
Appendix B: JMP Results

Exhibit B.8: JMP Output for Nested ANOVA of Information in Table 13 Using Fit Model with Random Factors (continued)

$\begin{array}{lr}\text { Response: Class Learning Scores (coded) } \\ \text { Summary of Fit } \\ \text { RSquare } & 0.94517 \\ \text { RSquare Adj } & 0.899478 \\ \text { Root Mean Square Error } & 2.645751 \\ \text { Mean of Response } & 15 \\ \text { Observations (or Sum Wgts) } & 12\end{array}$

Term

Intercept

School[Atlanta-San Fra]

School[Chicago-San Fra]

School[Atlanta]:Instruct[1-2]

School[Chicago]:Instruct[1-2]

School[San Fra]:Instruct[1-2]
Parameter Estimates

\section{Expected Mean Squares}

The Mean Square per row by the Variance Component per column
EMS

Intercept

School

Instructor[School]
Intercept

0

0

0
School Instructor[School]

$\begin{array}{rrrr}15 & 0.763763 & 19.64 & <.0001 \\ 4.75 & 1.080123 & 4.40 & 0.0046 \\ -0.75 & 1.080123 & -0.69 & 0.5134 \\ 7.25 & 1.322876 & 5.48 & 0.0015 \\ -5.75 & 1.322876 & -4.35 & 0.0048 \\ 7.5 & 1.322876 & 5.67 & 0.0013\end{array}$

plus 1.0 times Residual Error Variance

\section{Variance Component Estimates}

Component

School

Instructor[School]

Residual
Var Comp Est

$-27.7292$

91.08333 7

Source

Synthesis

School

Instructor[School]

These estimates based on equating Mean Squares to Expected Value.

\section{Test Denominator Synthesis}

MS Den

DF Den Denom MS

189.167

7

3 Instructor[School]

6 Residual 
Appendix B: JMP Results

Exhibit B.8: JMP Output for Nested ANOVA of Information in Table 13 Using Fit Model with Random Factors (continued)

Tests wrt Random Effects

$\begin{array}{lrrrrr}\text { Source } & \text { SS } & \text { MS Num } & \text { DF Num } & \text { F Ratio } & \text { Prob>F } \\ \text { School } & 156.5 & 78.25 & 2 & 0.4137 & 0.6940 \\ \text { Instructor[School] } & 567.5 & 189.167 & 3 & 27.0238 & 0.0007\end{array}$

Whole-Model Test

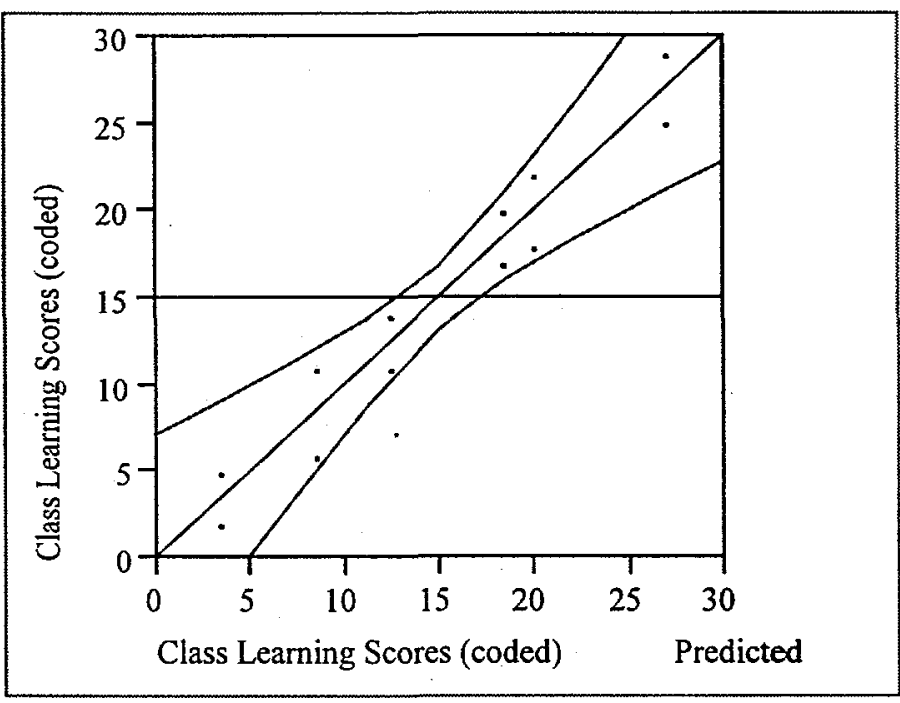

Analysis of Variance

Source

Model

Error

C Total
DF Sum of Squares

724.00000

42.00000

766.00000
Mean Square

144.800

7.000
F Ratio

20.6857

Prob $>$ F

0.0010 
Appendix B: JMP Results

Exhibit B.8: JMP Output for Nested ANOVA of Information in Table 13 Using Fit Model with Random Factors (continued)

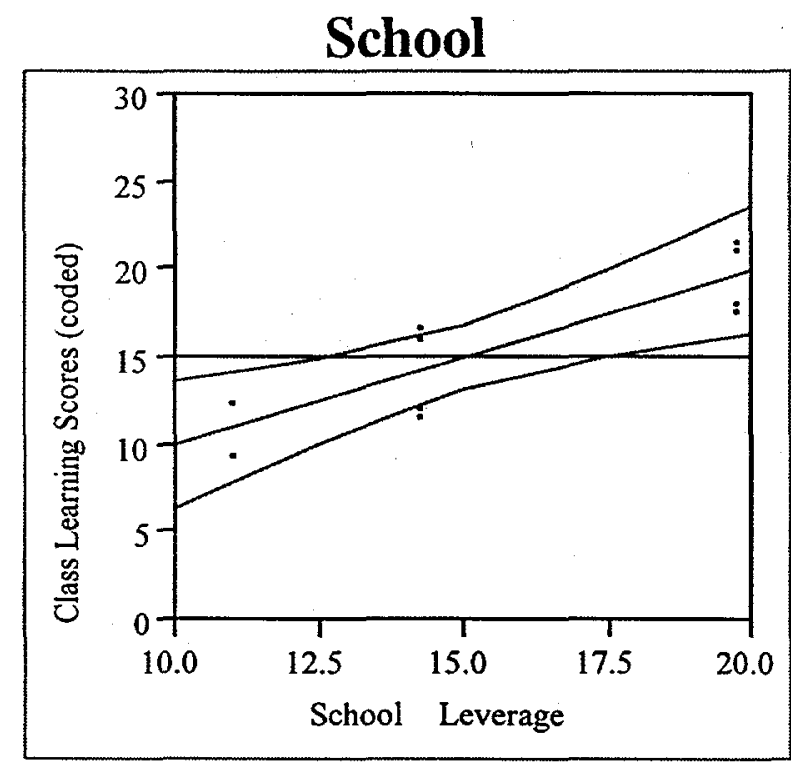

$$
\begin{array}{rrrr}
\text { Effect Test } & & \\
\text { Sum of Squares } & \text { F Ratio } & \text { DF } & \text { Prob>F } \\
156.50000 & 0.4137 & 2 & 0.6940
\end{array}
$$

Denominator MS Synthesis: Instructor[School]

\section{Least Squares Means}

Level

Atlanta

Chicago

San Francisco
Least Sq Mean

19.75000000

14.25000000

11.00000000
Std Error

6.876893679

6.876893679

6.876893679
Mean

19.7500

14.2500

11.0000

Warning: Std Err calculated with respect to Synthetic Denominator. 
Appendix B: JMP Results

Exhibit B.8: JMP Output for Nested ANOVA of Information in Table 13 Using Fit Model with Random Factors (continued)

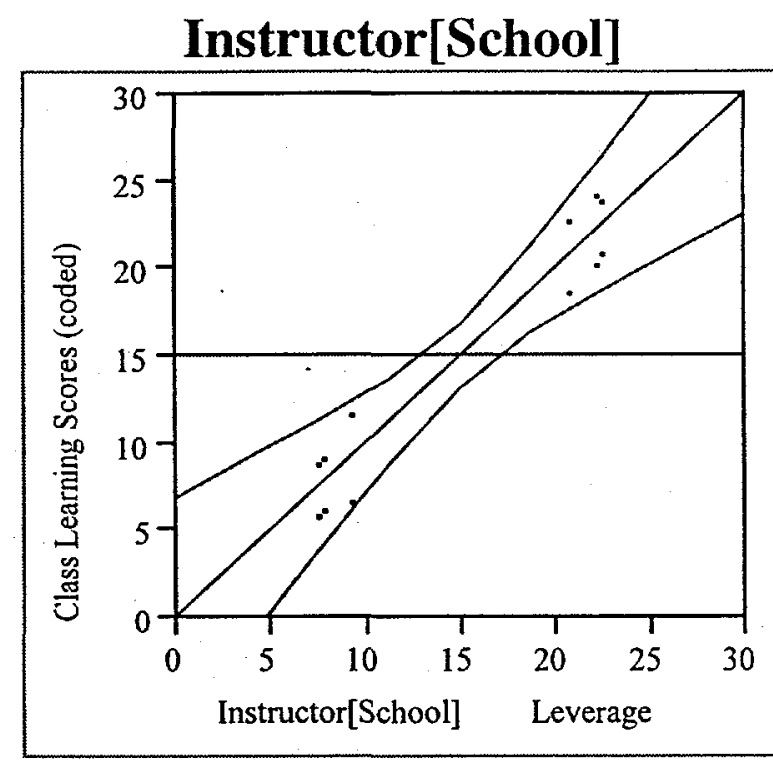

\section{Effect Test \\ Sum of Squares F Ratio DF Prob $>$ F

$\begin{array}{llll}567.50000 & 27.0238 & 3 & 0.0007\end{array}$

Denominator MS Synthesis: $\quad$ Residual

Level

[Atlanta] 1

[Atlanta]2

[Chicago]1

[Chicago]2

[San Francisco]1

[San Francisco]2

\section{Least Squares Means}

Least Sq Mean

27.00000000

12.50000000

8.50000000

20.00000000

18.50000000

3.50000000
Std Error

1.870828693

1.870828693

1.870828693

1.870828693

1.870828693

1.870828693

Warning: Std Err calculated with respect to Synthetic Denominator. 
Appendix B: JMP Results

Exhibit B.9: JMP Output for a Fractional Factorial Experiment using the Design Experiment Feature

\begin{tabular}{|c|c|c|c|c|c|c|}
\hline Pattern & $\mathbf{X 1}$ & $\mathbf{X} 2$ & $\mathbf{X 3}$ & $\mathbf{X} 4$ & $\mathbf{X 5}$ & $\mathbf{X 6}$ \\
\hline---- & -1 & -1 & -1 & -1 & -1 & -1 \\
\hline--+++ & -1 & -1 & -1 & 1 & 1 & 1 \\
\hline--+-++ & -1 & -1 & 1 & -1 & 1 & 1 \\
\hline--++- & -1 & -1 & 1 & 1 & -1 & -1 \\
\hline++-+- & -1 & 1 & -1 & -1 & 1 & -1 \\
\hline-+-+-+ & -1 & 1 & -1 & 1 & -1 & 1 \\
\hline-++-++ & -1 & 1 & 1 & -1 & -1 & 1 \\
\hline-++++- & -1 & 1 & 1 & 1 & 1 & -1 \\
\hline+---+ & 1 & -1 & -1 & -1 & -1 & 1 \\
\hline+-+++- & 1 & -1 & -1 & 1 & 1 & -1 \\
\hline+-+-+- & 1 & -1 & 1 & -1 & 1 & -1 \\
\hline++++-+ & 1 & -1 & 1 & 1 & -1 & 1 \\
\hline++-++ & 1 & 1 & -1 & -1 & 1 & 1 \\
\hline+++-- & 1 & 1 & -1 & 1 & -1 & -1 \\
\hline+++-- & 1 & 1 & 1 & -1 & -1 & -1 \\
\hline++++++ & 1 & 1 & 1 & 1 & 1 & 1 \\
\hline
\end{tabular}

Fractional Factorial structure

Factor Confounding Rules

$"$

$\mathrm{X} 5=\mathrm{X} 2 * \mathrm{X} 3 * \mathrm{X} 4$

$\mathrm{x} 6=\mathrm{x} 1 * \mathrm{X} 3 * \mathrm{X} 4$

Aliasing Structure

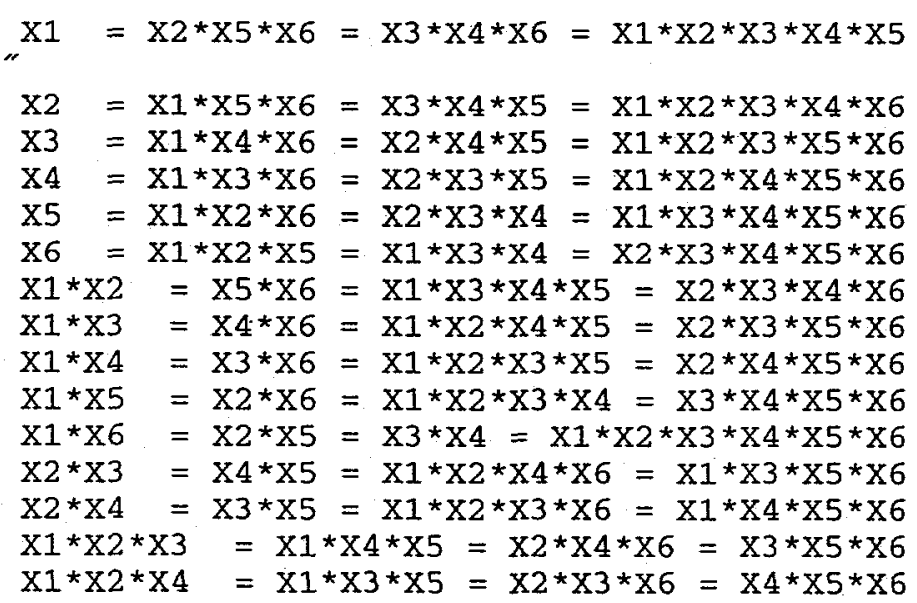


Appendix B: JMP Results

Revision 0

Exhibit B.10: JMP Output for Mixture Problem Defined by Equation (2)

\begin{tabular}{|c|c|c|c|}
\hline $\mathbf{X}_{\mathbf{1}}$ & $\mathbf{X}_{\mathbf{2}}$ & $\mathbf{X}_{\mathbf{3}}$ & Dimen \\
\hline 0.4 & 0.1 & 0.5 & 0 \\
\hline 0.6 & 0.1 & 0.3 & 0 \\
\hline 0.6 & 0.3 & 0.1 & 0 \\
\hline 0.2 & 0.3 & 0.5 & 0 \\
\hline 0.3 & 0.6 & 0.1 & 0 \\
\hline 0.2 & 0.6 & 0.2 & 0 \\
\hline 0.2 & 0.45 & 0.35 & 1 \\
\hline 0.6 & 0.2 & 0.2 & 1 \\
\hline 0.5 & 0.1 & 0.4 & 1 \\
\hline 0.25 & 0.6 & 0.15 & 1 \\
\hline 0.45 & 0.45 & 0.1 & 1 \\
\hline 0.3 & 0.2 & 0.5 & 1 \\
\hline 0.383333 & 0.333333 & 0.283333 & 2 \\
\hline
\end{tabular}

JMP is capable of evaluating more than just the extreme vertices of this region. A value of 0 for Dimen column indicates that the row corresponds to an extreme vertex of the mixture region, a value of 1 indicates an edge of the region, and finally, a 2 value indicates the centroid of the region. This centroid is computed as part of the discussion in [1], and the value reported there (on page 358 ) is $(0.384,0.333,0.283)$ the same value as shown in the table above. 
Appendix B: JMP Results

Exhibit B.11: JMP's D-Optimality Results

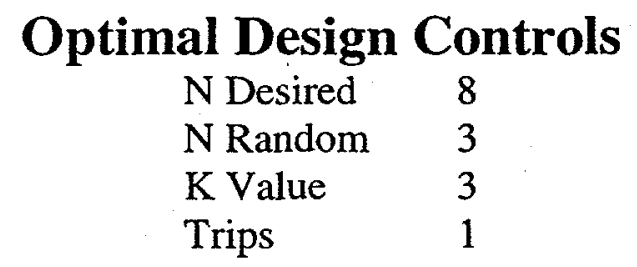

$\begin{array}{lll}\text { N } & 8 & ---- \text { Ready ---.- } \\ \text { Trips } & 1 & \end{array}$

\section{Best Design}

$\begin{array}{lr}\text { D-efficiency } & 100 \\ \text { A-efficiency } & 100 \\ \text { G-efficiency } & 100 \\ \text { AvgPredSE } & 0.5590 \\ \text { N } & 8.0000\end{array}$

Corr

Intercept

$\mathrm{X} 1$

\begin{tabular}{|c|c|c|c|c|c|c|}
\hline Pattern & $\mathbf{X 1}$ & $\mathrm{X} 2$ & $\mathbf{X 3}$ & Comment & OptCount & OptStdPred \\
\hline+00 & 1 & 0 & 0 & Axial & 0 & 0.5 \\
\hline$t+1$ & 1 & 1 (1) & (1) & WHF $\mathrm{FF}$. & 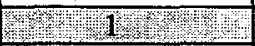 & 0,707107 \\
\hline 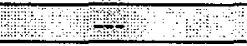 & 11 & 1 & 11 & FF, FE & 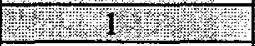 & 0,707107 \\
\hline 000 & 0 & 0 & 0 & Center-FF & 0 & 0.353553 \\
\hline 00 & 0 & 0 & -1 & Axial & 0 & 0.5 \\
\hline 000 & 0 & 0 & 0 & Center-FF & $\mathbf{0}$ & 0.353553 \\
\hline-00 & -1 & 0 & 0 & Axial & 0 & 0.5 \\
\hline $00+$ & 0 & 0 & 1 & Axial & 0 & 0.5 \\
\hline$+1+$ & 11 & 10 & 1 & FF & (1) & 0.707107 \\
\hline+4 & 1 & 41 & 114 & Wh FF & (1) 1 , & $0707107 \%$ \\
\hline 000 & 0 & 0 & 0 & Center-FF & 0 & 0.353553 \\
\hline $\mathrm{N}^{2} \mathrm{~s}+\mathrm{t}$ & 4 & -1 & 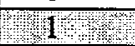 & $\mathrm{FF}$ & CU 1 & 0.707107 \\
\hline 4, & 11 & 1 & 1,? & FF $F$ & 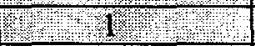 & 0707107 \\
\hline $0-0$ & 0 & -1 & 0 & Axial & 0 & 0.5 \\
\hline+- & 1 & -1 & -1 & $\mathrm{FF}$ & 1 & 0.707107 \\
\hline $0+0$ & 0 & 1 & 0 & Axial & 0 & 0.5 \\
\hline 000 & 0 & 0 & 0 & Center-Ax & 0 & 0.353553 \\
\hline 000 & 0 & 0 & 0 & Center-Ax & 0 & 0.353553 \\
\hline 000 & 0 & 0 & 0 & Center-FF & 0 & 0.353553 \\
\hline $10+1$ & -1 & 1 & 1 & 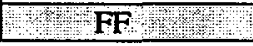 & 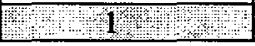 & 0.707107 \\
\hline
\end{tabular}

$\mathrm{X} 2$

$\mathrm{X3}$

Correlations

$\begin{array}{rrrr}\text { Intercept } & \mathbf{X 1} & \mathbf{X 2} & \mathbf{X 3} \\ 1: 0000 & 0.0000 & 0.0000 & 0.0000 \\ 0.0000 & 1.0000 & 0.0000 & 0.0000 \\ 0.0000 & 0.0000 & 1.0000 & 0.0000 \\ 0.0000 & 0.0000 & 0.0000 & 1.0000\end{array}$


Exhibit B.12: JMP Results for x-Bar and s Charts for Data in Table 18

\section{x-bar chart}

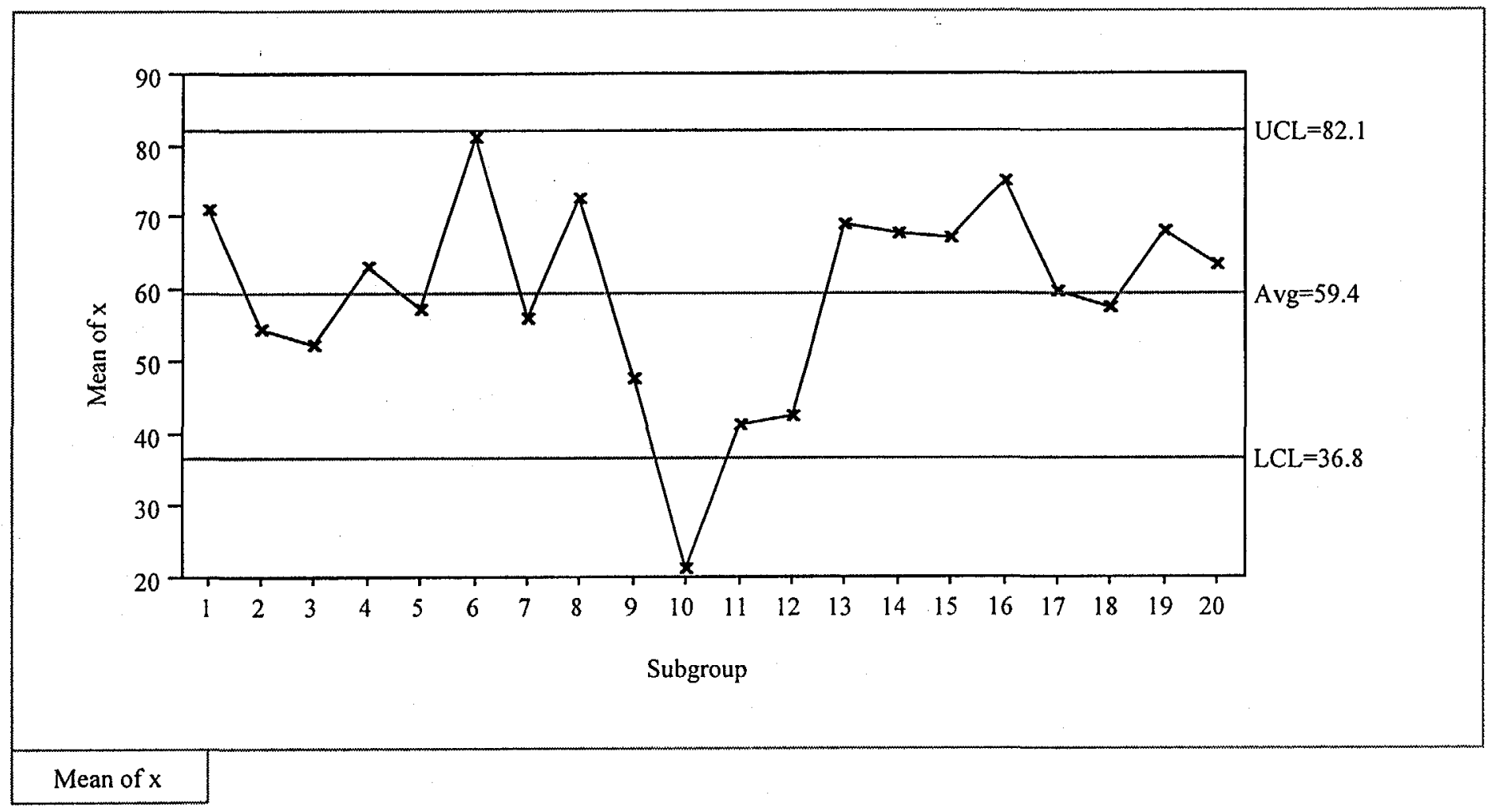


Exhibit B.12: JMP Results for $\mathrm{X}$-Bar and s Charts for Data in Table 18 (continued)

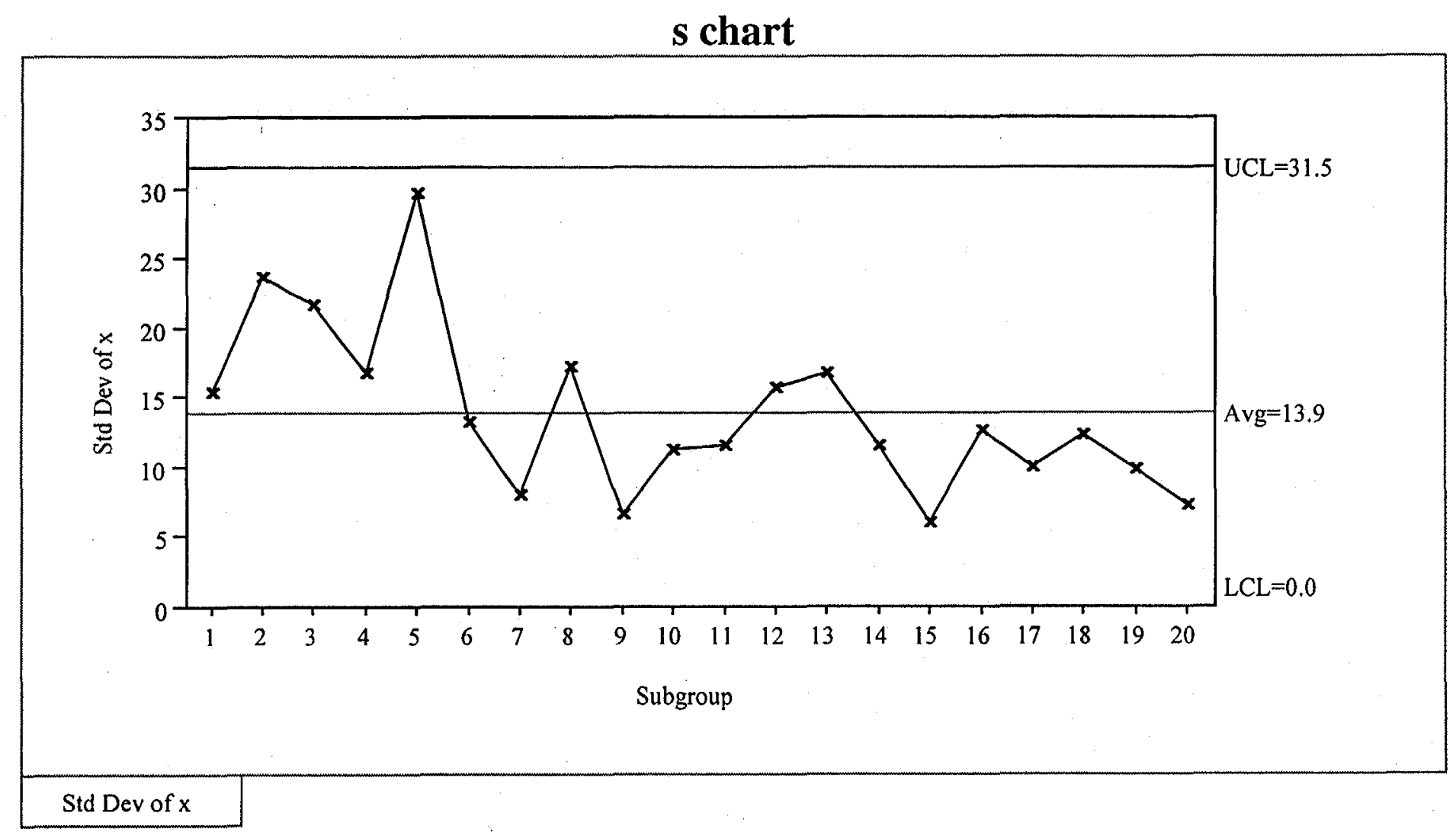




\section{Appendix C: SAS Results}

Exhibit C.1: SAS Input for and Results from Descriptive Statistics for Lot Size Values in Table 2

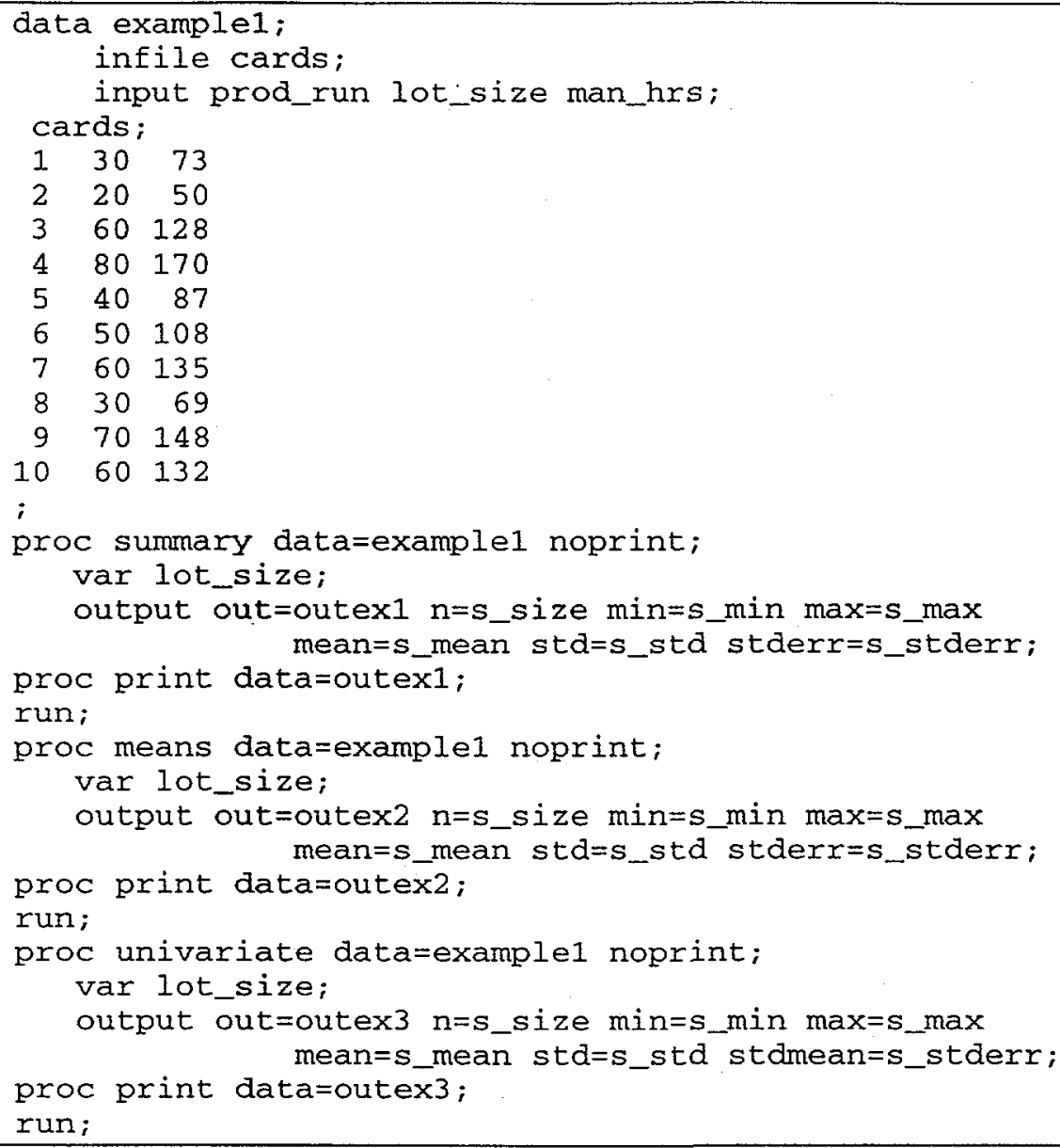

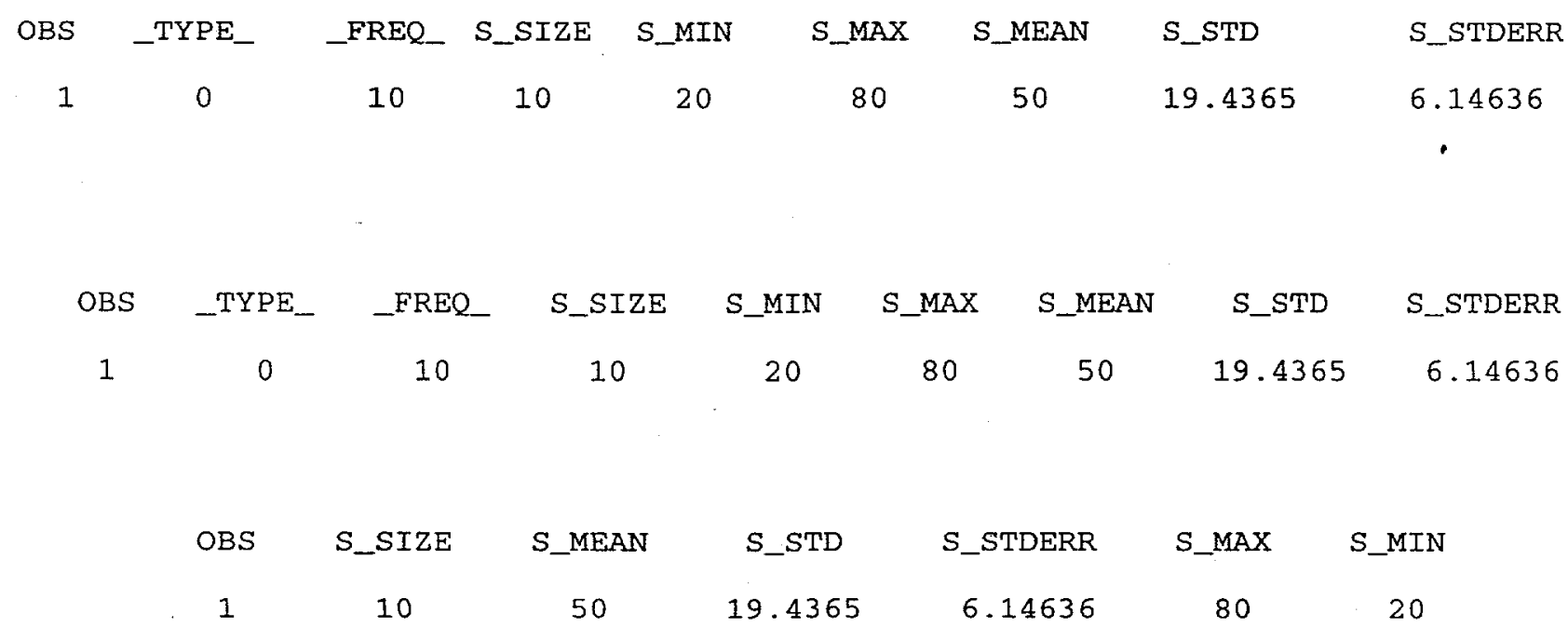




\section{Appendix C: SAS Results}

Exhibit C.2: SAS Input for and Results from PROC REG for Table 2 Data

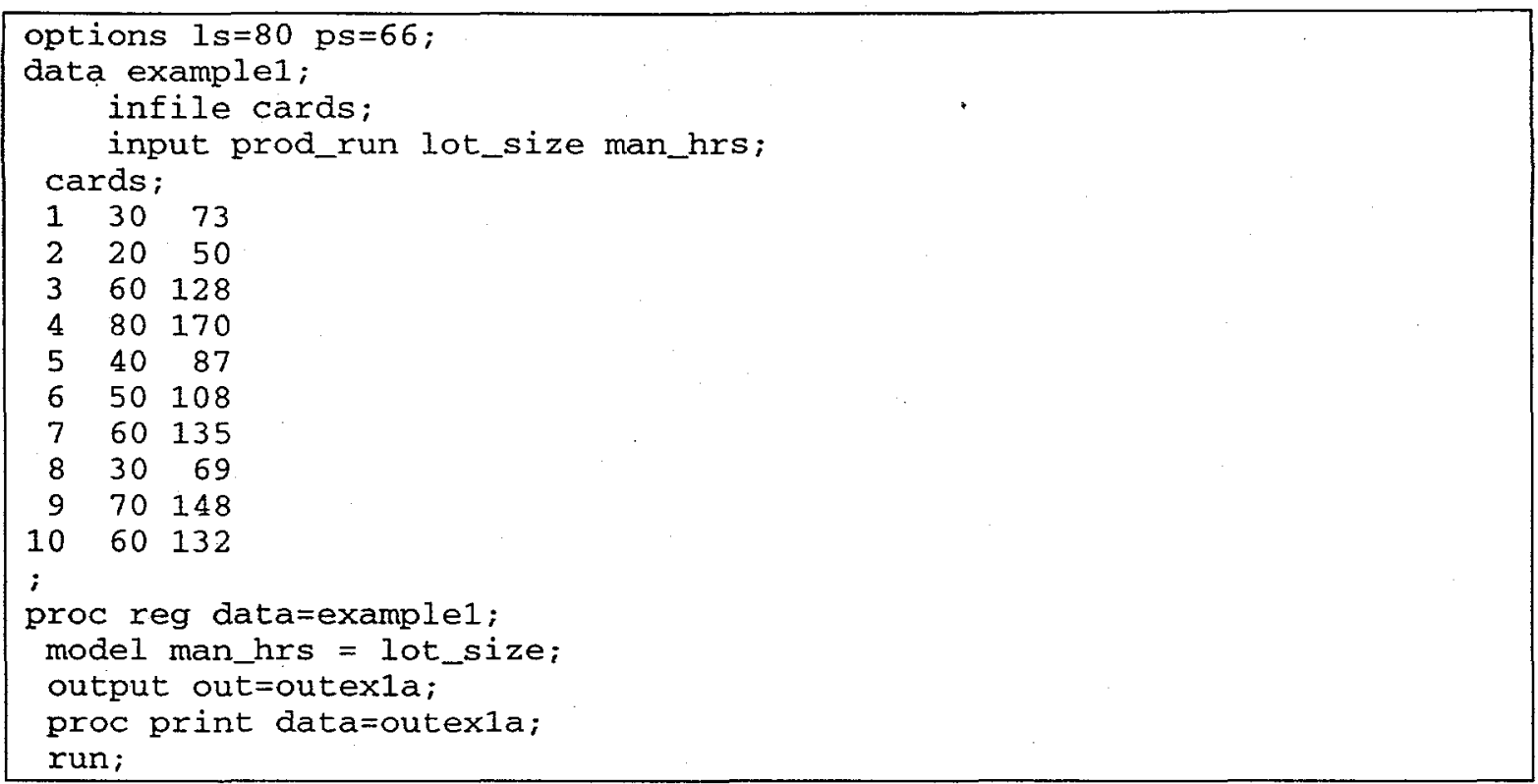

Model: MODEL1

Dependent Variable: MAN_HRS

Analysis of Variance

$\begin{array}{lrrrrr}\text { Source } & \text { DF } & \begin{array}{r}\text { Sum of } \\ \text { Squares }\end{array} & \begin{array}{r}\text { Mean } \\ \text { Square }\end{array} & \text { F Value } & \text { Prob>F } \\ \text { Mode1 } & 1 & 13600.00000 & 13600.00000 & 1813.333 & 0.0001 \\ \text { Error } & 8 & 60.00000 & 7.50000 & & \\ \text { C Total } & 9 & 13660.00000 & & & \end{array}$

Root MSE
Dep Mean
C.V.

$\begin{array}{rll}2.73861 & \text { R-square } & 0.9956 \\ 110.00000 & \text { Adj R-sq } & 0.9951 \\ 2.48965 & & \end{array}$

Parameter Estimates

$\begin{array}{lrrrrr}\text { Variable } & \text { DF } & \begin{array}{r}\text { Parameter } \\ \text { Estimate }\end{array} & \begin{array}{r}\text { Standard } \\ \text { Error }\end{array} & \begin{array}{r}\text { T for Ho: } \\ \text { Parameter }=0\end{array} & \text { Prob }>|T| \\ \text { INTERCEP } & 1 & 10.000000 & 2.50293945 & 3.995 & 0.0040 \\ \text { LOT_SIZE } & 1 & 2.000000 & 0.04696682 & 42.583 & 0.0001\end{array}$


Appendix C: SAS Results

Exhibit C.3: SAS Input for and Results from SAS/IML Program for Regression of Table 2 Data

proc iml;

reset noname;

$x=\left\{\begin{array}{llllllllllll}1 & 30,1 & 20,1 & 60,1 & 80,1 & 40,1 & 50,1 & 60,1 & 30,1 & 70,1 & 60\end{array}\right.$;

$y=\{73,50,128,170,87,108,135,69,148,132\}$;

betahat $=\operatorname{INV}\left(x^{\prime *} x\right) *\left(x^{\prime *} y\right)$;

reset name;

print betahat;

quit;

run;

BETAHAT

10

2 
Appendix C: SAS Results

Exhibit C.4: SAS Input for and Results from SAS/STAT PROC ANOVA for Analyzing of Table 5 Data

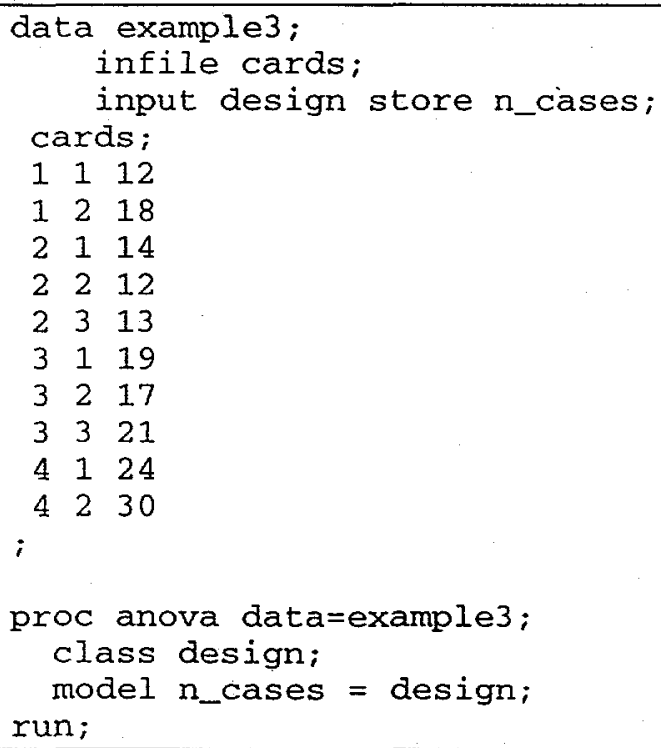

Error

6

Corrected Total

46.00000000

7.66666667

$9 \quad 3.04 .00000000$

$$
\begin{aligned}
& \text { R-Square } \\
& 0.848684
\end{aligned}
$$$$
\text { C.V. }
$$

Root MSE

15.38264

2.7688746

N_CASES Mean

Source

DF

Anova SS

Mean Square

F Value

18.000000

DESIGN

3

258.00000000

86.00000000

11.22

$\mathrm{Pr}>\mathrm{F}$

0.0071 


\section{Appendix C: SAS Results}

Exhibit C.5: SAS Input for and Results from SAS/STAT PROC GLM for Analyzing of Table 5 Data

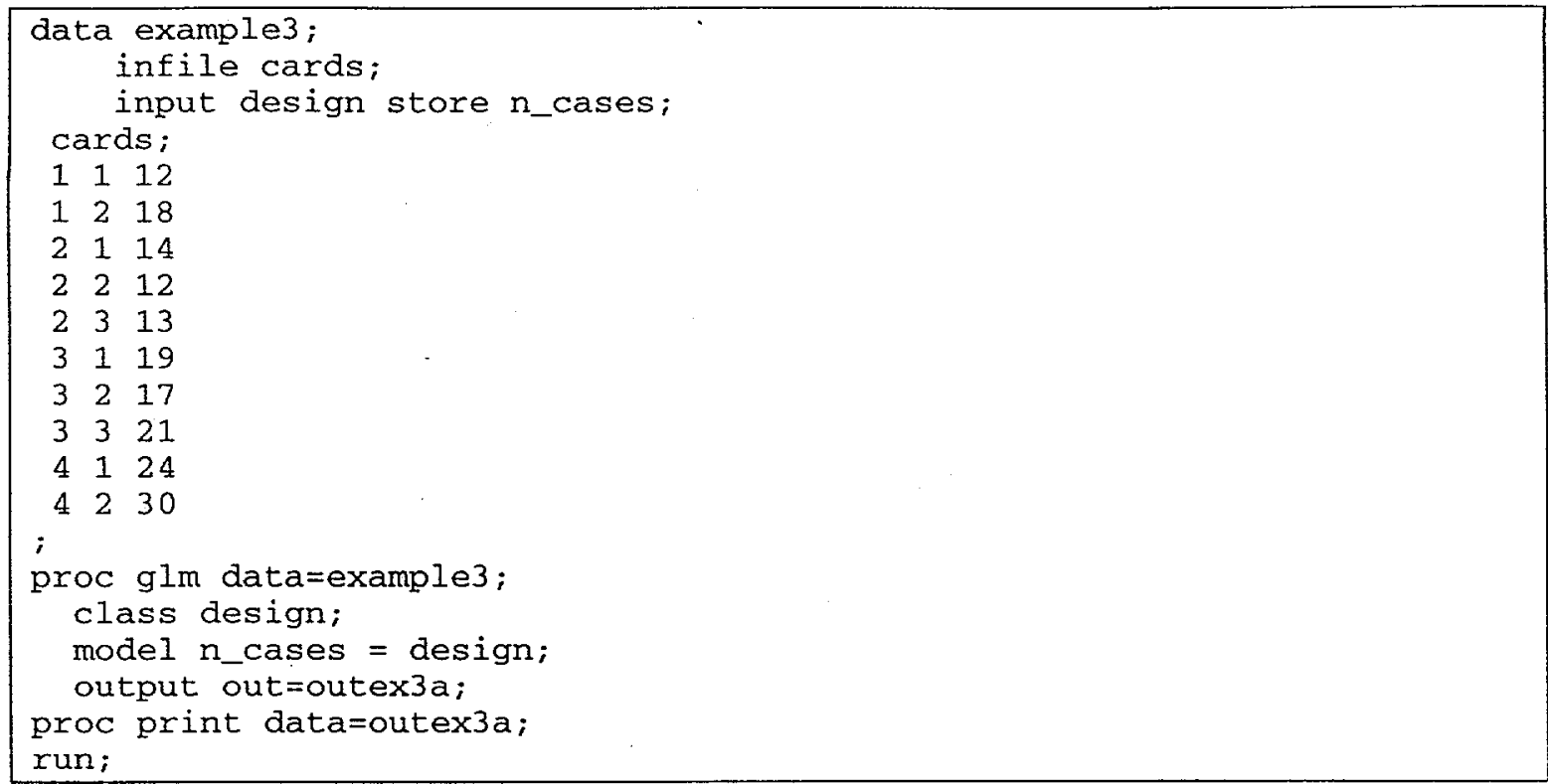

General Linear Models Procedure

$$
\begin{array}{lccc}
\text { Class Level Information } \\
\text { Class } & \text { Levels } & \text { Values } \\
\text { DESIGN } & 4 & 1234
\end{array}
$$

Number of observations in data set $=10$

General Linear Models Procedure

Dependent Variable: N_CASES

Source

DF

Model

3

Error

Corrected Total

$$
\begin{gathered}
\text { R-Square } \\
0.848684
\end{gathered}
$$

Source

DESIGN

Source

DESIGN
DF

3

DF

3
Sum of

Squares

258.00000000

46.00000000

304.00000000

C.V.

15.38264

Type I SS

258.00000000

Type III SS

258.00000000

$\begin{array}{rcc}\begin{array}{r}\text { Mean } \\ \text { Square }\end{array} & \text { F Value } & \text { Pr }>F \\ 86.00000000 & 11.22 & 0.0071 \\ 7.66666667 & & \\ & & \end{array}$

Root MSE

N_CASES Mean

2.7688746

18.000000

Mean Square

F Value

$\operatorname{Pr}>\mathrm{F}$

86.00000000

11.22

0.0071

Mean Square

F Value

$\operatorname{Pr}>\mathrm{F}$

86.00000000

11.22

0.0071 
Appendix C: SAS Results

Exhibit C.6: SAS Input for and Results from SAS/STAT PROC GLM for Analyzing of Table 8 Data

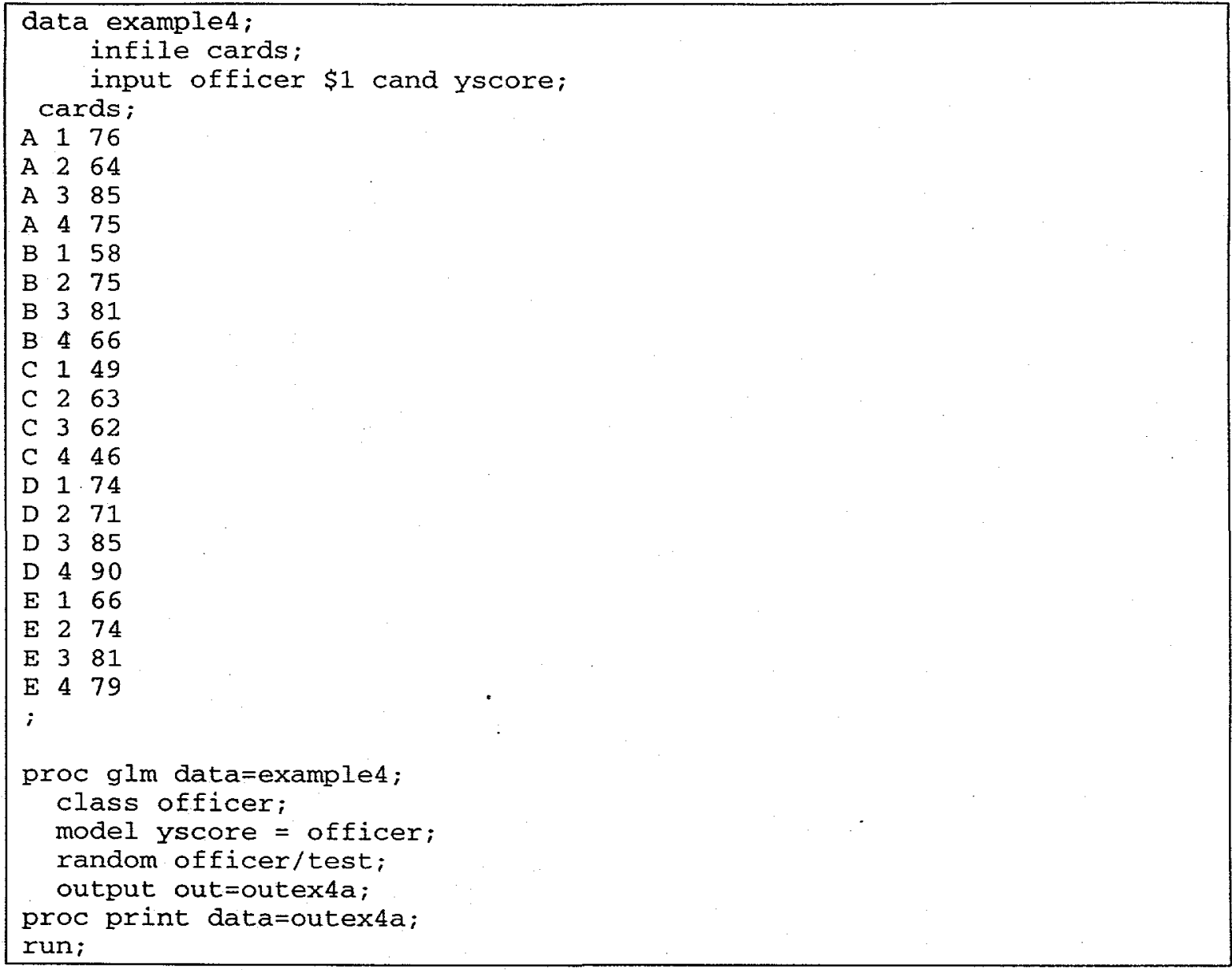

General Linear Models Procedure

Class Level Information

$\begin{array}{lrl}\text { Class } & \text { Levels } & \text { Values } \\ \text { OFFICER } & 5 & \text { A B C D E }\end{array}$

Number of observations in data set $=20$

General Linear Models Procedure

Dependent Variable: YSCORE

$\begin{array}{lrrrrr}\text { Source } & \text { DF } & \begin{array}{r}\text { Sum of } \\ \text { Squares }\end{array} & \begin{array}{r}\text { Mean } \\ \text { Square }\end{array} & \text { F Value } & \text { Pr }>\text { F } \\ \text { Model } & 4 & 1480.0000000 & 370.0000000 & 4.89 & 0.0100 \\ \text { Error } & 15 & 1134.0000000 & 75.6000000 & & \\ \text { Corrected Total } & 19 & 2614.0000000 & & & \end{array}$




\section{Appendix C: SAS Results}

Exhibit C.6: SAS Input for and Results from SASSTAT PROC GLM for Analyzing of Table 8 Data (Continued)

$\begin{array}{lrrrrr} & \text { R-Square } & \text { C.V. } & \text { Root MSE } & \text { YSCORE Mean } \\ & 0.566182 & 12.24623 & 8.6948260 & 71.000000 \\ \text { Source } & \text { DF } & \text { Type I SS } & \text { Mean Square } & \text { F Value } & \text { Pr }>\text { F } \\ \text { OFFICER } & 4 & 1480.0000000 & 370.0000000 & 4.89 & 0.0100 \\ \text { Source } & \text { DF } & \text { Type III SS } & \text { Mean Square } & \text { F Value } & \text { Pr }>\text { F } \\ \text { OFFICER } & 4 & 1480.0000000 & 370.0000000 & 4.89^{\circ} & 0.0100\end{array}$

General Linear Models Procedure

Source Type III Expected Mean Square

OFFICER Var(Error) + $4 \operatorname{Var}$ (OFFICER)

General Linear Models Procedure

Tests of Hypotheses for Random Model Analysis of Variance

Dependent Variable: YSCORE

Source: OFFICER

Error: MS (Error)

DF Type III MS

Denominator

$\mathrm{DF}$

15
Denominator

MS

75.6
F Value

4.8942
$\operatorname{Pr}>\mathrm{F}$

0.0100 
Appendix C: SAS Results

Exhibit C.7: SAS Input for and Results from SAS/STAT PROC VARCOMP for Analyzing of Table 8 Data

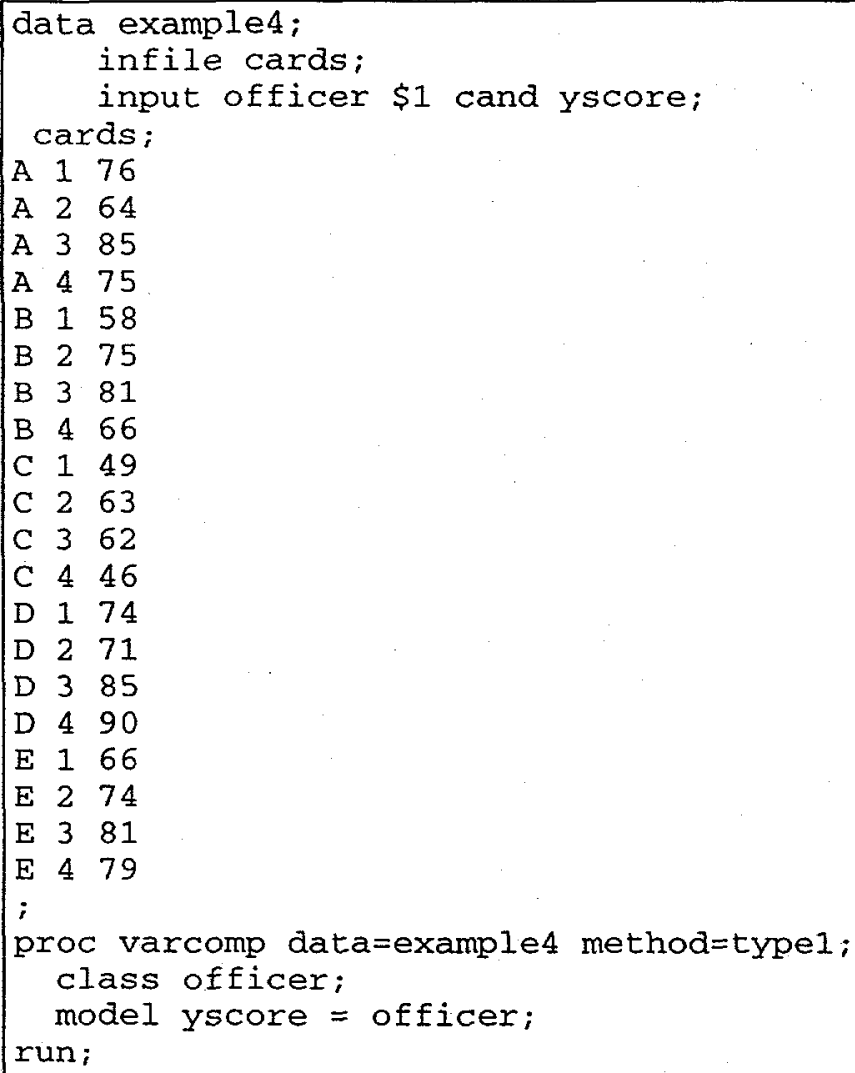

Source

OFFICER

Error

Variance Component

$\operatorname{Var}$ (OFFICER)

Var(Error)
Expected Mean Square

$\operatorname{Var}$ (Error) + $4 \operatorname{Var}$ (OFFICER)

$\operatorname{Var}$ (Error) 
Exhibit C.8: SAS Input for and Results from SAS/STAT PROC ANOVA for Analyzing of Table 10 Data

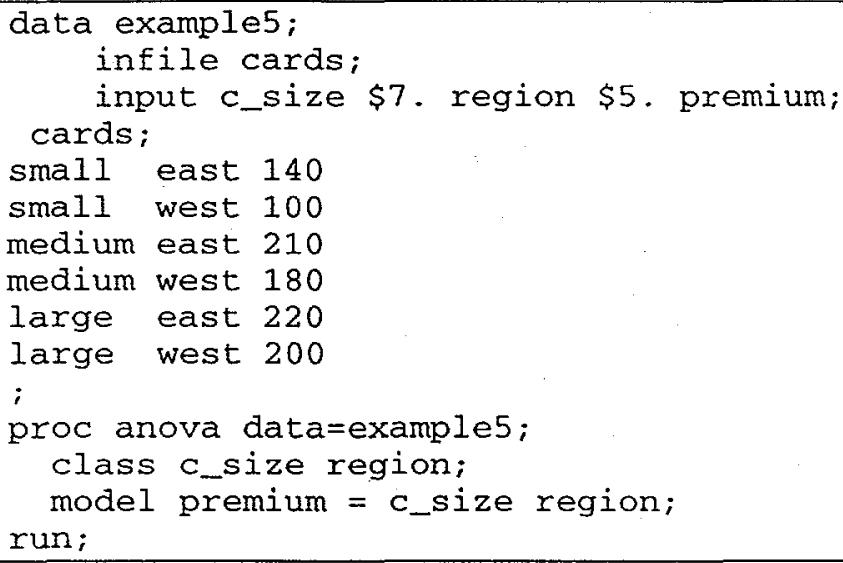

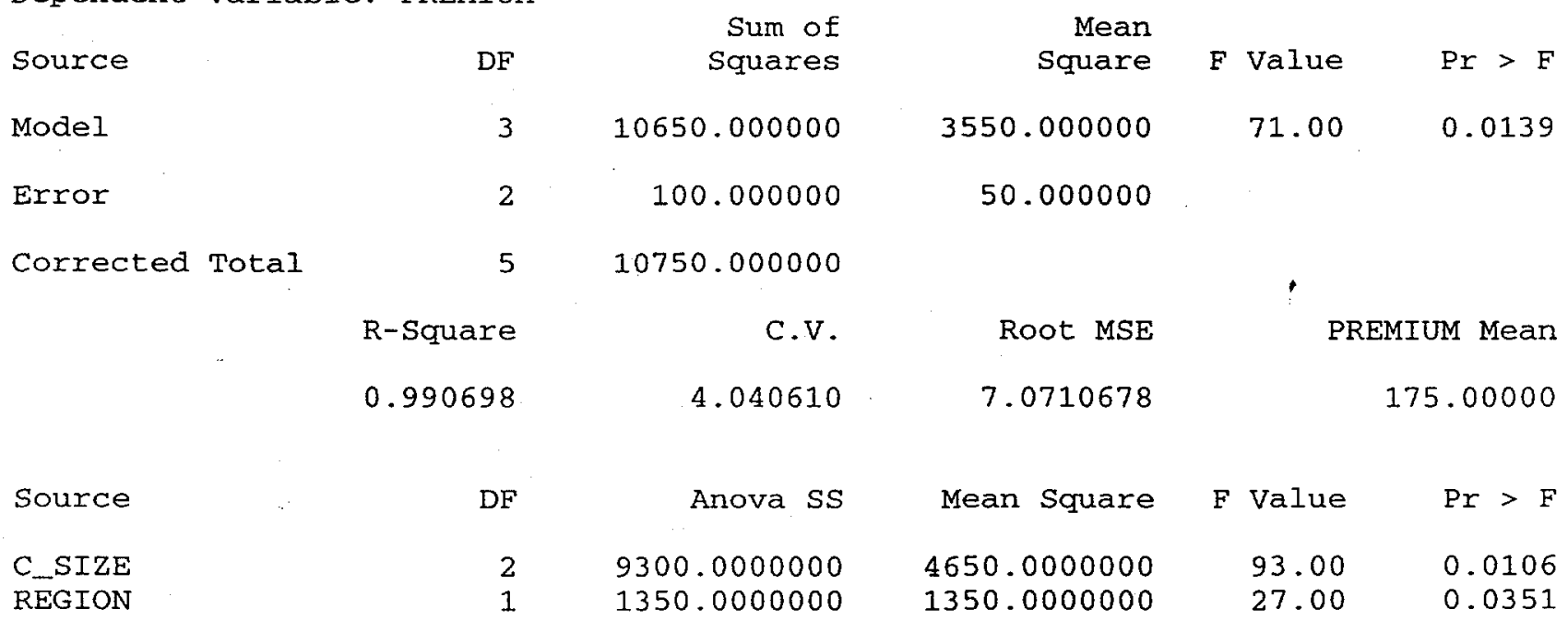


Appendix C: SAS Results

Exhibit C.9: SAS Input for and Results from SAS/STAT PROC GLM for Analyzing of Table 10 Data

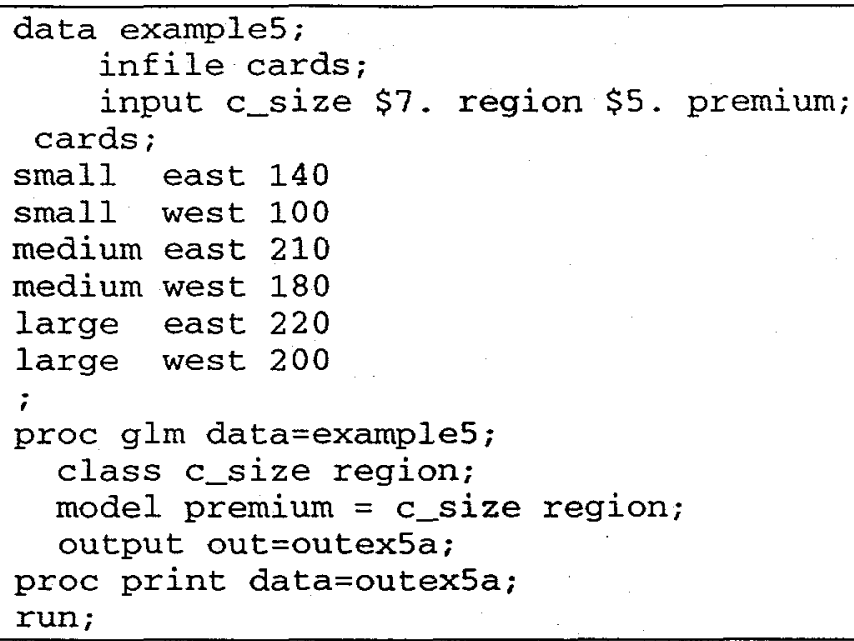

General Linear Models Procedure

Class Level Information

$\begin{array}{lrl}\text { Class } & \text { Levels } & \text { Values } \\ \text { C_SIZE } & 3 & \text { large medium small } \\ \text { REGION } & 2 & \text { east west }\end{array}$

Number of observations in data set $=6$

General Linear Models Procedure

Dependent Variable: PREMIUM

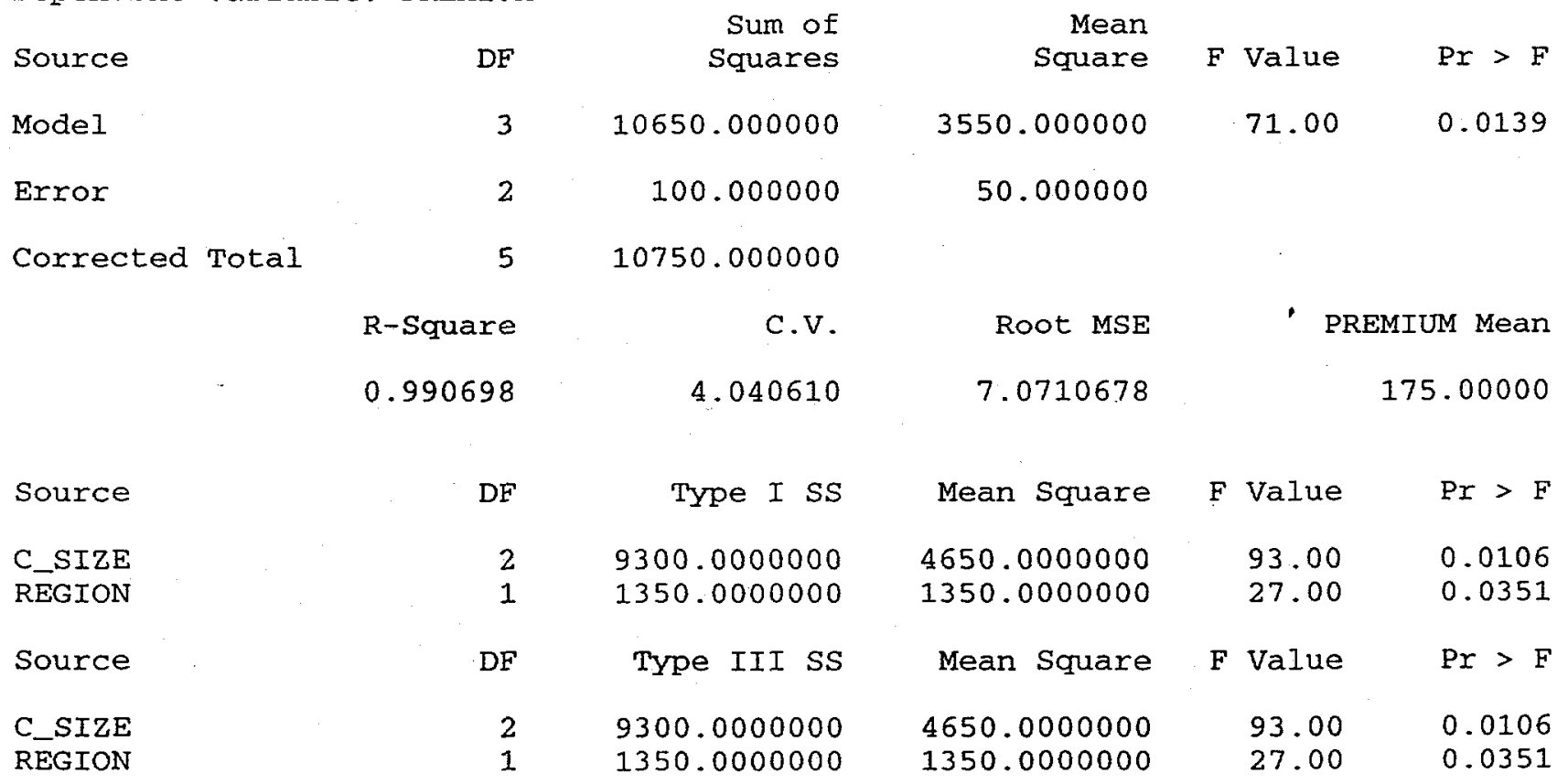


Appendix C: SAS Results

Exhibit C.10: SAS Input for and Results from SAS/STAT PROC ANOVA for Analyzing of Table 13 Data

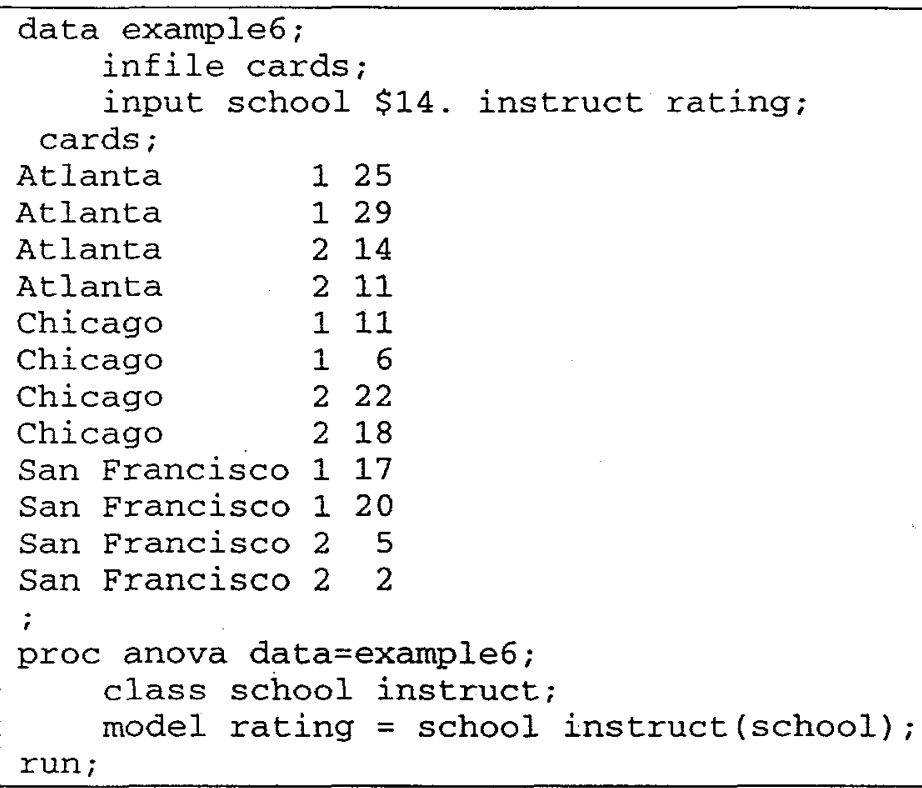

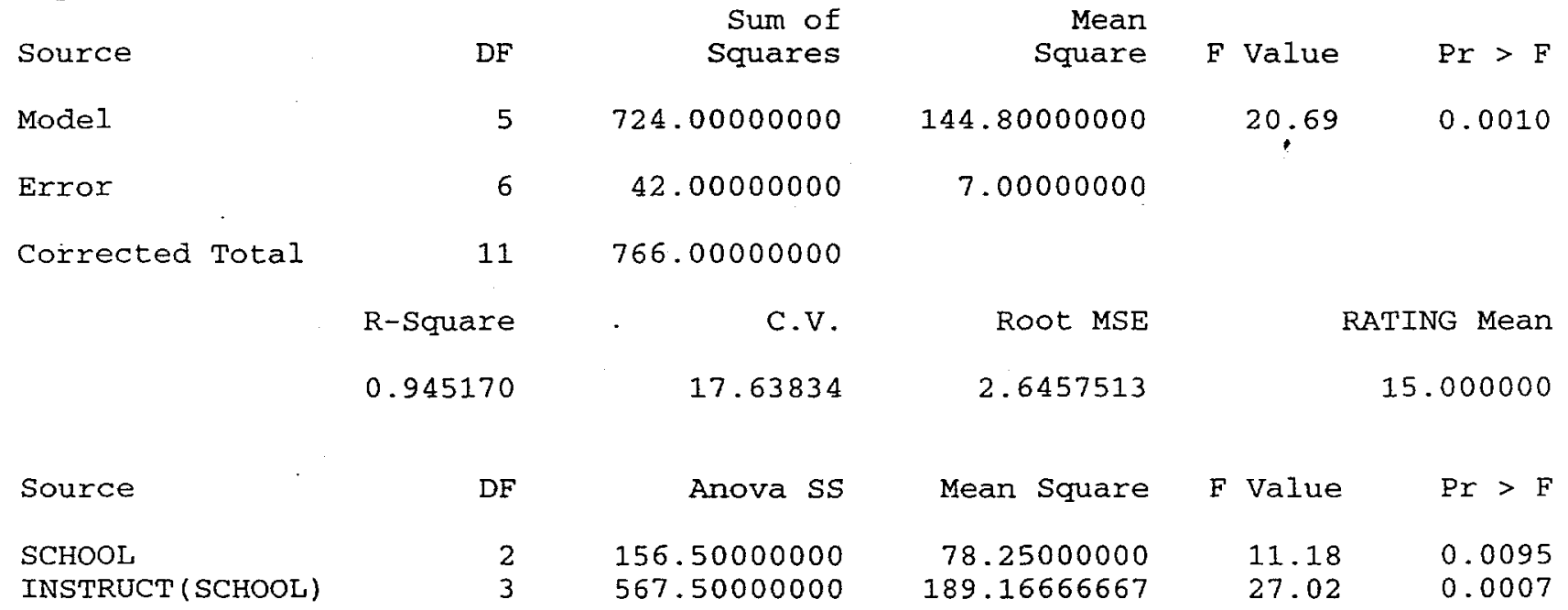




\section{Appendix C: SAS Results}

Exhibit C.11: SAS Input for and Results from SAS/STAT PROC GLM for Analyzing of Table 13 Data

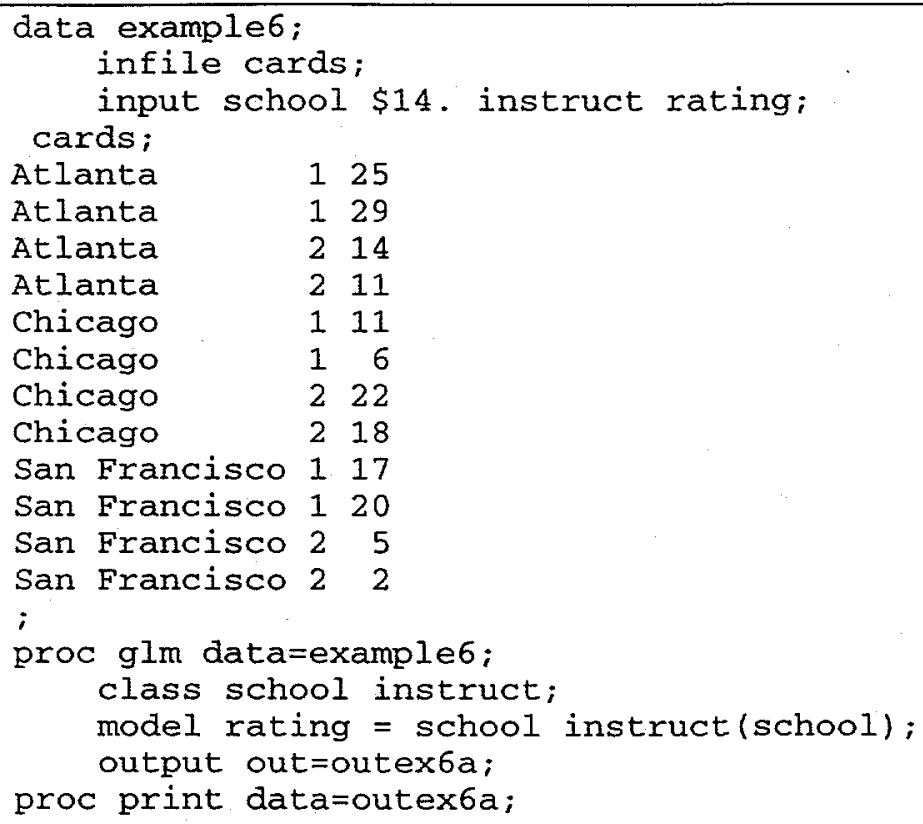

General Linear Models Procedure

$$
\text { Class Level Information }
$$

$\begin{array}{lrl}\text { Class } & \text { Levels } & \text { Values } \\ \text { SCHOOL } & 3 & \text { Atlanta Chicago San Francisco } \\ \text { INSTRUCT } & 2 & 12\end{array}$

$$
\text { Number of observations in data set }=12
$$

\section{General Linear Models Procedure}

\begin{tabular}{|c|c|c|c|c|c|c|c|}
\hline Source & & $\mathrm{DF}$ & $\begin{array}{r}\text { Sum of } \\
\text { Squares }\end{array}$ & $\begin{array}{r}\text { Mean } \\
\text { Square }\end{array}$ & $\mathrm{F}$ & Value & $\operatorname{Pr}>F$ \\
\hline Model & & 5 & 724.00000000 & 144.80000000 & & 20.69 & 0.0010 \\
\hline Error & & 6 & 42.00000000 & 7.00000000 & , & & \\
\hline \multirow[t]{3}{*}{ Corrected } & Total & 11 & 766.00000000 & & & & \\
\hline & & re & C.V. & Root MSE & & & RATING Mean \\
\hline & & 170 & 17.63834 & 2.6457513 & & & 15.000000 \\
\hline
\end{tabular}

Dependent Variable: RATING 
Appendix C: SAS Results

WSRC-RP-99-00422

Revision 0

Exhibit C.11: SAS Input for and Results from SAS/STAT PROC GLM for Analyzing of Table 13 Data (continued)

Source

SCHOOL

INSTRUCT (SCHOOL)

Source

SCHOOL

INSTRUCT (SCHOOL)
DF

$2 \quad 156.50000000$

$3 \quad 567.50000000$

DF

2156.50000000

3

Mean Square
78.25000000
189.16666667
Mean Square
78.25000000
189.16666667

F Value

$\operatorname{Pr}>F$

11.18

27.02

F Value

11.18

27.02
78.25000000
189.16666667
0.0095

0.0007

$\operatorname{Pr}>F$

0.0095

0.0007 


\section{Appendix C: SAS Results}

Exhibit C.12: SAS Input for and Results from SAS/STAT PROC GLM for Analyzing of Table 13 Data

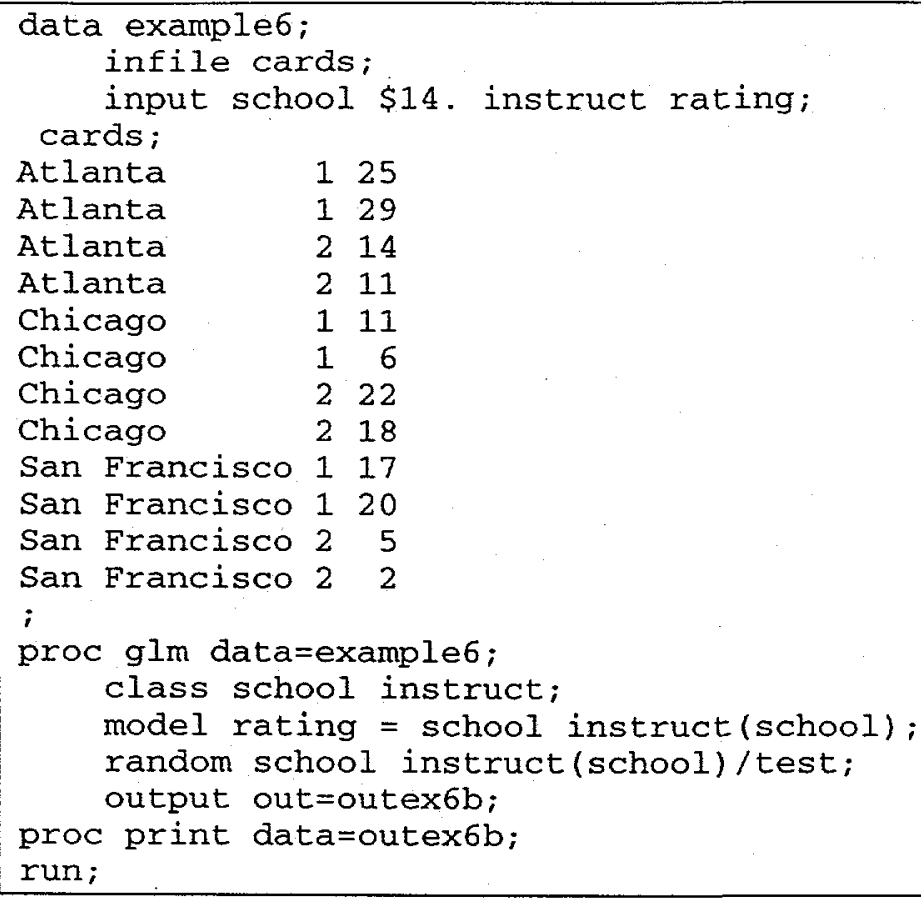

Source

Model

Error

Corrected Total
Sum of

Squares

724.00000000

42.00000000

11

766.00000000

R-Square

0.945170
C.V.

17.63834

$\begin{array}{rrr}\text { Mean } & \text { ' } & \\ \text { Square } & \text { F Value } & \operatorname{Pr}>\text { F } \\ 144.80000000 & 20.69 & 0.0010 \\ 7.00000000 & & \end{array}$

Root MSE

RATING Mean

2.6457513

15.000000 
WSRC-RP-99-00422

Revision 0

\section{Appendix C: SAS Results}

Exhibit C.12: SAS Input for and Results from SAS/STAT PROC GLM for Analyzing of Table 13 Data (continued)

$\begin{array}{lrrrrr}\text { Source } & \text { DF } & \text { Type I SS } & \text { Mean Square } & \text { F Value } & \text { Pr }>\text { F } \\ \text { SCHOOL } & 2 & 156.50000000 & 78.25000000 & 11.18 & 0.0095 \\ \text { INSTRUCT (SCHOOL) } & 3 & 567.50000000 & 189.16666667 & 27.02 & 0.0007 \\ \text { Source } & \text { DF } & \text { Type III SS } & \text { Mean Square } & \text { F Value } & \text { Pr }>\text { F } \\ \text { SCHOOL } & & & & \\ \text { INSTRUCT (SCHOOL) } & 2 & 156.50000000 & 78.25000000 & 11.18 & 0.0095 \\ \text { S } & 3 & 567.50000000 & 189.16666667 & 27.02 & 0.0007\end{array}$

General Linear Models Procedure

Source

Type III Expected Mean Square

SCHOOL

$\operatorname{Var}($ Error) $+2 \operatorname{Var}(\operatorname{INSTRUCT}(\mathrm{SCHOOL}))+4 \operatorname{Var}(\mathrm{SCHOOL})$

INSTRUCT (SCHOOL) Var(ErrOI) $+2 \operatorname{Var}($ INSTRUCT(SCHOOL))

General Linear Models Procedure

Tests of Hypotheses for Random Model Analysis of Variance

Dependent Variable: RATING

Source: SCHOOL

Error: MS (INSTRỤCT (SCHOOL))

$\begin{array}{rr}\text { DF Type III } & \text { MS } \\ 2 & 78.25\end{array}$

$\begin{array}{rr}\text { Denominator } & \text { Denominator } \\ \text { DF } & \text { MS } \\ 3 & 189.16666667\end{array}$

Denominator

DF
Denominator

MS
F Value

0.4137

$\operatorname{Pr}>\mathrm{F}$

0.6940

Source: INSTRUCT (SCHOOL)

Error: MS (Error)

DF Type III MS

$3 \quad 189.16666667$

F Value
27.0238

$\mathrm{Pr}>\mathrm{F}$

0.0007 
Appendix C: SAS Results

Revision 0

Exhibit C.13: SAS Input for and Results from SAS/STAT PROC VARCOMP for Analyzing of Table 13 Data

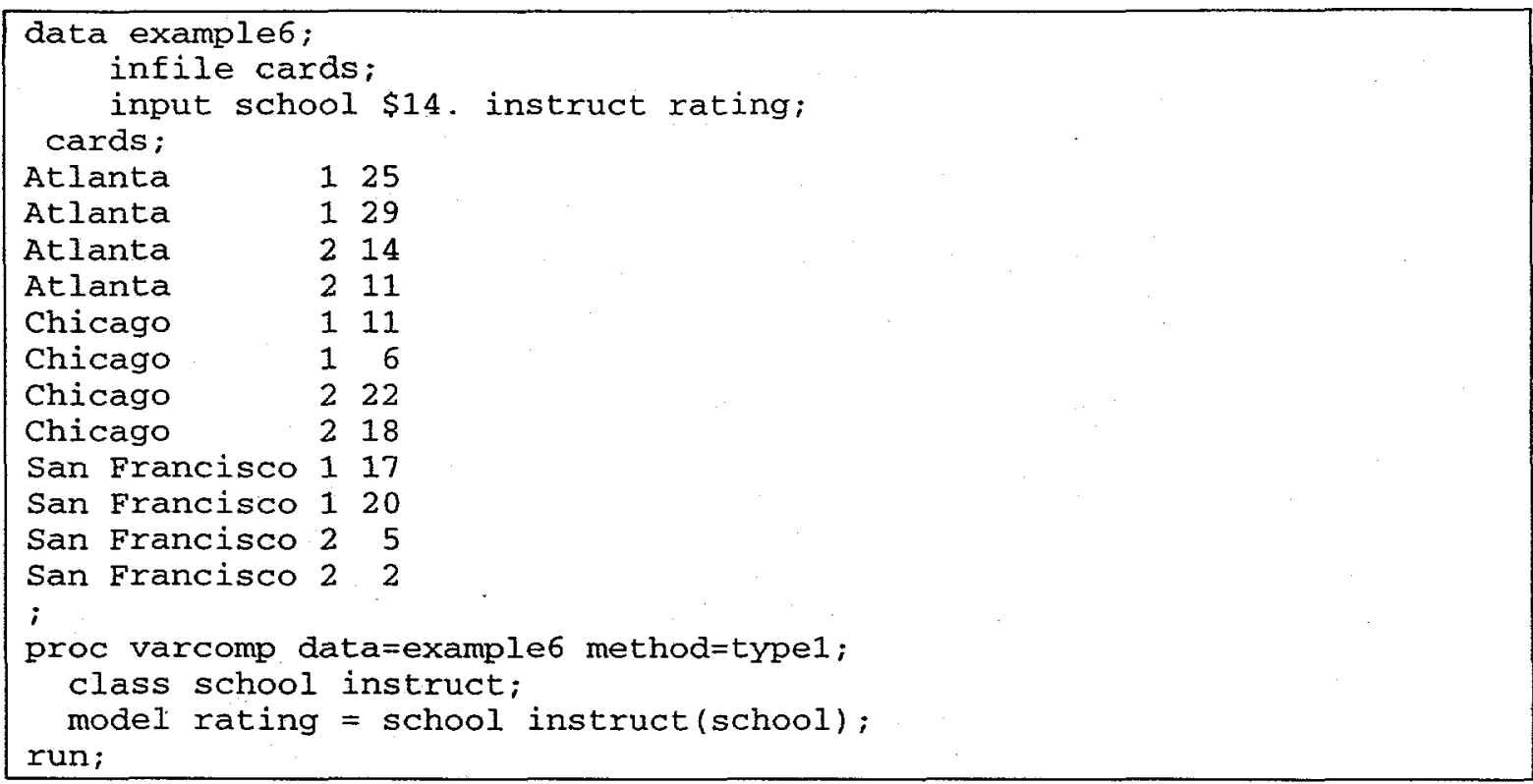

Variance Components Estimation Procedure

Class Level Information

$\begin{array}{lrl}\text { Class } & \text { Levels } & \text { Values } \\ \text { SCHOOL } & 3 & \text { Atlanta Chicago San Francisco } \\ \text { INSTRUCT } & 2 & 12\end{array}$

Number of observations in data set $=12$

Variance Components Estimation Procedure

Dependent Variable: RATING

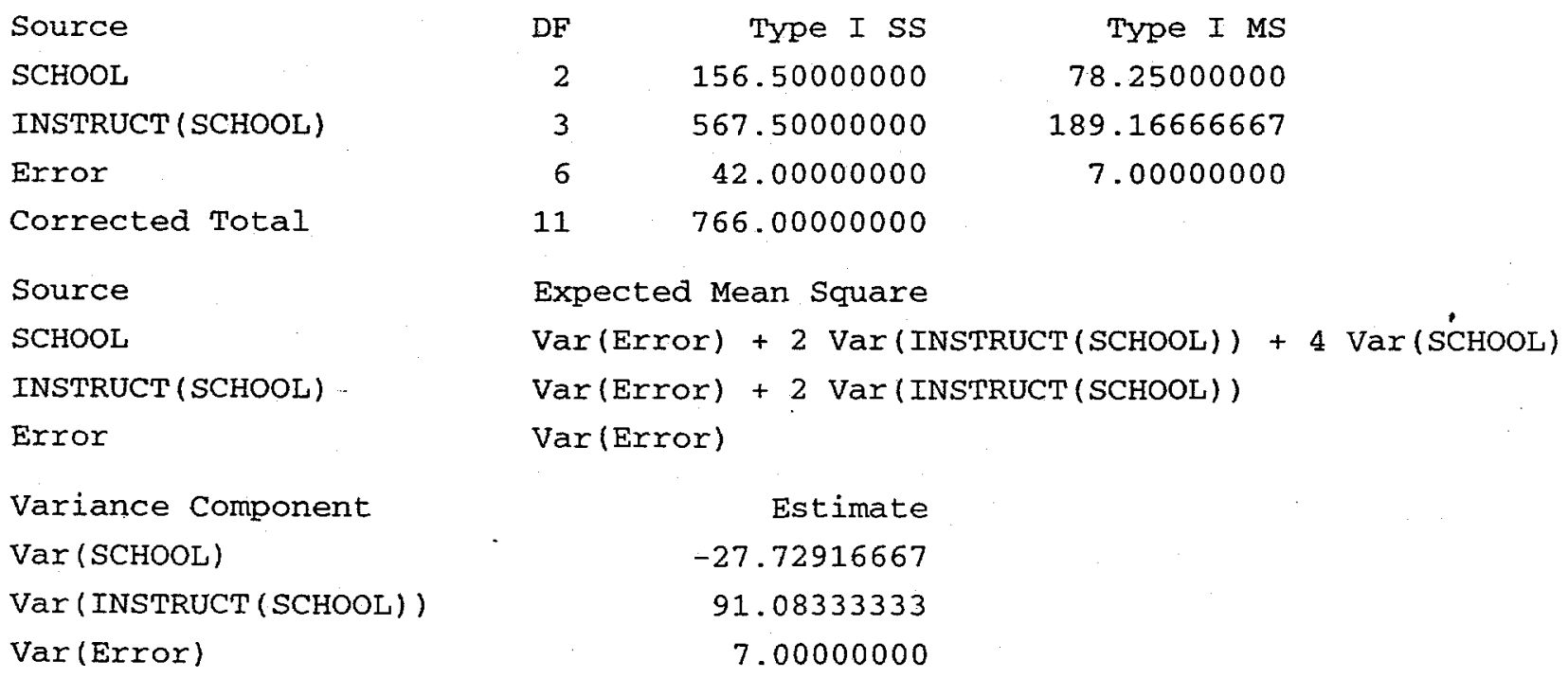


Appendix C: SAS Results

Exhibit C.14: SAS Input for and Results from SAS/QC PROC FACTEX for Experimental Design

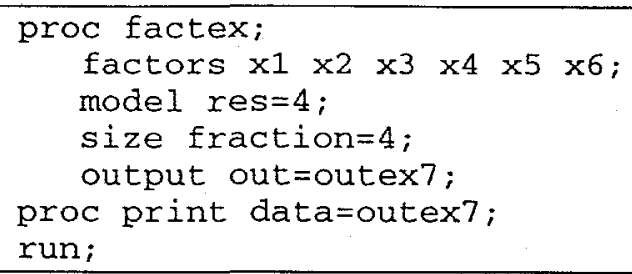

$\begin{array}{rrrrrrr}\text { OBS } & \mathrm{X} 1 & \mathrm{X} 2 & \mathrm{X} 3 & \mathrm{X} 4 & \mathrm{X} 5 & \mathrm{X} 6 \\ 1 & -1 & -1 & -1 & -1 & -1 & -1 \\ 2 & -1 & -1 & -1 & 1 & 1 & 1 \\ 3 & -1 & -1 & 1 & -1 & 1 & 1 \\ 4 & -1 & -1 & 1 & 1 & -1 & -1 \\ 5 & -1 & 1 & -1 & -1 & 1 & -1 \\ 6 & -1 & 1 & -1 & 1 & -1 & 1 \\ 7 & -1 & 1 & 1 & -1 & -1 & 1 \\ 8 & -1 & 1 & 1 & 1 & 1 & -1 \\ 9 & 1 & -1 & -1 & -1 & -1 & 1 \\ 10 & 1 & -1 & -1 & 1 & 1 & -1 \\ 11 & 1 & -1 & 1 & -1 & 1 & -1 \\ 12 & 1 & -1 & 1 & 1 & -1 & 1 \\ 13 & 1 & 1 & -1 & -1 & 1 & 1 \\ 14 & 1 & 1 & -1 & 1 & -1 & -1 \\ 15 & 1 & 1 & 1 & -1 & -1 & -1 \\ 16 & 1 & 1 & 1 & 1 & 1 & 1\end{array}$


Exhibit C.15: SAS Input and Output for Mixture Problem Defined by Equation (2)

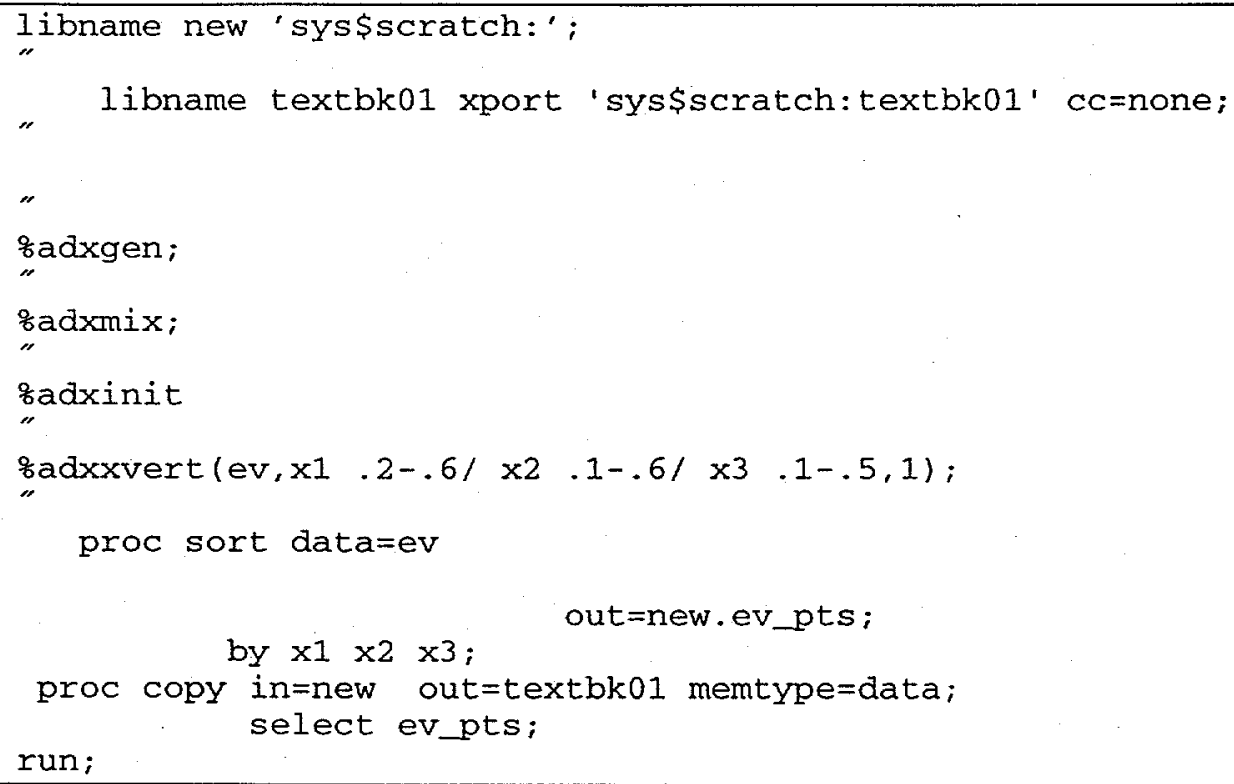

Extreme Vertices (Dimen=0) and Centroid (Dimen=2)

\begin{tabular}{|c|c|c|c|}
\hline $\mathbf{x}_{\mathbf{1}}$ & $\mathbf{x}_{\mathbf{2}}$ & $\mathbf{x}_{\mathbf{3}}$ & DIMEN \\
\hline 0.2 & 0.3 & 0.5 & 0 \\
\hline 0.2 & 0.6 & 0.2 & 0 \\
\hline 0.3 & 0.6 & 0.1 & 0 \\
\hline 0.383333 & 0.333333 & 0.283333 & 2 \\
\hline 0.4 & 0.1 & 0.5 & 0 \\
\hline 0.6 & 0.1 & 0.3 & 0 \\
\hline 0.6 & 0.3 & 0.1 & 0 \\
\hline
\end{tabular}

The output from this SAS run was "FTP'd" to the IBM PC using WS_FTP32 Version 3.00 by Ipswiteh, Inc., 1996, as a SAS transport file. The file was then imported into JMP and copy and pasted into this document. 


\section{Appendix C: SAS Results}

\section{Exhibit C.16: SAS Input for and Results from SAS/QC PROC OPTEX for D-Optimality}

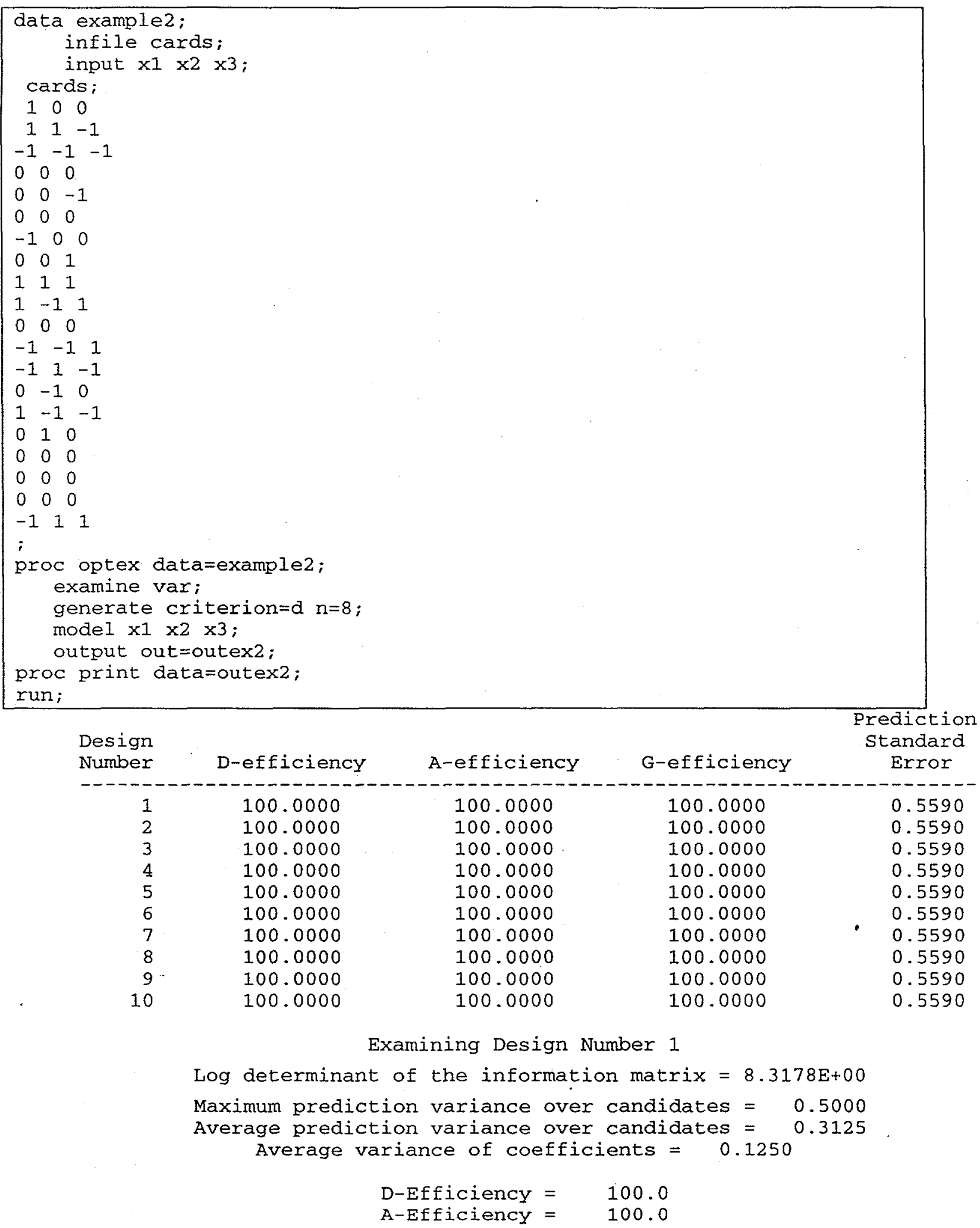


Appendix C: SAS Results

Exhibit C.16: SAS Input for and Results from SAS/QC PROC OPTEX for D-Optimality (Continued)

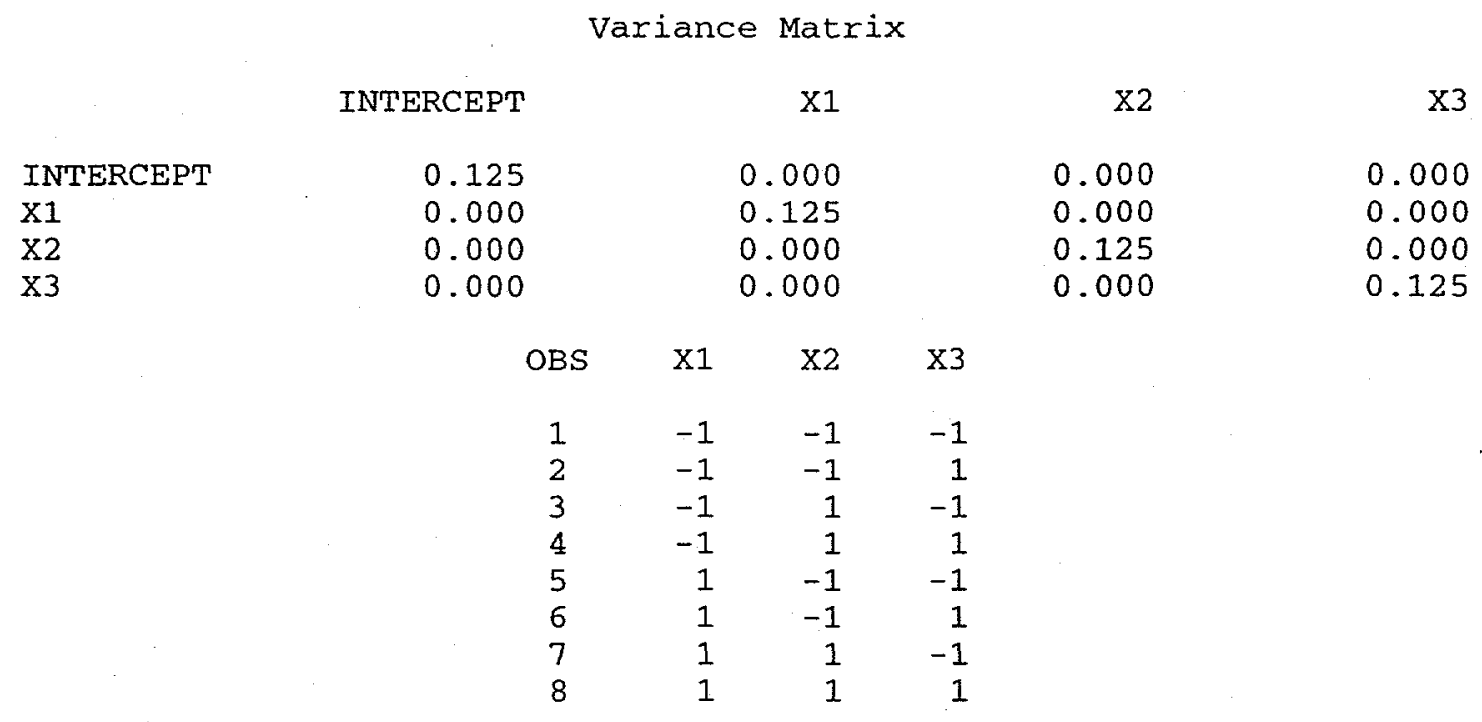




\section{Appendix C: SAS Results}

Exhibit C.17: SAS Input and Output for Control Chart Example from Table 18

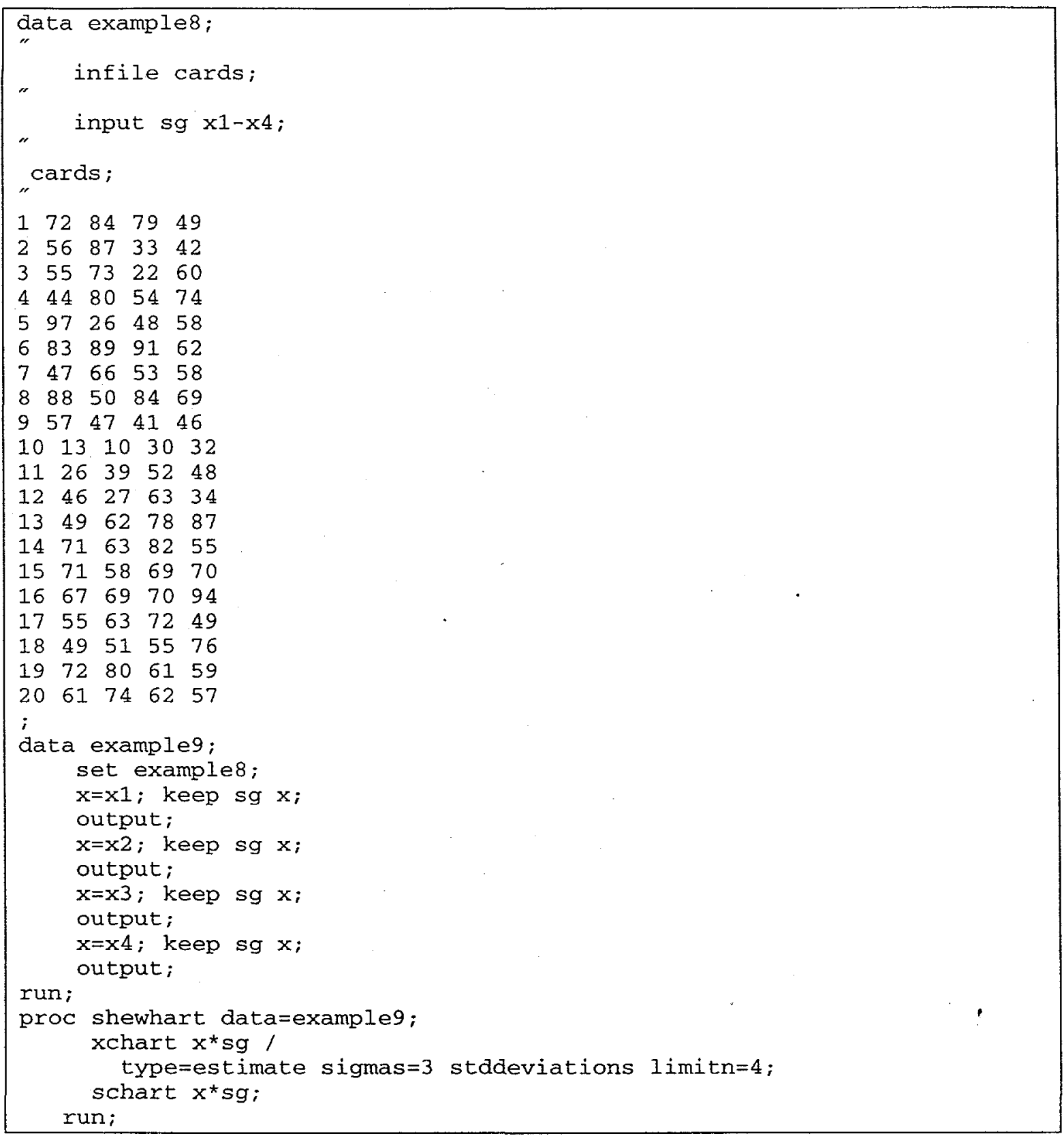


Appendix C: SAS Results

Exhibit C.17: SAS Input and Output for Control Chart Example from Table 18 (Continued)

3 Sigma Limits

For $n=4$ :

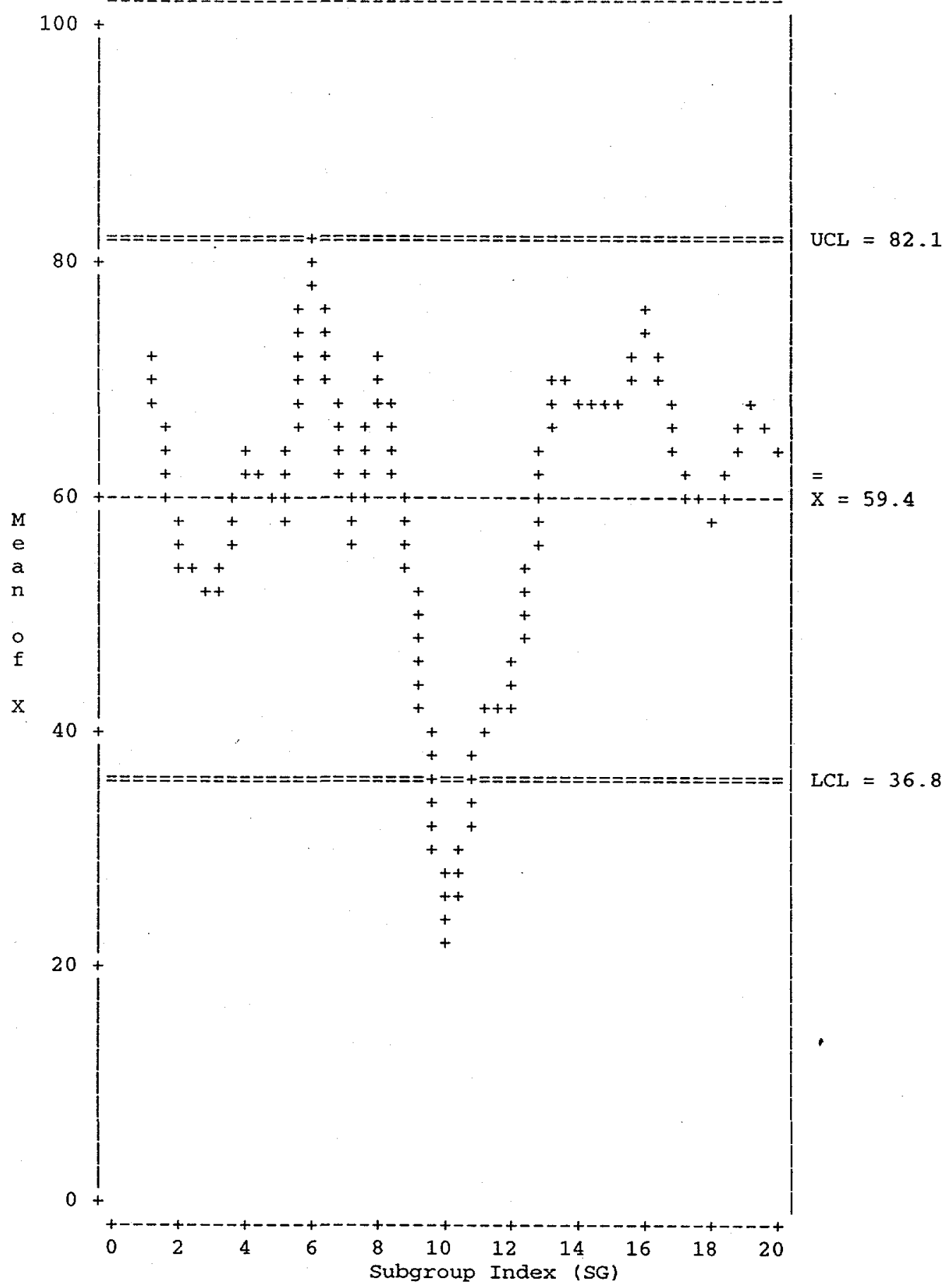

Subgroup Sizes: $n=4$ 
Revision 0

\section{Appendix C: SAS Results}

Exhibit C.17: SAS Input and Output for Control Chart Example from Table 18 (Continued)

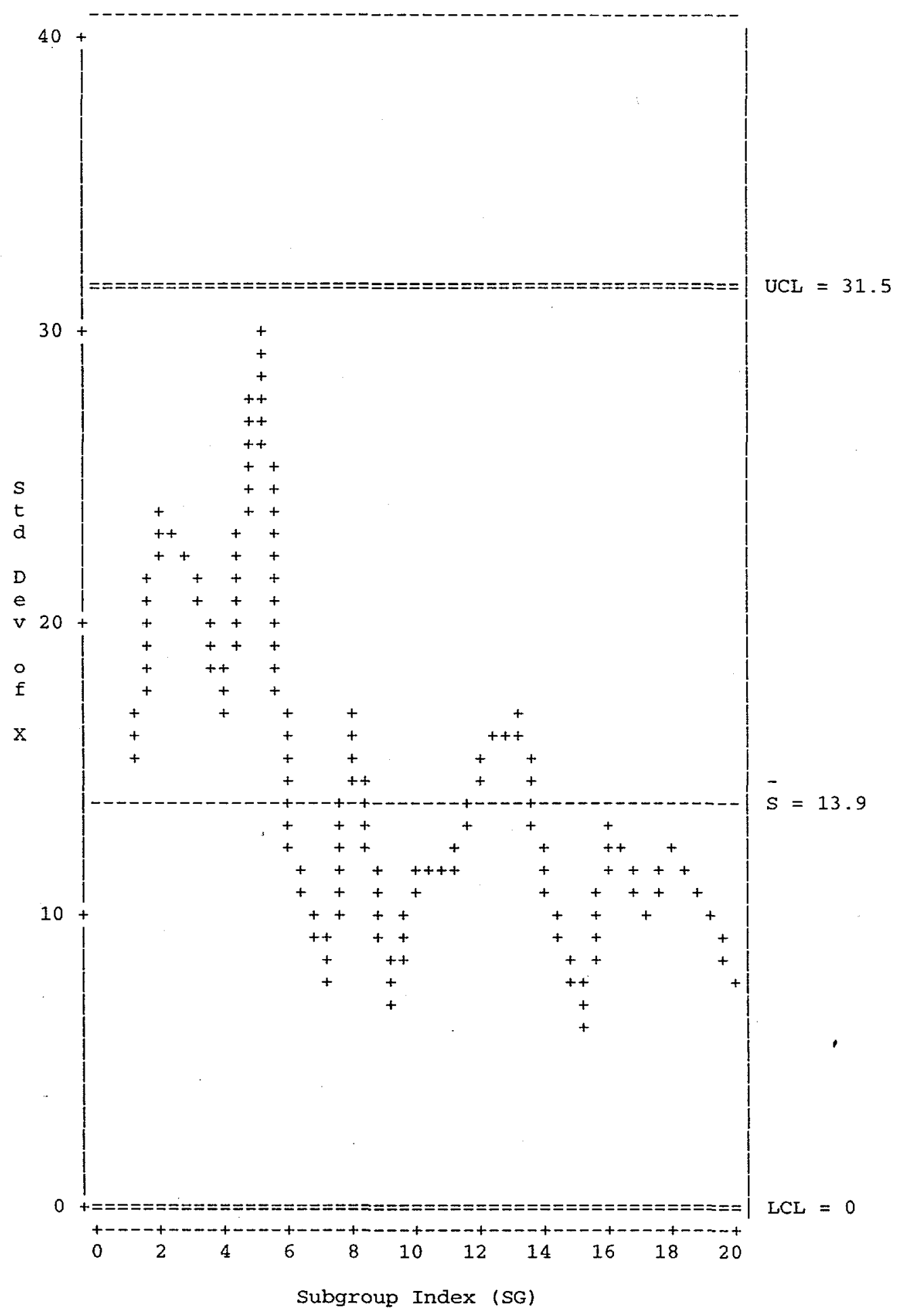

Subgroup Sizes: $n=4$ 
Appendix D: Mixsoft Results

\section{Exhibit D.1: Mixsoft Output for a Fractional Factorial Experiment using the Design Experiment Feature}

MIXSOFT VERSION 2.3, MARCH 1998

TWOLEV VERSION 2.3, MARCH 1998

COPYRIGHT (C) 1989-1998, GREGORY F. PIEPEL

ALL RIGHTS RESERVED

\section{VARIABLES}

CODED LEVELS OF -1 AND +1 USED FOR DESIGN VARIABLES.

FRACTIONAL FACTORIAL DESIGN, 16 POINTS

\begin{tabular}{|c|c|c|c|c|c|c|}
\hline Run & A & B & C & D & E & F \\
\hline 1 & -1 & -1 & -1 & -1 & -1 & -1 \\
\hline 2 & 1 & -1 & -1 & -1 & 1 & 1 \\
\hline 3 & -1 & 1 & -1 & -1 & 1 & 1 \\
\hline 4 & 1 & 1 & -1 & -1 & -1 & -1 \\
\hline 5 & -1 & -1 & 1 & -1 & 1 & -1 \\
\hline 6 & 1 & -1 & 1 & -1 & -1 & 1 \\
\hline 7 & -1 & 1 & 1 & -1 & -1 & 1 \\
\hline 8 & 1 & 1 & 1 & -1 & 1 & -1 \\
\hline 9 & -1 & -1 & -1 & 1 & -1 & 1 \\
\hline 10 & 1 & -1 & -1 & 1 & 1 & -1 \\
\hline 11 & -1 & 1 & -1 & 1 & 1 & -1 \\
\hline 12 & 1 & 1 & -1 & 1 & -1 & 1 \\
\hline 13 & -1 & -1 & 1 & 1 & 1 & 1 \\
\hline 14 & 1 & -1 & 1 & 1 & -1 & -1 \\
\hline 15 & -1 & 1 & 1 & 1 & -1 & -1 \\
\hline 16 & 1 & 1 & 1 & 1 & 1 & 1 \\
\hline
\end{tabular}




\section{Appendix D: Mixsoft Results}

Exhibit D.2: Mixsoft Input and Output for Mixture Problem Defined by Equation (2)

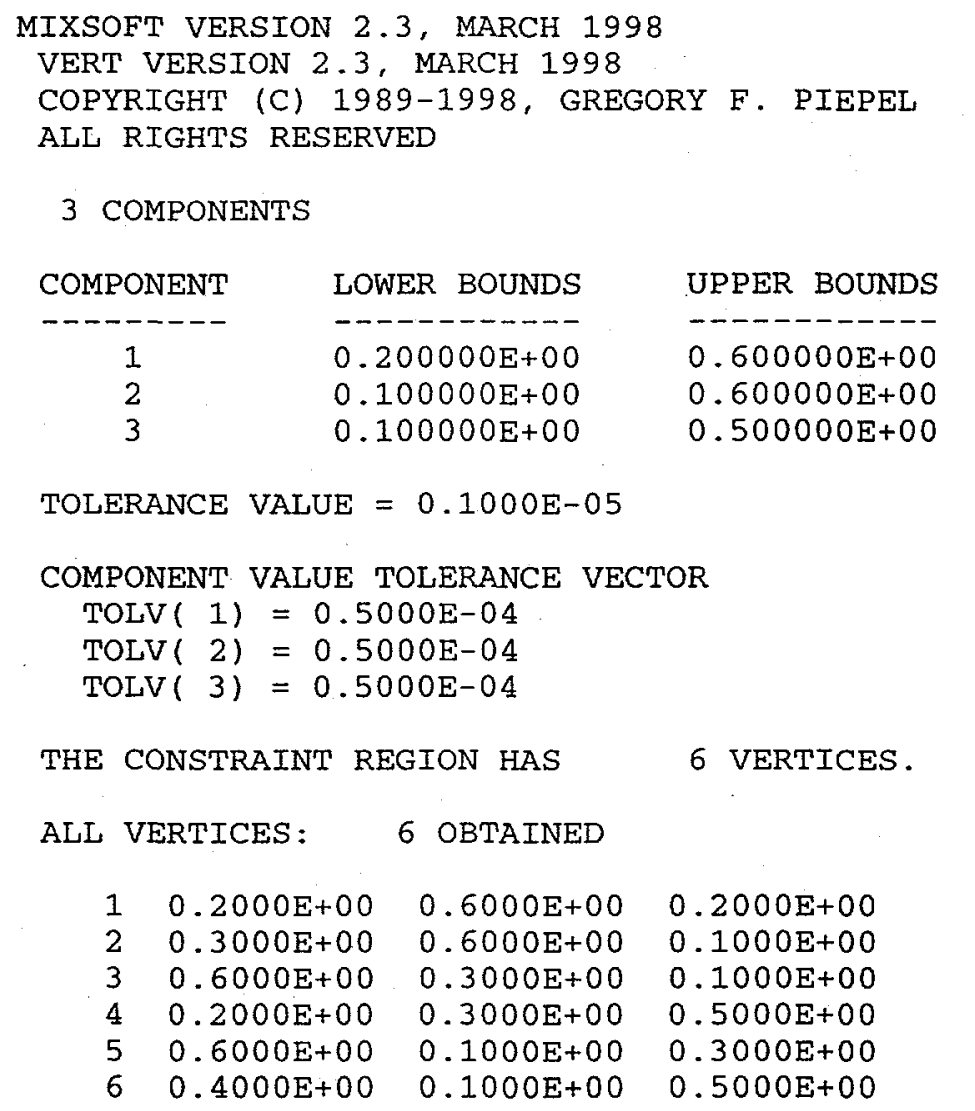


Appendix E: Statgraphics Results

Exhibit E.1: Statgraphics Output for Statistics of Lot Size Information in Table 2

\title{
Analysis Summary
}

Data variable: $\mathrm{X}$

10 values ranging from 20.0 to 80.0

Scatterplot for $\mathrm{X}$

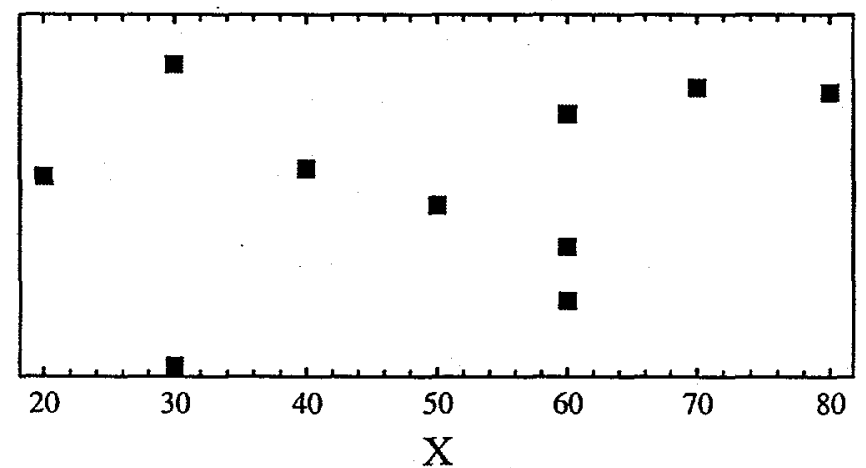

\section{Summary Statistics for $\mathbf{X}$}

\author{
Count $=10$ \\ Average $=50.0$ \\ Median $=55.0$ \\ Mode $=60.0$ \\ Geometric mean $=46.1205$ \\ Variance $=377.778$ \\ Standard deviation $=19.4365$ \\ Standard error $=6.14636$ \\ Minimum $=20.0$ \\ Maximum $=80.0$ \\ Range $=60.0$ \\ Lower quartile $=30.0$ \\ Upper quartile $=60.0$ \\ Interquartile range $=30.0$ \\ Skewness $=-0.113492$ \\ Stnd. skewness $=-0.146517$ \\ Kurtosis $=-1.06661$ \\ Stnd. kurtosis $=-0.688493$ \\ Coeff. of variation $=38.873 \%$ \\ Sum $=500.0$
}


Appendix E: Statgraphics Results

Revision 0

Exhibit E.1: Statgraphics Output for Statistics of Lot Size Information in Table 2

(continued)

Box-and-Whisker Plot

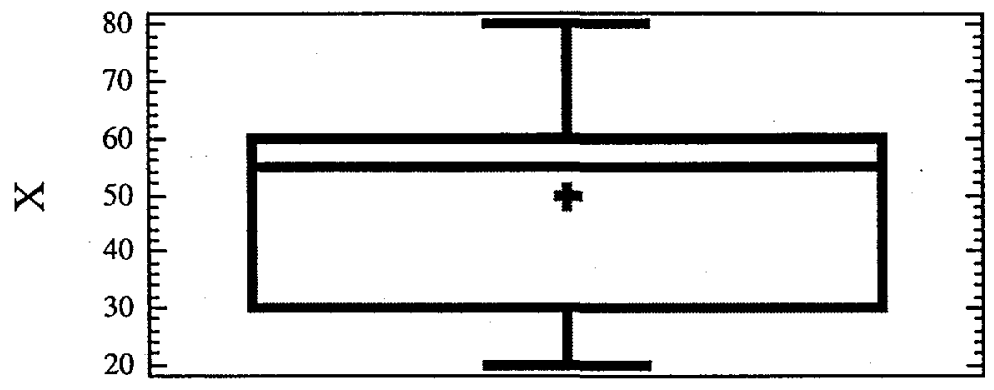

\section{Percentiles for $\mathbf{X}$}

$$
\begin{aligned}
& 0.5 \%=20.0 \\
& 2.5 \%=20.0 \\
& 10.0 \%=25.0 \\
& 25.0 \%=30.0 \\
& 50.0 \%=55.0 \\
& 75.0 \%=60.0 \\
& 90.0 \%=75.0 \\
& 97.5 \%=80.0 \\
& 99.5 \%=80.0
\end{aligned}
$$

Note: There are several ways to determine estimates of quantiles. Statgraphics computes these as outlined in Hayes [13]. The Pth quantile is estimated as $100(\mathrm{i}-0.5) / \mathrm{N}$ where $\mathrm{i}$ is the rank. Linear interpolation is used for other quantiles.

\section{Moments}

Histogram for X

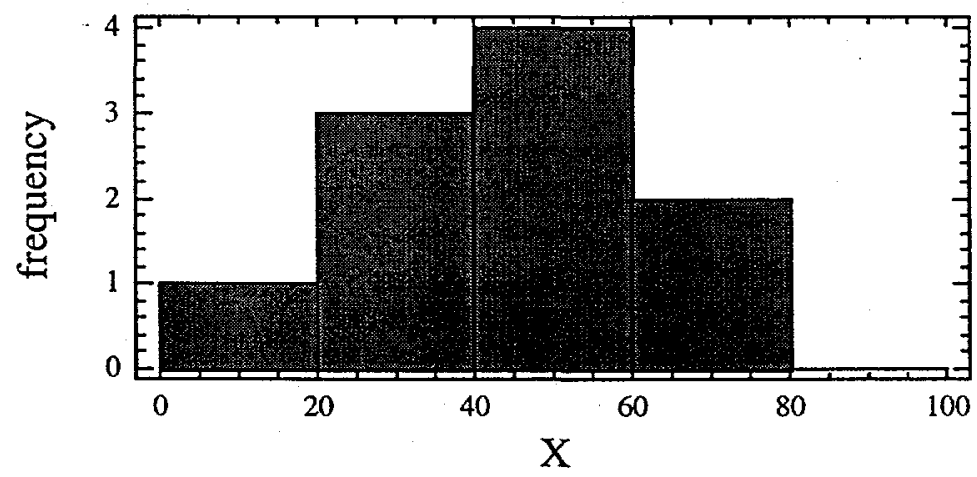


Appendix E: Statgraphics Results

Exhibit E.1: Statgraphics Output for Statistics of Lot Size Information in Table 2 (continued)

Quantile Plot for X

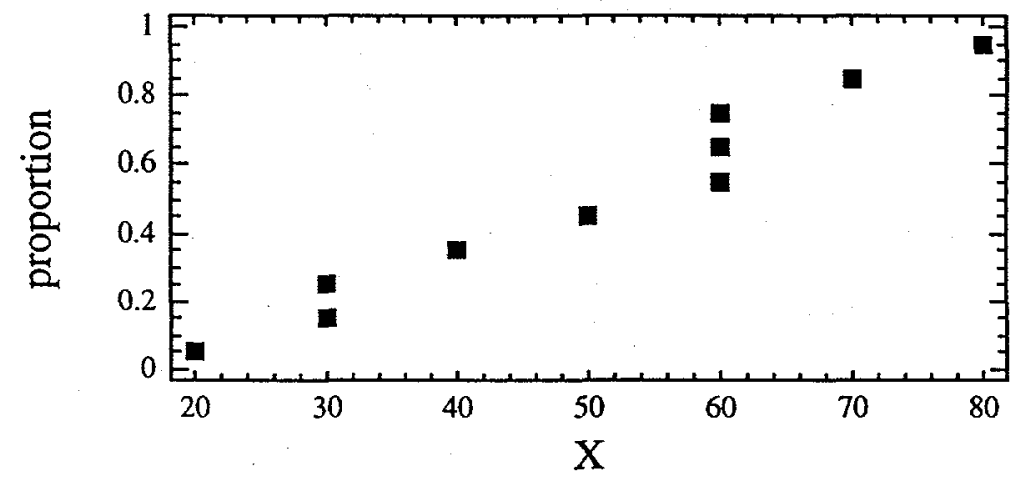

\section{Stem-and-Leaf Display for X: unit $=1.0 \quad 1 / 2$ represents 12.0}

$\begin{array}{ll}1 & 210 \\ 3 & 3100 \\ 4 & 410 \\ 5 & 510 \\ 5 & 61000 \\ 2 & 710 \\ 1 & 810\end{array}$

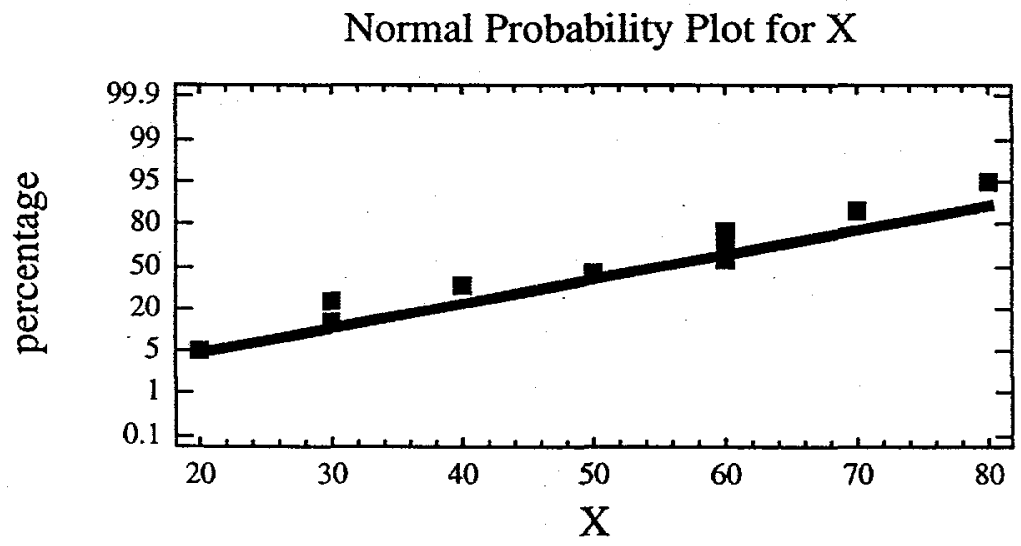

\section{Confidence Intervals for $\mathbf{X}$}

95.0\% confidence interval for mean: $50.0+/-13.9041$ [36.0959,63.9041]

$95.0 \%$ confidence interval for standard deviation: [13.3691,35.4835] 
Appendix E: Statgraphics Results

Exhibit E.2: Statgraphics Output for Table 2 Data Using Simple Regression

\section{Regression Analysis - Linear model: $\mathrm{Y}=\mathbf{a}+\mathbf{b}^{*} \mathbf{X}$}

Dependent variable: $\mathrm{Y}$

Independent variable: $\mathrm{X}$

\begin{tabular}{llccc} 
& \multicolumn{3}{c}{ Standard } & $T$ \\
Parameter & Estimate & Error & Statistic & P-Value \\
\hline Intercept & 10.0 & 2.50294 & 3.9953 & 0.0040 \\
Slope & 2.0 & 0.0469668 & 42.5833 & 0.0000 \\
\hline
\end{tabular}

Analysis of Variance

\begin{tabular}{lccccc}
\hline Source & Sum of Squares & Df & Mean Square & F-Ratio & P-Value \\
\hline Model & 13600.0 & 1 & 13600.0 & 1813.33 & 0.0000 \\
Residual & 60.0 & 8 & 7.5 & & \\
\hline & & & & \\
\hline
\end{tabular}

$\begin{array}{lll}\text { Total (Corr.) } & 13660.0 & 9\end{array}$

Correlation Coefficient $=0.997801$

R-squared $=99.5608$ percent

Standard Error of Est. $=2.73861$

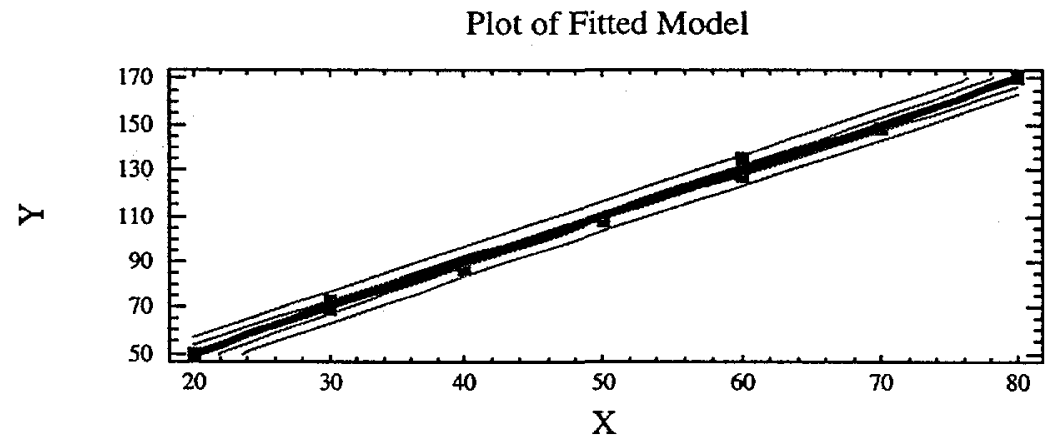

\section{Analysis of Variance with Lack-of-Fit}

\begin{tabular}{|c|c|c|c|c|c|}
\hline Source & Sum of Squares & Df $\mathrm{N}$ & ean Square & F-Ratio & P-Value \\
\hline Model & 13600.0 & 1 & 13600.0 & 1813.33 & 0.0000 \\
\hline Residual & 60.0 & 8 & 7.5 & & \\
\hline Lack-of-Fit & 27.3333 & 5 & 5.46667 & 0.50 & 0.7662 \\
\hline Pure Error & 32.6667 & 3 & 10.8889 & & \\
\hline
\end{tabular}


Appendix E: Statgraphics Results

Exhibit E.3: Statgraphics Output for Table 5 Data Using One-Way ANOVA

Dependent variable: Sales

Factor: Design

Number of observations: 10

Number of levels: 4

Scatterplot by Level Code

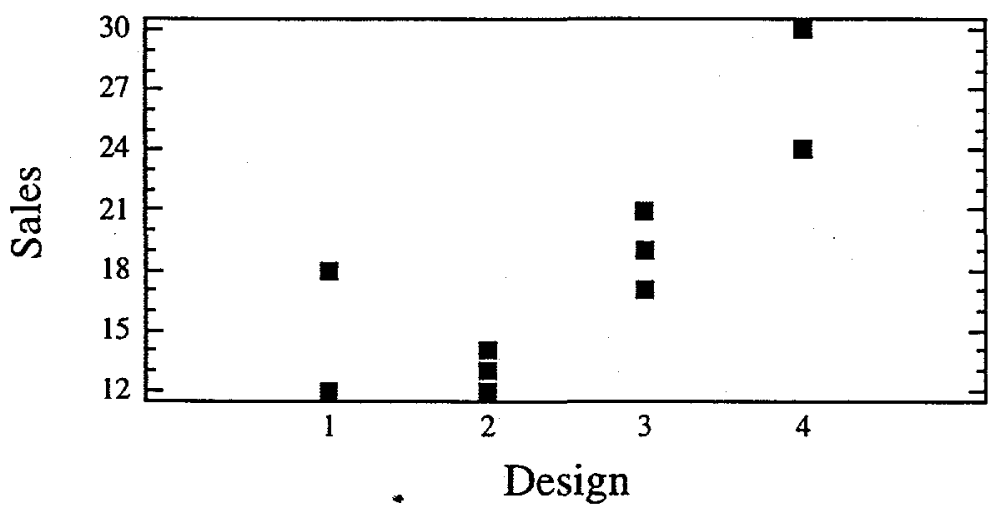

\section{Summary Statistics for Sales}

\begin{tabular}{llll} 
Design & Count & Average & Variance \\
\hline 1 & 2 & 15.0 & 18.0 \\
2 & 3 & 13.0 & 1.0 \\
3 & 3 & 19.0 & 4.0 \\
4 & 2 & 27.0 & 18.0 \\
\hline Total & 10 & 18.0 & 33.7778
\end{tabular}

\begin{tabular}{lccc} 
Design & Standard deviation & Minimum & Maximum \\
\hline 1 & 4.24264 & 12.0 & 18.0 \\
2 & 1.0 & 12.0 & 14.0 \\
3 & 2.0 & 17.0 & 21.0 \\
4 & 4.24264 & 24.0 & 30.0 \\
\hline Total & 5.81187 & 12.0 & 30.0 \\
Design & Range & Stnd. skewness & Stnd. kurtosis \\
\hline 1 & 6.0 & & \\
2 & 2.0 & 0.0 & \\
3 & 4.0 & 0.0 & \\
4 & 6.0 & & 0.358593 \\
\hline Total & 18.0 & 1.23305 &
\end{tabular}


Appendix E: Statgraphics Results

Exhibit E.3: Statgraphics Output for Table 5 Data Using One-Way ANOVA (continued)

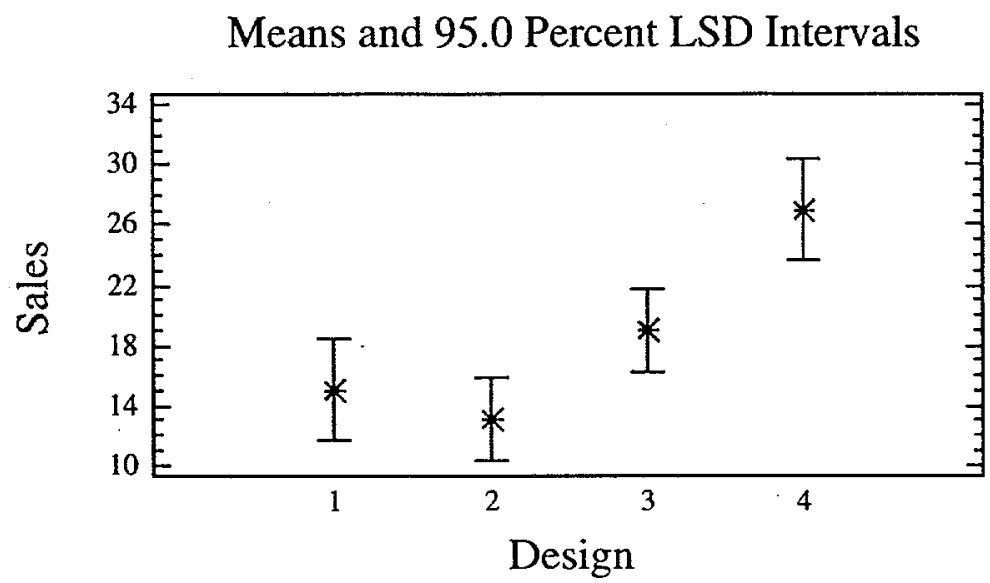

\section{ANOVA Table for Sales by Design}

\begin{tabular}{lccccc}
\hline Source & Sum of Squares & Df & Mean Square & F-Ratio & P-Value \\
\hdashline Between groups & 258.0 & 3 & 86.0 & 11.22 & 0.0071 \\
Within groups & 46.0 & 6 & 7.66667 & & \\
\hline Total (Corr.) & 304.0 & 9 & & & \\
\hline
\end{tabular}

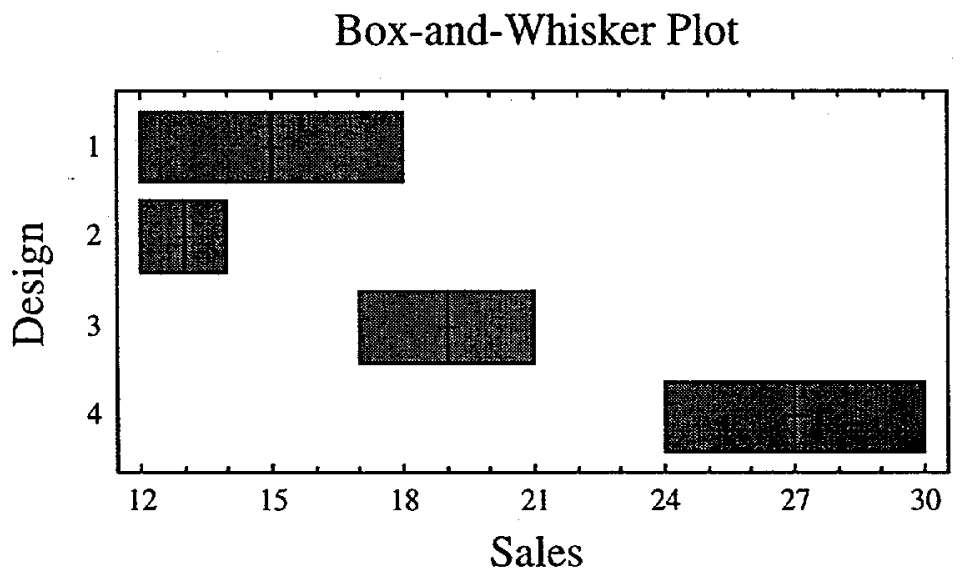


Appendix E: Statgraphics Results

Exhibit E.3: Statgraphics Output for Table 5 Data Using One-Way ANOVA (continued)

Table of Means for Sales by Design with 95.0 percent LSD intervals

\begin{tabular}{llllll} 
& & \multicolumn{3}{c}{ Stnd. error } & \\
Design & Count & Mean & (pooled s) & Lower limit & Upper limit \\
\hdashline 1 & 2 & 15.0 & 1.95789 & 11.6124 & 18.3876 \\
2 & 3 & 13.0 & 1.59861 & 10.234 & 15.766 \\
3 & 3 & 19.0 & 1.59861 & 16.234 & 21.766 \\
4 & 2 & 27.0 & 1.95789 & 23.6124 & 30.3876 \\
\hline Total & 10 & 18.0 & & & \\
\hline
\end{tabular}


Appendix E: Statgraphics Results

Exhibit E.4: Statgraphics Output for Table 8 Data using Variance Components Analysis

Dependent variable: $Y$

Factors: Officer

Number of complete cases: 20

\section{Analysis of Variance for $\mathbf{Y}$}

\begin{tabular}{|c|c|c|c|c|c|}
\hline Source & Sum of Squares & Df & Mean Square & Var. Comp. & . Percen \\
\hline TOTAL (CORRECTED) & 2614.0 & 19 & & & \\
\hline Officer & 1480.0 & 4 & 370.0 & 73.6 & 49.33 \\
\hline ERROR & 1134.0 & 15 & 75.6 & 75.6 & 50.67 \\
\hline
\end{tabular}

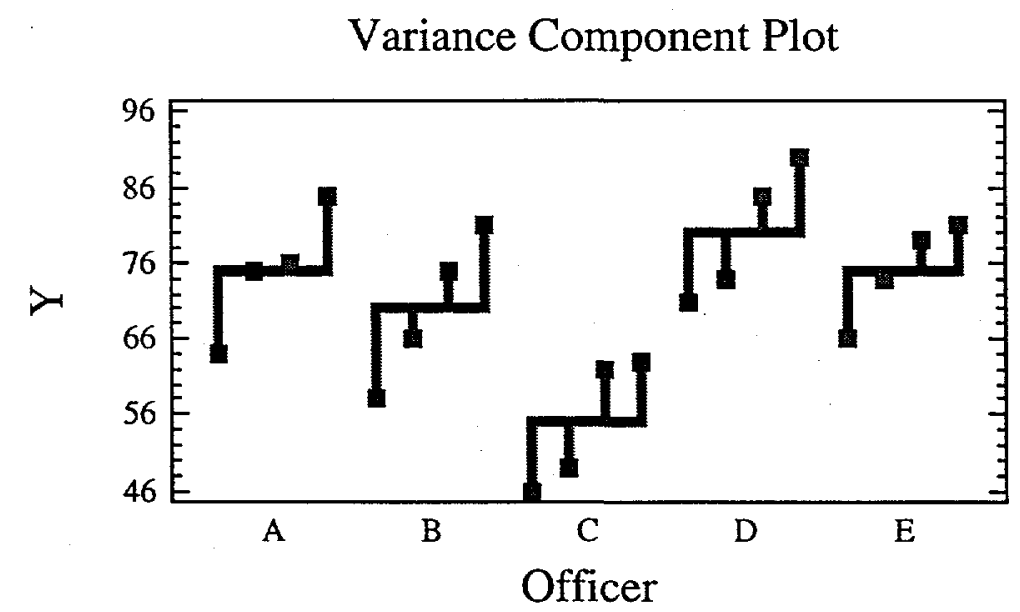

$\mathrm{Y}$

\begin{tabular}{lccc} 
Level & Count & Mean & $\begin{array}{l}\text { Standard } \\
\text { Deviation }\end{array}$ \\
\hline GRAND MEAN & 20 & 71.0 & 11.7294
\end{tabular}

Officer

$\begin{array}{llll}\text { A } & 4 & 75.0 & 8.60233 \\ \text { B } & 4 & 70.0 & 10.0995 \\ \text { C } & 4 & 55.0 & 8.75595 \\ \text { D } & 4 & 80.0 & 8.98146 \\ \text { E } & 4 & 75.0 & 6.68331\end{array}$


Appendix E: Statgraphics Results

Exhibit E.5: Statgraphics Output for Table 10 Data using Two Factor ANOVA

Multifactor ANOVA - Y

Dependent variable: $\mathrm{Y}$

Factors:

Size

Region

Number of complete cases: 6

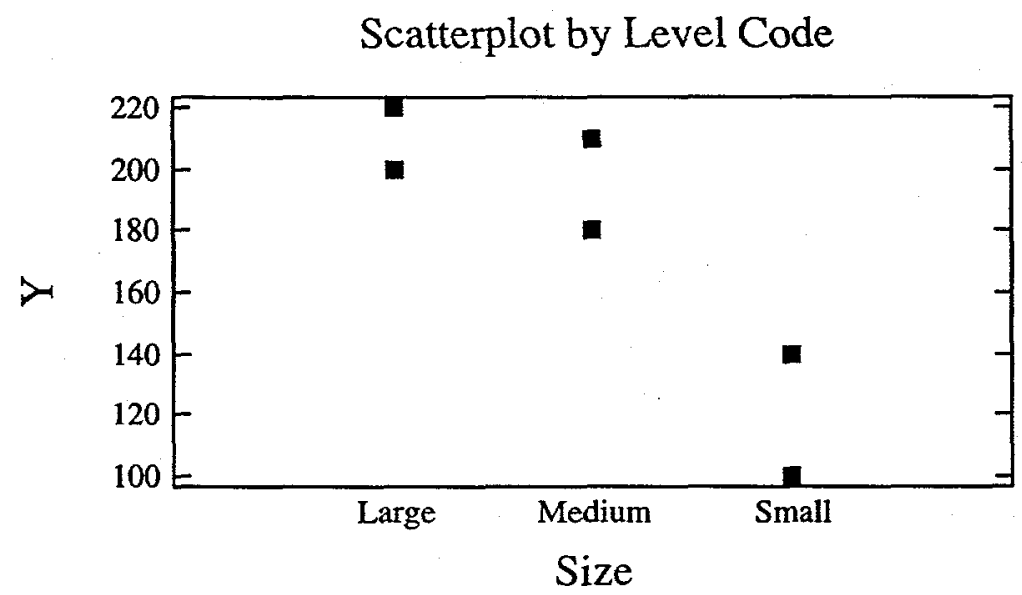

\section{Analysis of Variance for $Y$}

Type III Sums of Squares

\begin{tabular}{llllll}
\hline Source & Sum of Squares & Df & Mean Square & F-Ratio & P-Value \\
\hline MAIN EFFECTS & & & & & \\
A:Size & 9300.0 & 2 & 4650.0 & 93.00 & 0.0106 \\
B:Region & 1350.0 & 1 & 1350.0 & 27.00 & 0.0351 \\
RESIDUAL & 100.0 & 2 & 50.0 & & \\
\hline
\end{tabular}

TOTAL (CORRECTED) 10750.0

5

All F-ratios are bäsed on the residual mean square error. 
Appendix E: Statgraphics Results

Exhibit E.5: Statgraphics Output for Table 10 Data using Two Factor ANOVA (continued)

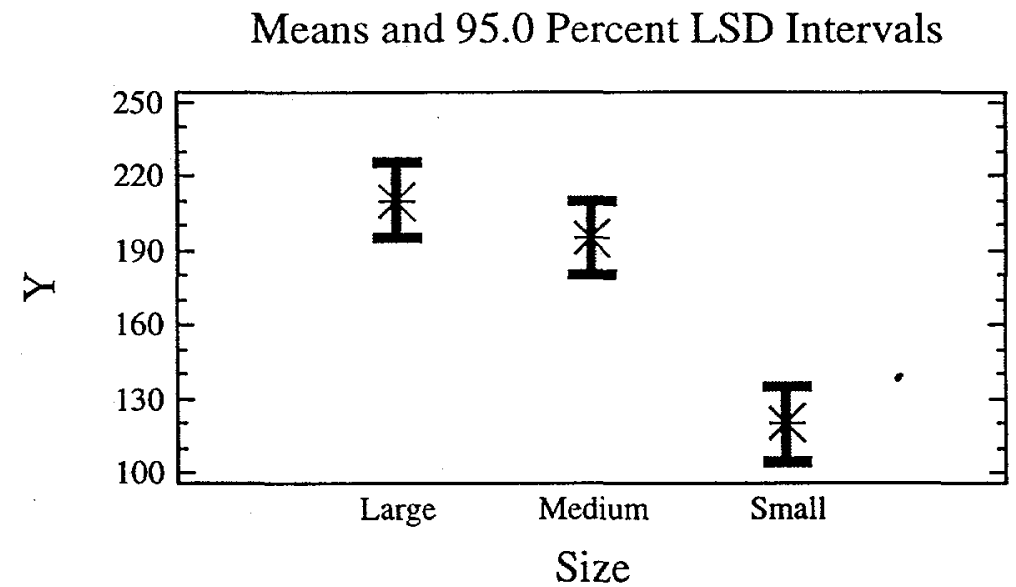

Table of Least Squares Means for Y with 95.0 Percent Confidence Intervals

\begin{tabular}{llllll} 
Level & Count & Mean & $\begin{array}{l}\text { Stnd. } \\
\text { Error }\end{array}$ & $\begin{array}{l}\text { Lower } \\
\text { Limit }\end{array}$ & $\begin{array}{l}\text { Upper } \\
\text { Limit }\end{array}$ \\
\hline GRAND MEAN & 6 & 175.0 & & & \\
Size & & & & & \\
Large & 2 & 210.0 & 5.0 & 188.487 & 231.513 \\
Medium & 2 & 195.0 & 5.0 & 173.487 & 216.513 \\
Small & 2 & 120.0 & 5.0 & 98.4867 & 141.513 \\
Region & 3 & 190.0 & 4.08248 & 172.434 & 207.566 \\
East & 3 & 160.0 & 4.08248 & 142.434 & 177.566 \\
West & & & &
\end{tabular}

\section{Multiple Range Tests for Y by Size}

Method: 95.0 percent LSD

\begin{tabular}{lcccc} 
Size & Count & LS Mean & Homogeneous Groups \\
\hline Small & 2 & 120.0 & $\mathrm{X}$ & \\
Medium & 2 & 195.0 & $\mathrm{X}$ & \\
Large & 2 & 210.0 & $\mathrm{X}$ & \\
\hline Contrast & \multicolumn{2}{c}{ Difference } & +/- Limits \\
\hline Large - Medium & & 15.0 & 30.4243 \\
Large - Small & & $* 90.0$ & 30.4243 \\
Medium - Small & & $* 75.0$ & 30.4243
\end{tabular}

* denotes a statistically significant difference. 
Appendix E: Statgraphics Results

Exhibit E.6: Statgraphics Output for Table 13 Data using a Nested Model

\section{General Linear Models}

Number of dependent variables: 1

Number of categorical factors: 2

Number of quantitative factors: 0

\section{Analysis of Variance for $Y$}

\begin{tabular}{lccccc}
\hline Source & Sum of Squares & Df & Mean Square & F-Ratio & P-Value \\
\hline Model & 724.0 & 5 & 144.8 & 20.69 & 0.0010 \\
Residual & 42.0 & 6 & 7.0 & & \\
\hline Total (Corr.) & 766.0 & 11 & & & \\
\multicolumn{7}{c}{ Type III SumS of Squares } & & & \\
\hline Source & Sum of Squares & Df & Mean Square & F-Ratio & P-Value \\
\hline School & 156.5 & 2 & 78.25 & 11.18 & 0.0095 \\
Instructor(School) & 567.5 & 3 & 189.167 & 27.02 & 0.0007 \\
Residual & 42.0 & 6 & 7.0 & &
\end{tabular}

Total (corrected)

$766.0 \quad 11$

All F-ratios are based on the residual mean square error.

R-Squared $=94.517$ percent

R-Squared (adjusted for d.f.) $=89.9478$ percent

Standard Error of Est. $=2.64575$

Mean absolute error $=1.83333$

Durbin-Watson statistic $=1.89881$ 
Appendix E: Statgraphics Results

Exhibit E.6: Statgraphics Output for Table 13 Data using a Nested Model (continued)

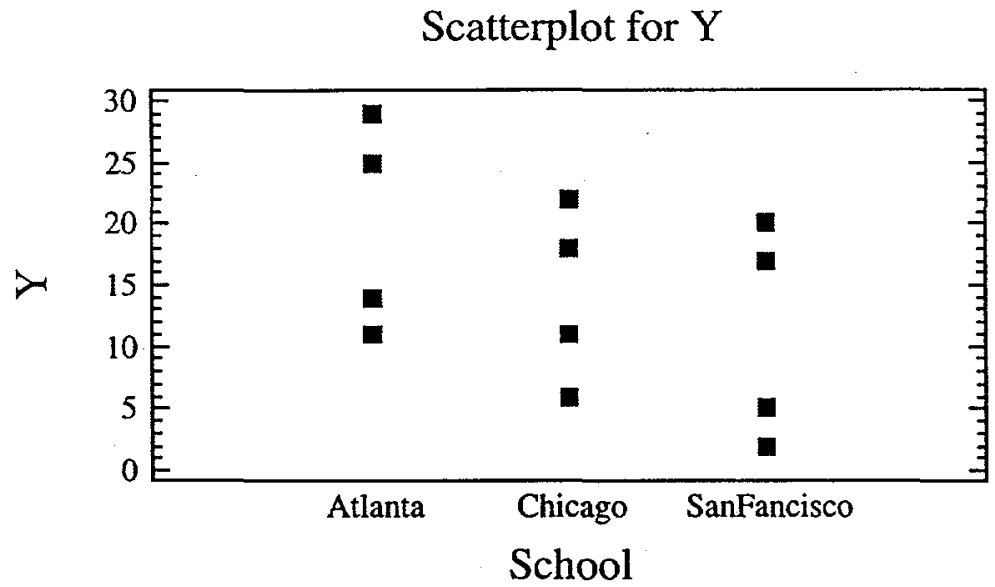

95.0\% confidence intervals for coefficient estimates $(Y)$

\begin{tabular}{|c|c|c|c|c|c|}
\hline \multirow[b]{2}{*}{ Parameter } & \multicolumn{2}{|c|}{ Standard } & \multirow[b]{2}{*}{ Lower Limit } & \multirow[b]{2}{*}{ Upper Limit } & \multirow[b]{2}{*}{ V.I.F. } \\
\hline & Estimate & Error & & & \\
\hline CONSTANT & 15.0 & 0.763763 & 13.1311 & 16.8689 & \\
\hline School & 4.75 & 1.08012 & 2.10703 & 7.39297 & 1.33333 \\
\hline School & -0.75 & 1.08012 & -3.39297 & 1.89297 & 1.33333 \\
\hline Instructor(School) & 7.25 & 1.32288 & 4.01303 & 10.487 & 1.0 \\
\hline Instructor(School) & -5.75 & 1.32288 & -8.98697 & -2.51303 & 1.0 \\
\hline Instructor(School) & 7.5 & 1.32288 & 4.26303 & 10.737 & 1.0 \\
\hline
\end{tabular}

Means and 95.0 Percent LSD Intervals

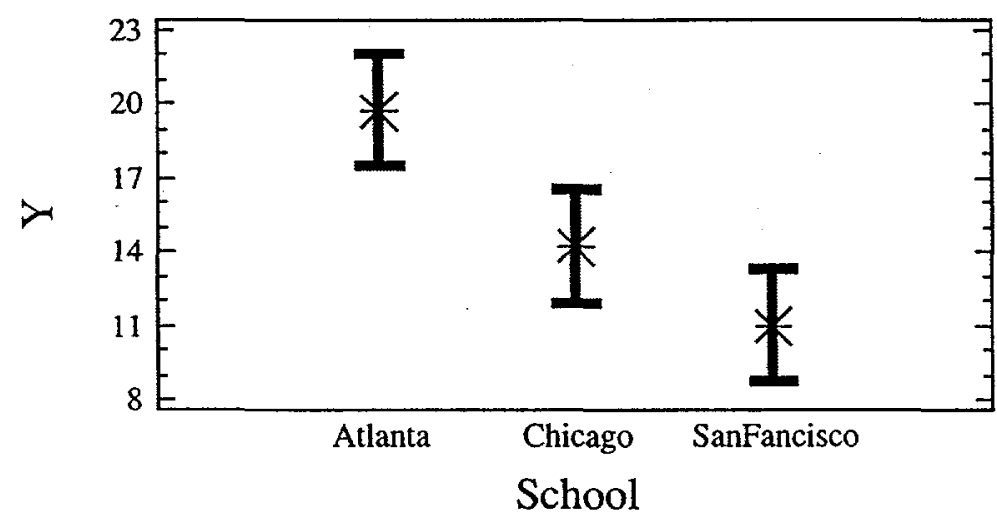


Appendix E: Statgraphics Results

Exhibit E.6: Statgraphics Output for Table 13 Data using a Nested Model (continued)

\section{Table of Least Squares Means for $Y$ with 95.0 Percent Confidence Intervals}

\begin{tabular}{|c|c|c|c|c|c|c|}
\hline \multicolumn{2}{|c|}{ Level } & \multicolumn{2}{|c|}{ Mean } & $\begin{array}{l}\text { Stnd. } \\
\text { Error }\end{array}$ & $\begin{array}{l}\text { Lower } \\
\text { Limit }\end{array}$ & $\begin{array}{l}\text { Upper } \\
\text { Limit }\end{array}$ \\
\hline \multicolumn{2}{|c|}{ GRAND MEAN } & 12 & 15.0 & 0.763763 & 13.1311 & 16.8689 \\
\hline \multicolumn{2}{|c|}{ Atlanta } & 4 & 19.75 & 1.32288 & 16.513 & 22.987 \\
\hline \multicolumn{2}{|c|}{ Chicago } & 4 & 14.25 & 1.32288 & 11.013 & 17.487 \\
\hline \multirow{2}{*}{\multicolumn{7}{|c|}{$\begin{array}{l}\text { SanFancisco } \\
\text { Instructor within School }\end{array}$}} \\
\hline & & & & & & \\
\hline \multicolumn{2}{|c|}{$1 \quad$ Atlanta } & 2 & 27.0 & 1.87083 & 22.4222 & 31.5778 \\
\hline 1 & Chicago & 2 & 8.5 & 1.87083 & 3.92224 & 13.0778 \\
\hline 1 & SanFancisc & 2 & 18.5 & 1.87083 & 13.9222 & 23.0778 \\
\hline 2 & Atlanta & 2 & 12.5 & 1.87083 & 7.92224 & 17.0778 \\
\hline 2 & Chicago & 2 & 20.0 & 1.87083 & 15.4222 & 24.5778 \\
\hline 2 & SanFancisc & 2 & 3.5 & 1.87083 & -1.07776 & 8.07776 \\
\hline
\end{tabular}

\section{Multiple Comparisons for $\mathbf{Y}$ by School}

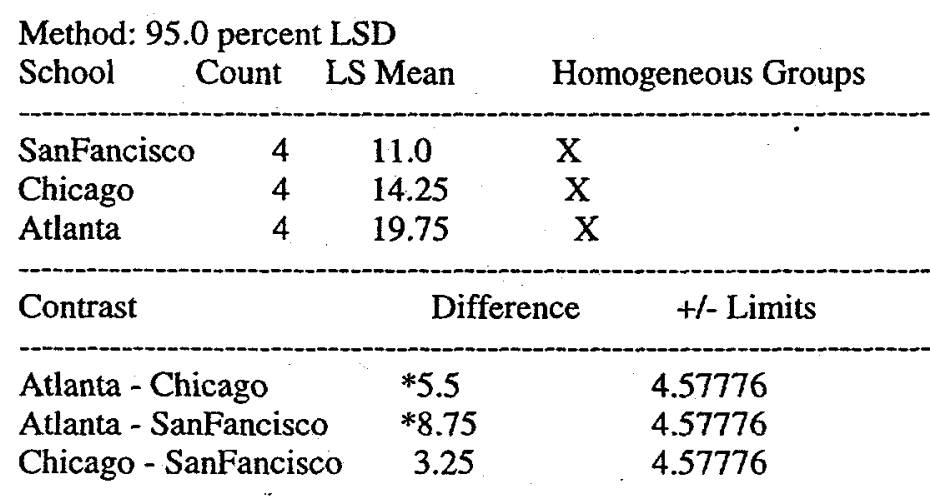

* denotes a statistically significant difference. 
Appendix E: Statgraphics Results

Exhibit E.7: Statgraphics Output for Table 13 Data using Variance Component Analysis

Dependent variable: $\mathrm{Y}$

Factors:

School

Instructor

Number of complete cases: 12

\section{Analysis of Variance for $Y$}

\begin{tabular}{lccccc}
\hline Source & Sum of Squares & Df & Mean Square & Var. Comp. Percent \\
\hline TOTAL (CORRECTED) & 766.0 & 11 & & & \\
\hline School & 156.5 & 2 & 78.25 & 0.0 & 0.00 \\
Instructor & 567.5 & 3 & 189.167 & 91.0833 & 92.86 \\
ERROR & 42.0 & 6 & 7.0 & 7.0 & 7.14
\end{tabular}

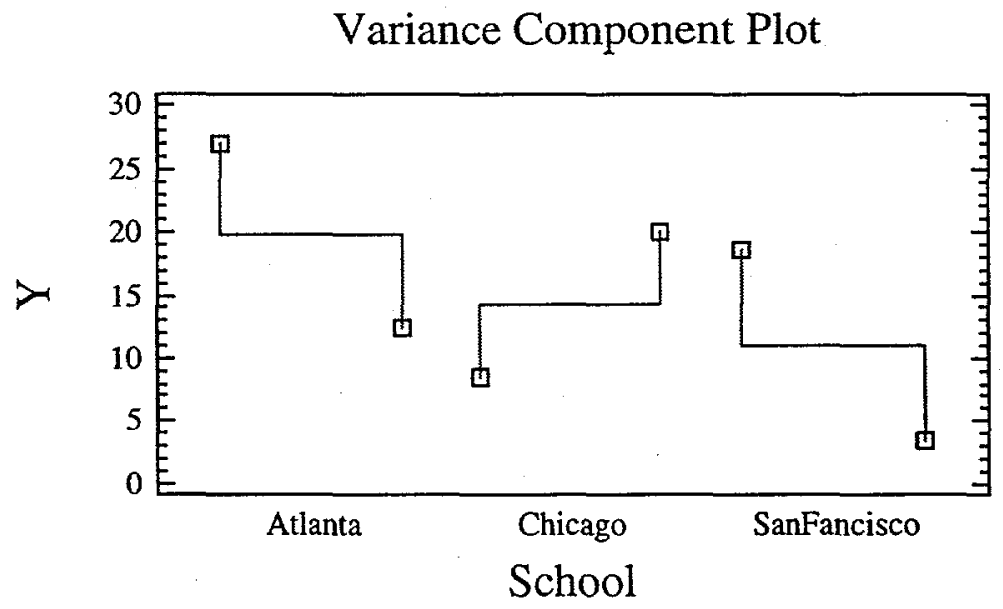

$\mathbf{Y}$

\begin{tabular}{lccc} 
Level & Count & Mean & $\begin{array}{l}\text { Standard } \\
\text { Deviation }\end{array}$ \\
\hline GRAND MEAN & 12 & 15.0 & 8.34484
\end{tabular}

School

Atlanta

Chicago

SanFancisco

$\begin{array}{ll}4 & 19.75 \\ 4 & 14.25 \\ 4 & 11.0\end{array}$

8.61684

7.13559

8.83176 
Appendix E: Statgraphics Results

Exhibit E.7: Statgraphics Output for Table 13 Data using Variance Component Analysis (continued)

\begin{tabular}{llrl} 
Instructor & & & \\
1 & 2 & 27.0 & 2.82843 \\
2 & 2 & 12.5 & 2.12132 \\
1 & 2 & 8.5 & 3.53553 \\
2 & 2 & 20.0 & 2.82843 \\
1 & 2 & 18.5 & 2.12132 \\
2 & 2 & 3.5 & 2.12132 \\
\hline
\end{tabular}


Appendix E: Statgraphics Results

Exhibit E.8: Statgraphics Output for Fractional Factorial Design

Screening Design Attributes

Design Summary

Design class: Screening

Design name: Quarter fraction

\section{Base Design}

Number of experimental factors: 6

Number of responses: 1

Number of runs: 16

Number of blocks: 1

Randomized: No

Error degrees of freedom: 2

\begin{tabular}{lccl} 
Factors & Low & High & Continuous \\
\hline X1 & -1.0 & 1.0 & Yes \\
X4 & -1.0 & 1.0 & Yes \\
X3 & -1.0 & 1.0 & Yes \\
X2 & -1.0 & 1.0 & Yes \\
X6 & -1.0 & 1.0 & Yes \\
X5 & -1.0 & 1.0 & Yes
\end{tabular}

\begin{tabular}{|r|r|r|r|r|r|r|}
\hline Run & X1 & X2 & X3 & X4 & X5 & X6 \\
\hline 1 & -1 & -1 & -1 & -1 & -1 & -1 \\
\hline 2 & -1 & -1 & -1 & 1 & 1 & 1 \\
\hline 3 & -1 & -1 & 1 & -1 & 1 & 1 \\
\hline 4 & -1 & -1 & 1 & 1 & -1 & -1 \\
\hline 5 & -1 & 1 & -1 & -1 & 1 & -1 \\
\hline 6 & -1 & 1 & -1 & 1 & -1 & 1 \\
\hline 7 & -1 & 1 & 1 & -1 & -1 & 1 \\
\hline 8 & -1 & 1 & 1 & 1 & 1 & -1 \\
\hline 9 & 1 & -1 & -1 & -1 & -1 & 1 \\
\hline 10 & 1 & -1 & -1 & 1 & 1 & -1 \\
\hline 11 & 1 & -1 & 1 & -1 & 1 & -1 \\
\hline 12 & 1 & -1 & 1 & 1 & -1 & 1 \\
\hline 13 & 1 & 1 & -1 & -1 & 1 & 1 \\
\hline 14 & 1 & 1 & -1 & 1 & -1 & -1 \\
\hline 15 & 1 & 1 & 1 & -1 & -1 & -1 \\
\hline 16 & 1 & 1 & 1 & 1 & 1 & 1 \\
\hline
\end{tabular}


Appendix E: Statgraphics Results

Exhibit E.8: Statgraphics Output for Fractional Factorial Design (continued)

Alias Structure

Contrast Estimates

$1 \quad \mathrm{~A}$

2 B

3 C

$4 \quad \mathrm{D}$

$5 \quad \mathrm{E}$

$6 \quad F$

$7 \quad \mathrm{AB}+\mathrm{CE}$

$8 \quad \mathrm{AC}+\mathrm{BE}$

$9 \quad \mathrm{AD}+\mathrm{EF}$

$10 \quad \mathrm{AE}+\mathrm{BC}+\mathrm{DF}$

$11 \quad \mathrm{AF}+\mathrm{DE}$

$12 \mathrm{BD}+\mathrm{CF}$

$13 \mathrm{BF}+\mathrm{CD}$ 
Appendix E: Statgraphics Results

Exhibit E.9: Statgraphics Output for Extreme Vertices

Design Summary

Design class: Mixture

Design name: Extreme vertices

Base Design

Number of components: 3

Number of responses: 1

Number of runs: 6

Model type: Linear

Randomized: Yes

\begin{tabular}{llll} 
Components & Low & High & Units \\
\hdashline X1 & 0.2 & 0.6 & \\
X2 & 0.1 & 0.6 \\
X3 & 0.1 & 0.5
\end{tabular}

Mixture total $=1.0$

\begin{tabular}{|r|r|r|r|}
\hline \multicolumn{1}{|c|}{ Run } & \multicolumn{1}{|c|}{ X1 } & \multicolumn{1}{|c|}{ X2 } & \multicolumn{1}{c|}{ X3 } \\
\hline 1 & 0.6 & 0.3 & 0.1 \\
\hline 2 & 0.6 & 0.1 & 0.3 \\
\hline 3 & 0.3 & 0.6 & 0.1 \\
\hline 4 & 0.2 & 0.6 & 0.2 \\
\hline 5 & 0.4 & 0.1 & 0.5 \\
\hline 6 & 0.2 & 0.3 & 0.5 \\
\hline
\end{tabular}


Appendix E: Statgraphics Results

Exhibit E.10: Statgraphics D-Optimality Results

\section{Optimize Experiment}

Selection criterion: D-optimality Desired number of runs: 8

Selection method: Forward

Model order: 1

Number of runs already completed: 0

Additional candidate runs: 20

\section{D-optimal Design}

Design has been reduced to 8 runs.

D-efficiency $=100.0 \%$

A-efficiency $=100.0 \%$

G-efficiency $=100.0 \%$

\begin{tabular}{|l|r|r|r|r|}
\hline Select & Condition & X1 & X2 & X3 \\
\hline$*$ & 1 & -1 & -1 & 1 \\
\hline$*$ & 2 & 0 & 0 & 0 \\
\hline & 3 & 1 & -1 & 1 \\
\hline & 4 & 0 & 1 & 0 \\
\hline$*$ & 5 & 1 & 1 & 1 \\
\hline$*$ & 6 & 0 & 0 & 0 \\
\hline$*$ & 7 & 0 & 0 & 0 \\
\hline & 8 & 1 & -1 & -1 \\
\hline & 9 & -1 & 1 & 1 \\
\hline & 10 & 0 & 0 & -1 \\
\hline & 11 & -1 & 1 & -1 \\
\hline & 12 & -1 & 0 & 0 \\
\hline & 13 & 0 & 0 & 1 \\
\hline & 14 & 0 & 0 & 0 \\
\hline & 15 & 0 & 0 & 0 \\
\hline & 16 & 0 & -1 & 0 \\
\hline & 17 & -1 & -1 & -1 \\
\hline & 18 & 0 & 0 & 0 \\
\hline & 19 & 1 & 0 & 0 \\
\hline & 20 & 1 & 1 & -1 \\
\hline
\end{tabular}

* indicates a run selected to achieve D-optimality 
Appendix E: Statgraphics Results

Exhibit E.11: Statgraphics X-bar and S Charts - X

Initial Study for X

Number of subgroups $=20$

Average subgroup size $=4.0$

0 subgroups excluded

\section{X-bar Chart}

UCL: +3.0 sigma $=82.0667$

Centerline $=59.4375$

LCL: -3.0 sigma $=36.8083$

\section{S Chart}

UCL: +3.0 sigma $=31.496$

Centerline $=13.8991$

LCL: -3.0 sigma $=0.0$

\section{Estimates}

Process mean $=59.4375$

Process sigma $=15.0861$

Mean sigma $=13.8991$

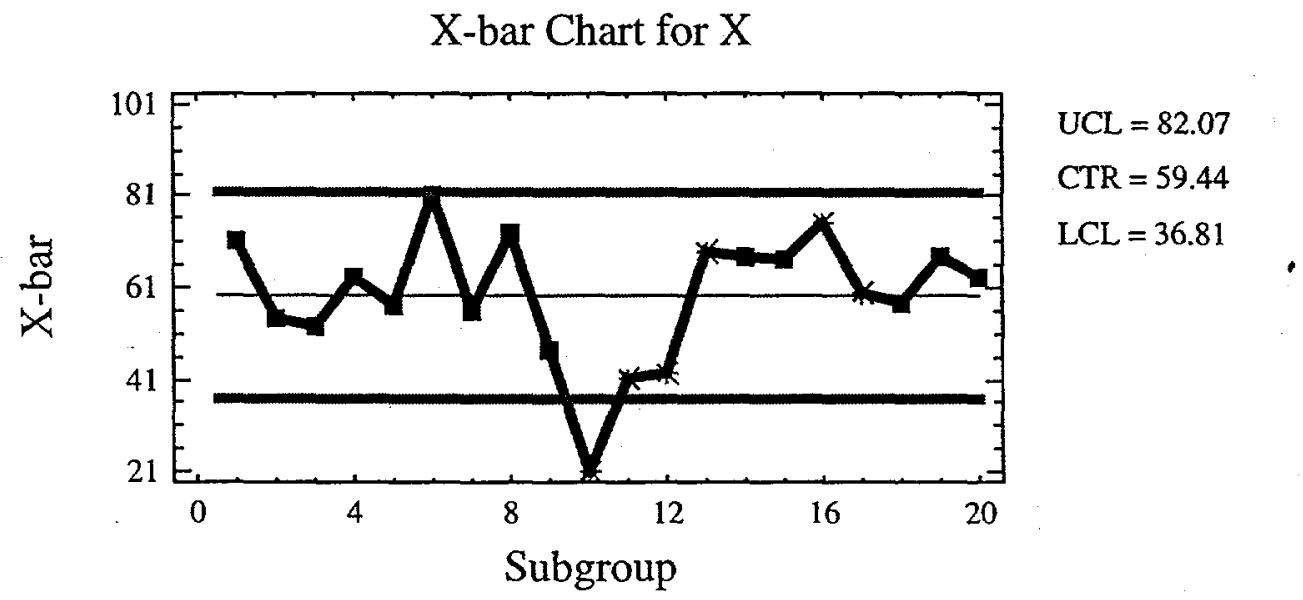


Appendix E: Statgraphics Results

Exhibit E.11: Statgraphics X-bar and S Charts - X

(continued)

\section{Subgroup Reports}

\begin{tabular}{|c|c|c|c|}
\hline All Subgroups & & \multicolumn{2}{|c|}{$*=$ Beyond Limits } \\
\hline Subgroup & Size & X-bar & $\mathbf{S}$ \\
\hline 1 & 4 & 71.0 & 15.4704 \\
\hline 2 & 4 & 54.5 & 23.6432 \\
\hline 3 & 4 & 52.5 & 21.7025 \\
\hline 4 & 4 & 63.0 & 16.8523 \\
\hline 5 & 4 & 57.25 & 29.6802 \\
\hline 6 & 4 & 81.25 & 13.2759 \\
\hline 7 & 4 & 56.0 & 8.04156 \\
\hline 8 & 4 & 72.75 & 17.2313 \\
\hline 9 & 4 & 47.75 & 6.70199 \\
\hline 10 & 4 & * 21.25 & 11.3541 \\
\hline 11 & 4 & 41.25 & 11.5289 \\
\hline 12 & 4 & 42.5 & 15.7586 \\
\hline 13 & 4 & 69.0 & 16.8721 \\
\hline 14 & 4 & 67.75 & 11.5289 \\
\hline 15 & 4 & 67.0 & 6.0553 \\
\hline 16 & 4 & 75.0 & 12.7279 \\
\hline 17 & 4 & 59.75 & 9.97914 \\
\hline 18 & 4 & 57.75 & 12.4197 \\
\hline 19 & 4 & 68.0 & 9.83192 \\
\hline 20 & 4 & 63.5 & 7.32575 \\
\hline
\end{tabular}

S Chart for X

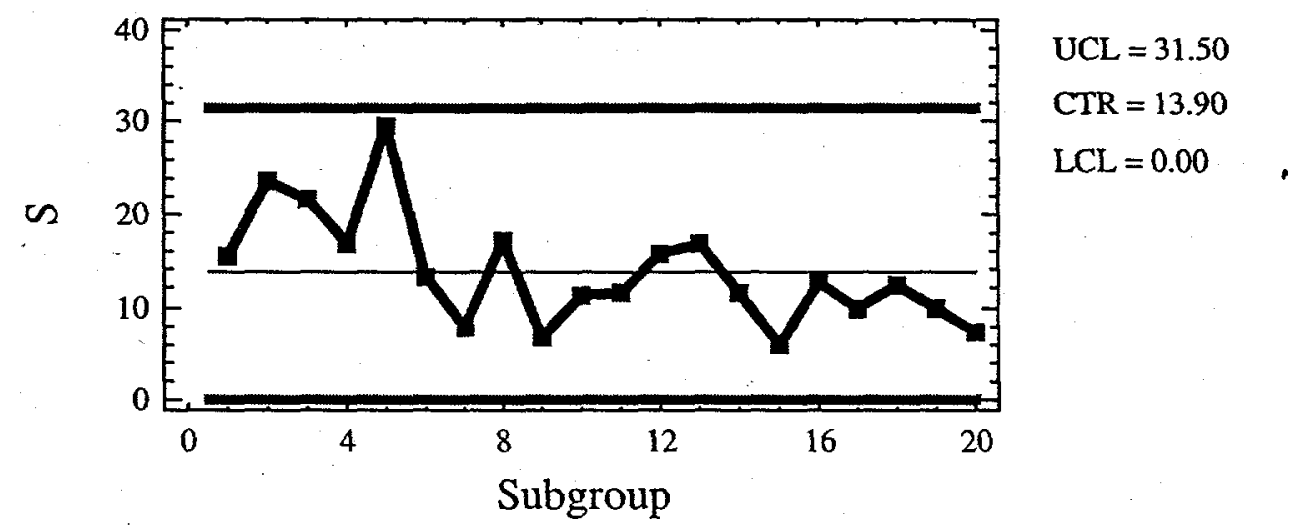




\title{
DISTRIBUTION
}

\author{
R. A. Baker, 773-42A \\ K. G. Brown, 704-1T \\ T. B. Edwards, 773-42A \\ S. P. Harris, 773-42A \\ C D. Harvel, 773-42A \\ E.W. Holtzscheiter, 773-A \\ P. E. Lowe, 773-41A \\ S. L. Marra, 704-T \\ D. Moore-Shedrow, 773-A \\ K. E. Mottle, 773-43A \\ C. T. Randall, 773-42A \\ C. P. Reeve, 773-42A \\ E. P. Shine, 773-42A \\ T. K. Snyder, 704-T \\ R. C. Tuckfield, 773-42A \\ J. H. Weber, 773-42A
}

